\title{
The effects of varying concentration and duration of CFC-113 exposure on end-exhaled breath CFC-113 concentration
}

\author{
Demetra Grace Dalamagas \\ West Virginia University
}

Follow this and additional works at: https://researchrepository.wvu.edu/etd

\section{Recommended Citation}

Dalamagas, Demetra Grace, "The effects of varying concentration and duration of CFC-113 exposure on end-exhaled breath CFC-113 concentration" (1999). Graduate Theses, Dissertations, and Problem Reports. 3194.

https://researchrepository.wvu.edu/etd/3194

This Thesis is protected by copyright and/or related rights. It has been brought to you by the The Research Repository @WVU with permission from the rights-holder(s). You are free to use this Thesis in any way that is permitted by the copyright and related rights legislation that applies to your use. For other uses you must obtain permission from the rights-holder(s) directly, unless additional rights are indicated by a Creative Commons license in the record and/ or on the work itself. This Thesis has been accepted for inclusion in WVU Graduate Theses, Dissertations, and Problem Reports collection by an authorized administrator of The Research Repository @ WVU. For more information, please contact researchrepository@mail.wvu.edu. 
THE EFFECTS OF VARYING CONCENTRATION AND DURATION OF CFC-113 EXPOSURE ON END-EXHALED BREATH CFC-113 CONCENTRATION

By

Demetra G. Dalamagas

A THESIS

Submitted to

The College of Engineering and Mineral Resources

at

West Virginia University

in partial fulfillment of the requirements

for the degree of

Master of Science

in

Occupational Hygiene and Occupational Safety

Warren R. Myers, Ph.D., Chair

Christopher C. Coffey, Ph.D.

Dianne L. McMullin, Ph.D.

Department of Industrial and Management Systems Engineering

Morgantown, West Virginia

1999

Keywords: CFC-113, Freon-113, exposure assessment, pharmacokinetics 


\begin{abstract}
THE EFFECTS OF VARYING CONCENTRATION AND DURATION OF CFC-113 EXPOSURE ON END-EXHALED BREATH CFC-113 CONCENTRATIONS
\end{abstract}

by Demetra G. Dalamagas

\begin{abstract}
Subjects were exposed to different concentrations of CFC-113 for variable duration while conducting 30-minute exercise regiments. End-exhaled breath samples were collected 25, 30 and 35 minutes after the exercise regiment and quantified using gas chromatography. Three comparative studies were conducted.

A short duration administration delivered at the beginning or at the end of the regiment was compared to a long duration administration delivered at the beginning or at the end of the exercise regiment. The second study compared breath samples when $500 \mathrm{ppm}$ of CFC-113 was administered at the beginning or end six minutes of the regiment. The third compared continuous exposures (30 min of $100 \mathrm{ppm}$ ) to intermittent exposures (three intermittent 2-min exposures of $500 \mathrm{ppm}$ ). This study determined that equivalent doses of CFC-113 administered with variable exposure profiles to human subjects produced statistically equivalent end-exhaled CFC-113 concentration, except in two cases.
\end{abstract}




\begin{abstract}
AKNOWLEDGEMENTS
I would like to acknowledge the financial support and professional guidance from Dr. Chris Coffey and Dr. Warren Myers, without whom I would not have undertaken this project. Thank you for encouraging me to go a step beyond. Thanks to Dr. Dianne McMullin whose ready humor kept everything in perspective. I would especially like to thank Dr. Terry Stobbe, the modern sage, whose philosophy and insight has taught me more than any textbook. A special thanks to Lori Robey for bailing me out at least once a semester.

I would like to thank my family for trusting my judgement and believing in me. Much thanks to Mary Musallam and Nicole Demos, my second family, for knowing when to call and proffer much needed encouragement. I am forever grateful to Colleen Wright for introducing me to this field and believing in my abilities. I thank Rich Schneider and Carolyn Gatty for sharing the poetry of each day with me. A special thanks goes to Michelle Marsh and Mike Berakis for making the whole ride so much more fun.
\end{abstract}




\section{Table of Contents}

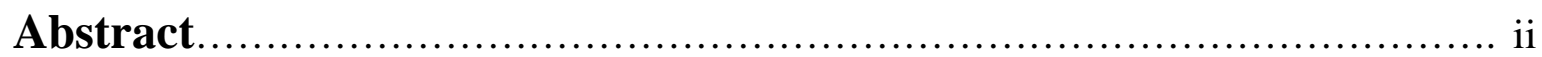

Acknowledgements.....................................................................

List of Tables............................................................... vi

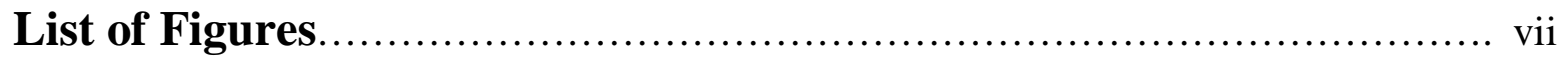

List of Abbreviations........................................................... vii

\section{Chapter 1}

Introduction

Experiment Rationale and Design............................... 1

\section{Chapter 2}

Review of Literature

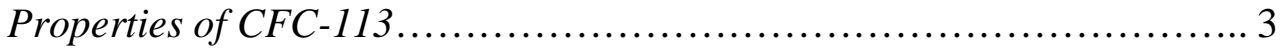

Pharmacokinetics.................................................... 4

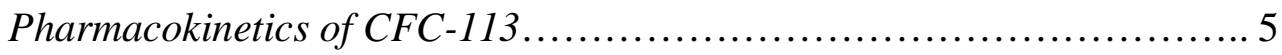

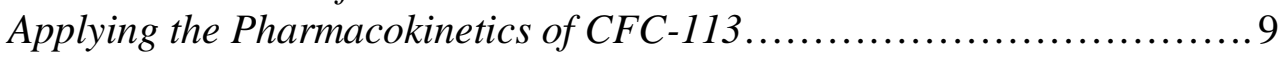

\section{Chapter 3}

Materials and Methods

Subject Selection.................................................. 11

Experimental Design............................................... 11

Phase One................................................... 12

Phase Two Beginning vs. End Exposure Scenarios................ 13

Phase Three Continuous vs. Intermittent Exposure Scenarios....... 14

CFC-113 Delivery System........................................ 15

Exercise Regiment............................................... 16

Breath Sample Collection.............................................. 17

Breath Sample Analysis........................................... 17

Exposure Concentration.......................................... 18

\section{Chapter 4}

Results.............................................................. 20

Phase One Results............................................... 20

Phase Two Results................................................. 23

Phase Three Results.................................................. 25 


\section{Chapter 5}

Statistical Analysis.................................................. 57

\section{Chapter 6}

Discussion and Conclusion

Scenario Equivalence.......................................... 59

Variance ........................................................ 61

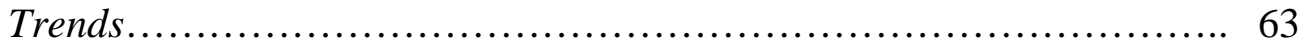

\section{Chapter 7}

Recommendations.

66

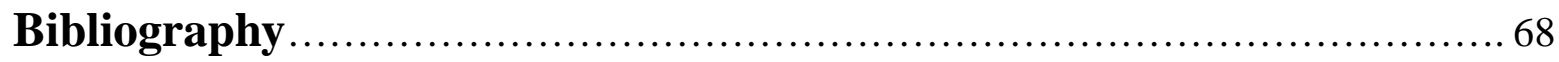

\section{Appendix A}

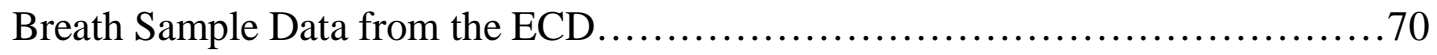

\section{Appendix B}

Photos of the CFC-113 Delivery System and Chamber....................... 74

\section{Appendix C}

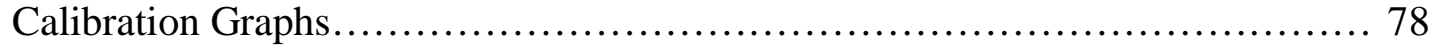

\section{Appendix D}

SAS Results. 


\section{List of Tables}

Table 3.1-Experimental Design............................................. 19

Table 4.1-Area to Concentration Coefficients for the ECD-GC ........................ 28

Table 4.2a-Phase 1 Results for Subject 1...................................... 29

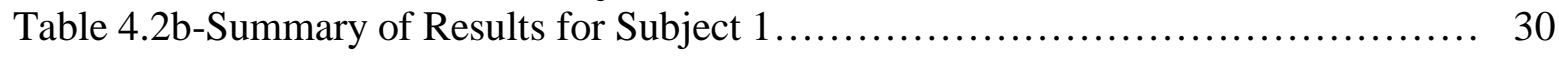

Table 4.3a-Phase 1 Results for Subject 45..................................... 32

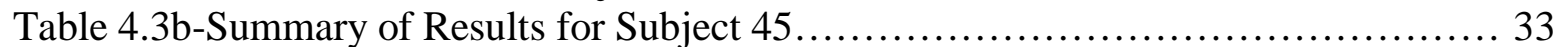

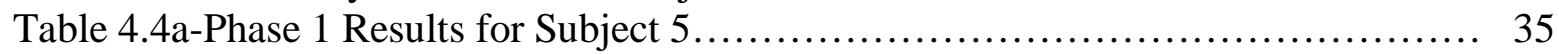

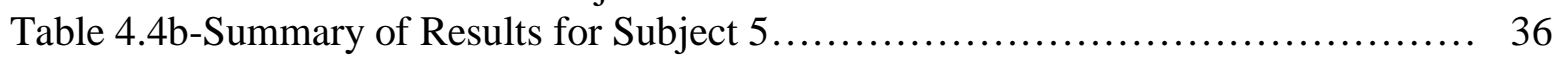

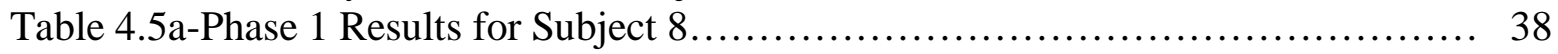

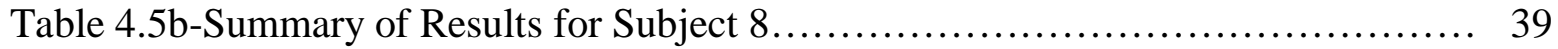

Table 4.6a-Results for Subject 3 Comparison of Beginning vs. End Scenarios........... 41

Table 4.6b-Summary of Result for Subject 3 ................................ 41

Table 4.7a-Results for Subject 16 Comparison of Beginning vs. End Scenarios........... 43

Table 4.7b-Summary of Result for Subject 16.................................. 43

Table 4.8a-Results for Subject 22 Comparison of Beginning vs. End Scenarios........... 45

Table 4.8b-Summary of Result for Subject 22 ................................... 45

Table 4.9a-Results for Subject 26 Comparison of Beginning vs. End Scenarios.......... 47

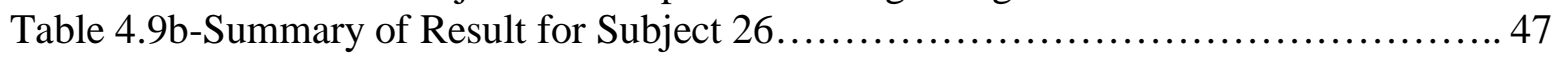

Table 4.10a-Results for Subject 4 Comparison of Continuous vs.

Intermittent Scenarios.............................................. 49

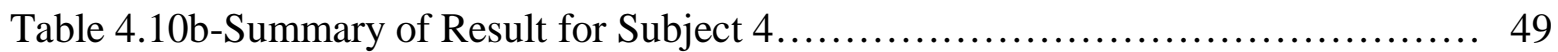

Table 4.11a-Results for Subject 10 Comparison of Continuous vs.

Intermittent Scenarios............................................ 51

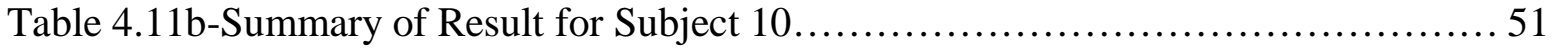

Table 4.12a-Results for Subject 19 Comparison of Continuous vs.

Intermittent Scenarios ............................................. 53

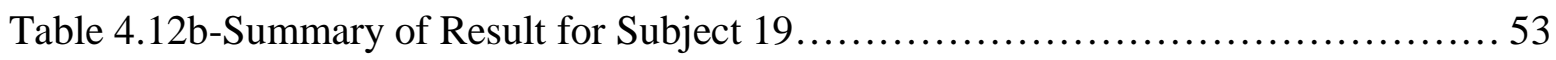

Table 4.13a-Results for Subject 29 Comparison of Continuous vs.

Intermittent Scenarios.......................................... 55

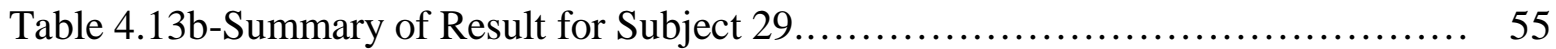




\section{List of Figures}

Figure 4.1 Comparison of Phase 1 Scenarios for Subject $1 \ldots \ldots \ldots \ldots \ldots \ldots \ldots \ldots \ldots \ldots \ldots \ldots \ldots$

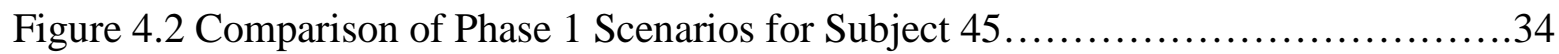

Figure 4.3 Comparison of Phase 1 Scenarios for Subject $5 \ldots \ldots \ldots \ldots \ldots \ldots \ldots \ldots \ldots \ldots \ldots$

Figure 4.4 Comparison of Phase 1 Scenarios for Subject $8 \ldots \ldots \ldots \ldots \ldots \ldots \ldots \ldots \ldots \ldots . \ldots \ldots$

Figure 4.5 Comparison of Beginning vs. End Scenarios for Subject 3.............. 42

Figure 4.6 Comparison of Beginning vs. End Scenarios for Subject $16 \ldots \ldots \ldots \ldots \ldots \ldots \ldots 44$

Figure 4.7 Comparison of Beginning vs. End Scenarios for Subject $22 \ldots \ldots \ldots \ldots \ldots \ldots . \ldots$

Figure 4.8 Comparison of Beginning vs. End Scenarios for Subject $26 \ldots \ldots \ldots \ldots \ldots \ldots . .48$

Figure 4.9 Comparison of Intermittent vs. Continuous Scenarios for Subject $4 \ldots \ldots \ldots \ldots 50$

Figure 4.10 Comparison of Intermittent vs. Continuous Scenarios for Subject 10...... 52

Figure 4.11 Comparison of Intermittent vs. Continuous Scenarios for Subject 19....... 54

Figure 4.12 Comparison of Intermittent vs. Continuous Scenarios for Subject 29...... 56

Figure B1 CFC-113 Delivery System................................... 75

Figure B2 Subject Donning CFC-113 Delivery System........................ 76

Figure B3 Subject in Charged Chamber.................................... 77 


\section{List of Abbreviations}

ECD = Electron Capture Device; Type of detector fitted to the Gas Chromatograph.

$\mathrm{GC}=$ Gas Chromatograph

LB = Long, Beginning Scenario; A long exposure (15.15 minutes of $33 \mathrm{ppm}$ of CFC) administered at the beginning of the 30 minute exercise regiment.

LE = Long, End Scenario; A long exposure (15.15 minutes of 33 ppm of CFC) administered at the end of the 30 minute exercise regiment.

$\mathrm{SB}=$ Short, Beginning Scenario; A short exposure (1 minute of $500 \mathrm{ppm}$ of CFC) administered at the beginning of the 30 minute exercise regiment.

$\mathrm{SE}=$ Short, End Scenario; A short exposure (1 minute of $500 \mathrm{ppm}$ of CFC) administered at the end of the 30 minute exercise regiment.

END = End Scenario; A six minute exposure of $500 \mathrm{ppm} \mathrm{CFC} \mathrm{administered} \mathrm{at} \mathrm{the} \mathrm{end} \mathrm{of} \mathrm{the}$ exercise regiment.

BEG = Beginning Scenario; $\mathrm{A}$ six minute exposure of $500 \mathrm{ppm}$ CFC administered at the beginning of the exercise regiment.

$\mathrm{CON}=$ Continuous Scenario; A continuous exposure of $100 \mathrm{ppm} \mathrm{CFC} \mathrm{administered} \mathrm{throughout}$ the exercise regiment.

INT = Intermittent Scenario; An intermittent exposure of 500 ppm CFC administered in 2minute intervals, three times during the exercise regiment.

$\mathrm{SD}=$ Standard Deviation; Let $\mathrm{X}$ be a random variable with probability distribution $\mathrm{f}(\mathrm{x})$ and mean $\mu$. The variance of $X$ is $\sigma^{2}=\sum_{x}(x-\mu)^{2} f(x)$, if $X$ is continuous. The positive square root of the variance, $\sigma$, is called the standard deviation of X (Walpole et. al. , 1998).

$\mathrm{CV}=$ Coefficient of Variation; $\mathrm{CV}=\mathrm{SD} / \mu . \times 100$ 


\section{Chapter 1}

\section{Introduction}

\section{Experiment Rationale and Design}

Coffey et. al. are in the process of correlating fit factors acquired from quantitative fit testing to actual exposure by utilizing CFC-113 (chlorofluorocarbon-113, Freon-113, or 1,1,2trichloro-1,2,2-trifluoroethane) as a biomarker to measure exposure in air purifying respirators (Coffey et. al., 1998; Coffey et. al., 1998; Coffey, 1997). The subject's actual exposure is determined by measuring the amount of CFC-113 in the exhaled breath after they perform a standardized exercise regiment while in a chamber containing CFC-113. Presence of CFC-113 in the exhaled breath represents evidence of respirator leaks and allow the investigators to correlate actual exposure to quantitative respirator fit factors. This thesis was conducted to determine if different exposure scenarios affected end-exhaled CFC-113 concentrations.

This study questions whether equivalent doses (in ppm-min) of CFC-113 administered with variable exposure profiles to human subjects produced statistically equivalent end-exhaled air CFC-113 concentration. That is, if the different exposure scenarios of our study represent different ways in which leaks might occur during respirator tests, then does the onset, duration, and magnitude of the leaks affect the exhaled breath sample CFC-113 concentration given that the overall dose remains the same? If our work shows that the various scenarios of CFC-113 exposure does not influence the exhaled breath concentration of CFC-113, then the differing onsets and duration of leaks during the 30 minute exercise regiment will not confound the exhaled breath data for the respirator tests. In this way, the Coffey studies can be sure that the end-exhaled breath sample is representative of the dose to which the wearer was exposed and not a factor of the leak profile. 
In our study, subjects were exposed to different concentrations of CFC-113 for variable duration while conducting 30-minute exercise regiments. End-exhaled breath samples were collected 25, 30 and 35 minutes after the exercise regiment and the CFC-113 concentration in the breath samples was quantified using gas chromatography. Three comparative CFC-113 exposure scenarios were conducted.

In the first scenario a short duration, high exposure administration of CFC-113 delivered at the beginning or at the end of the half-hour exercise regiment was compared to a long duration, low exposure administration delivered at the beginning or at the end of the exercise regiment. The first scenario questioned whether exhaled breath concentrations from a short duration exposure to a high concentration (1 $\mathrm{min}$ of $500 \mathrm{ppm}$ ) was statistically equivalent to exhaled breath concentration from a long duration exposure to a lower concentration (15.15 min of $33 \mathrm{ppm}$ and a total dose of $500 \mathrm{ppm}-\mathrm{min})$.

The second study compared breath samples when the 500 ppm of CFC-113 was administered at the beginning six minutes of the exercise regiment to those when $\mathrm{CFC}$ was administered at the last six minutes of the regiment (total dose 3,000 ppm-min).

The third study compared continuous CFC-113 exposure (30 min of $100 \mathrm{ppm}$ ) to intermittent exposure (three intermittent 2-min exposures of $500 \mathrm{ppm}$ ) that results in a total dose of 3,000 ppm-min. 


\section{Chapter 2}

\section{Review of Literature}

\section{Properties of CFC-113}

CFC-113 serves as an excellent biomarker because of its chemical properties. Monitoring the exhaled air is best with volatile chemicals such as CFC-113 because they do not decompose upon contact with tissue, they are insoluble in water and thus in the mucus coating of the lungs, and their metabolites are not volatile (Fiserova-Bergerova, 1989). Furthermore, monitoring the exhaled air is convenient and a simple chemical analysis, although it is susceptible to intricate changes of concentration during expiration (Fiserova-Bergerova, 1989).

CFC-113 has a molecular weight of $187.38 \mathrm{~g} / \mathrm{mol}$ and a density of $1.57 \mathrm{~g} / \mathrm{ml}$ (NIOSH, 1997). Its solubility into the blood from the lungs is relatively low, and it is only minimally metabolized, if at all, and is quickly washed out from the tissues in the breath. Since it is quickly eliminated via the lungs after exposure, $\mathrm{CFC}-113$ acts as a perfect non-toxic challenging agent for respirator protection. Exposure can be determined easily by sampling the breath after exposure. Post-exposure, the alveolar air is enriched by CFC-113 carried in the blood from the tissues. Ideally the concentration of vapor in the end-exhaled air equals the concentration in the alveolar air (Fiserova-Bergerova, 1989). In this study, I have collected only end-exhaled breath samples; this reflects the breath at the end of expiration.

CFC-113 has commercial uses as a degreaser, dry cleaning agent and a refrigerant, thus, many studies have been conducted in humans and animals to determine its toxicity (Vainio et. al., 1980; Reinhardt et. al., 1971; Stopps and McLaughlin, 1967). The studies consider liver toxicity, psychomotor skills and psychophysiological tests; the tests revealed that CFC-113 has a 
comparatively low degree of toxicity for very elevated concentrations. The Occupational Safety and Health Administration (OSHA) Permissible Exposure Limit (PEL), the National Institute of Occupational Safety and Health (NIOSH) Recommended Exposure Limit (REL) and the American Conference of Government Industrial Hygienist (ACGIH) Threshold Limit Value (TLV) for CFC-113 is 1000 ppm as an 8 hour time weighted average (29 CFR 1910.100; NIOSH, 1997; ACGIH, 1998). Its principle hazard is narcosis. This study exposes human subjects to a variety of CFC-113 concentrations, however, the maximum exposure is $500 \mathrm{ppm}$ of CFC-113 for 6 minutes, which is well below the PEL.

\section{Pharmacokinetics}

The pharmacokinetics of a substance can be loosely defined as the movement that it undergoes through the body once the body has taken it in via dermal, respiratory, ocular, or ingestive routes. The movement entails absorption into the circulatory system, distribution among the tissues and then elimination from the body through the urine, and as pulmonary washout (Stine and Brown, 1996).

Absorption and elimination are opposite processes and cannot be estimated when both are in operation. For some substances the rate of loss from the body is independent of the concentration in the body and is thus constant over time. This form of elimination is described as a zero-order kinetic process. If however, the elimination of a substance is at first very rapid and then less rapid with subsequent sampling, it follows a first-order process of elimination. A plot of the elimination concentration over time follows a logarithmic decay. In this case, the rate of loss is dependent upon the concentration of the substance in the body. Most substances 
eliminate in a process that resembles first-order pharmacokinetics, however the process is usually more complicated.

The complication arises because the body does not function as a single compartment. Substances move between multiple body compartments. How a substance is absorbed and eliminated from various tissues depends on the lipid content of that tissue, the solubility of the substance, the location of the tissue and the metabolism of the substance (Fiserova-Bergerova et. al., 1980, Astrand, 1975). Therefore there may be 2 or more first-order processes by which the substance is eliminated.

Although a first-order elimination from a single compartment can be determined from the log concentration vs. time plot, a multi-compartment model can only determine the final rate constant from the slowest compartment (Stine and Brown, 1996). Only with more complex mathematical modeling can the faster processes be estimated.

With lipophilic substances, a simple one-dimensional model is not realistic because there is poor solubility in the blood plasma and high solubility in the body lipids. Fatty tissue such as adipose and liver will dissolve lipophilic substances and only slowly eliminate it over days or weeks (Stine and Brown, 1996).

\section{Pharmacokinetics of CFC-113}

CFC-113 is inhaled into the lungs and penetrates to the alveoli where the force of diffusion allows it to be exchanged between the air and the blood. The transfer forms an equilibrium between the concentrations in the alveolar air and in the arterial blood leaving the lungs. The lining of the lungs is only two cells thick and thus transfer occurs very rapidly. Once in the blood, CFC-113 is transferred to the tissues of the body depending on the halogenated 
hydrocarbon's solubility in that tissue compartment. The body tissues are modeled as a small number of discrete compartments characterized by specific perfusion rates and partition coefficients (Auton and Woollen, 1991).

The partition coefficient of a substance describes the solubility of a gas in blood and air and reflects the quotient between them such that a higher partition coefficient reflects a higher concentration in the blood as compared to air (Astrand, 1975). The blood-air partition coefficients affect the transportation rate of organic solvents from the external environment to the tissue and visa versa (Fiserova-Bergerova et. al., 1980). The partition coefficient of CFC113 in the blood is quite low at 0.8 (Morgan et. al., 1972). CFC-113 is absorbed quite slowly from the alveolar air and washes out rapidly from the tissue through the breath (Morgan et. al., 1972; Sato and Nakajime, 1979). CFC-113 is good biomarker for challenging respirators because penetration of the respirator can be associated to CFC-113 in the exhaled breath relatively quickly after the exposure.

The compartments that are commonly described after absorption into the blood are the liver, viscera and brain (rapidly perfused tissue), muscle and skin (slowly perfused) and fat (adipose tissue) (Auton and Woollen, 1991).

Woollen et. al. (1990) described the pharmacokinetics of CFC-113 with a three compartment model whose average half lives of elimination in breath were $0.22,2.3$ and $29 \mathrm{~h}$. They exposed 7 volunteers to 1004, 535, and 258 ppm of CFC-113 for 4 hours and analyzed whole breath samples, end-exhaled breath samples, and blood samples for CFC-113 concentration. They found that collecting end-exhaled samples produced concentrations that were consistently higher than whole breath samples (because it is undiluted by dead space in the 
upper respiratory tract). It is therefore preferable to use this means to collect samples of CFC113 from exposed subjects.

In the Woollen et. al. experiment, only $4.3 \%$ of the dose was recovered unchanged in the breath after exposure which they suggested was due to metabolism of CFC-113, but which has since been shown not to be conclusive (Woollen, 1990; Auton and Woollen, 1991). They also found that the low blood:breath ratios where consistent with the low solubility of CFC-113.

In the Woollen et. al. study, the blood concentrations plateaued after approximately 30 minutes of exposure, which suggests that it only takes that long to equilibrate CFC-113 in the blood. The breath data showed a consistent downward trend. The CFC-113 elimination profile following 4 hour of exposure initially had a very rapid decline (mean $\mathrm{t}_{1 / 2} @ 0.22 \mathrm{~h}$ ) followed by a slower decline (mean $\mathrm{t}_{1 / 2} @ 2.3 \mathrm{~h}$ ). The final phase was a very slow one that could be detected in the breath 7 days after exposure (mean $\mathrm{t}_{1 / 2} @ 29 \mathrm{~h}$ ). Woollen et. al. suggest that the first compartment corresponds to blood, the second to tissues and the third to fatty tissues.

In a companion study, which used a physiologically based mathematical model to determine the pharmacokinetics of CFC-113, Auton and Woolen described the absorption, distribution and elimination of CFC-113 as that of styrene (Auton and Woollen, 1991; Ramsey and Anderson, 1984). They measured the breath and blood concentration for volunteers exposed to 250 ppm CFC-113, and determined that metabolism has only minor influences on the pharmacokinetics following inhalation exposure. Furthermore, exhalation remained the major route of elimination and the rate limiting step for elimination was the perfusion of muscles and fatty tissue which occurs at a half-life of 1.8 and 41 hours, respectively

Fiserova-Bergerova et. al. (1980) used a five compartment model to outline the effects of metabolism and solubility on uptake distribution and exhalation of organic solvents, such as 
CFC-113. They found that rate constants were determined by tissue perfusion, where the five compartments were the lung tissue, the vessel rich brain, the vapor metabolism tissue (such as the liver, kidneys, glands, heart, and GI tract), the muscles and skin, and the adipose tissue. A significant finding was that the exposure duration has a striking effect on the ratio of the substance that gets exhaled and metabolized. More is recovered in the exhaled breath after a short duration than after a long duration exposure. Cardiac output also affects pulmonary washout because physical exertion increases solubility (Fiserova-Bergerova et. al., 1984). These are relevant findings because my report questions how the exposure duration of CFC-113 affects the end-exhaled breath concentrations.

Decker and Crutchfield (1993), attempted to define the relationship between measured respirator fit and actual workplace protection by using CFC-113 as the challenging agent. They determined respirator performance through biological monitoring of exhaled air for levels of the challenging agent, CFC-113. In order to determine the appropriate sampling times, they describe an elimination profile for CFC-113 in their subjects. They used the method of residuals or backfeathering to define CFC-113 elimination curves for their study. This allowed them to separate a complex exponential function into its two underlying functions. In their study each subject was exposed to $1.25,6.0$ and 12.0 ppm CFC-113 for 30 minutes and breath samples were taken ranging from 1 minute to 60 minutes post-exposure. They found that their data fit best into a two compartment pharmacokinetic model, which had the general form:

$$
C=A * \exp ^{-\alpha \tau}+B * \exp ^{-\beta \tau}
$$

Where:

$\mathrm{C}=$ Concentration in breath

$A=$ Concentration at time 0 for central compartment 
$\alpha=$ first-order elimination rate constant for the central compartment

$\beta=$ first order elimination rate constant for the peripheral compartment

$\mathrm{B}=$ concentration at time 0 for the peripheral compartment

They defined the central compartment as that into which the blood is directly absorbed, such as the blood and other highly perfused tissues. The peripheral compartment is that with which the central compartments interacts. They felt that the since the central and peripheral compartments had a desaturation half-life of 4.2 and 52 minutes, respectively, that measurement of the CFC-113 concentration in the breath could begin at 25 minutes. At 25 minutes postexposure the contribution from the central compartment would be minimal. Their desaturation curve reaches a plateau at 30 minutes and remains constant for the entire 60 minutes.

The discrepancy between two-compartment model of Decker and Crutchfield and the three-compartment model of Woollen et. al. lies in the fact that Decker and Crutchfield used very low concentration of CFC-113 and stopped their analysis at 60 minutes, which is $28 \mathrm{~h}$ before the third compartment purge that Woollen et. al. found.

\section{Applying the Pharmacokinetics of CFC-113}

The pharmacokinetic findings are relevant to this report because they are the bases of the decision to use 25, 30 and 35 minutes as the post-exposure breath sampling points. Pilots studies conducted by Sampas Das agree with the pharmacokinetic studies; the pilot revealed that the desaturation profile of CFC-113 stabilizes at approximately 30 minutes post exposure (Das, 1995). This project is a part of the Coffey experiments to relate respirator fit to actual exposure

(Coffey et. al., 1998; Coffey et. al., 1998; Coffey, 1997) and the decision to collect the breath 
samples at 25, 30 and 35 minutes post-exposure is consistent with the experimental design of those two projects.

Furthermore, the pilot study supports my hypothesis that various 30-minute exposure scenarios of CFC-113 should not affect the end-exhaled breath concentrations of CFC-113, because the desaturation profile stays relatively consistent for an hour post exposure. The pharmacokinetic studies place the second compartment desaturation half-life at around 1.8 to 2.3 hours post exposure, which implies that if CFC-113 exposure occurs at the very beginning of the 30 minute exercise regiment, the concentration in the breath sample will consist entirely of peripheral compartment purging. The maximal duration between exposure and sample collect is 65 minutes and the minimal duration is 25 minutes; the pharmacokinetic models suggest that the breath sample concentration should be unaffected by the difference in exposure scenarios. 


\section{Chapter 3}

\section{Materials and Methods}

\section{Subject Selection}

A total of 12 subjects were utilized in these series of experiments, four for each phase. Each of the volunteers for this study participated in the CQAB Human Test Subject Medical Surveillance Program. As part of the program, they completed a health questionnaire and received a medical evaluation when they entered the program and yearly thereafter. These evaluations were approved by the NIOSH Human Subjects Review Board. The evaluation also includes a section on previous exposure to CFC-113. If the subject has a history of exposure to CFC-113 and resulting symptoms, he/she would not be allowed to participate in the study. Furthermore, the tests where scheduled so that no subject would be exposed to CFC-113 without a 72 hour interim between tests.

The type of tests that the subjects performed for this project involved no more than mild physiologic stress. The exertion required was no greater than the certification tests for which the subjects were medically cleared.

\section{Experimental Design}

This project was laboratory based. The purpose of this study is to determine if different CFC-113 exposure scenarios to subjects affect their end-exhaled breath concentrations of CFC113. This study is of interest because CFC-113 has been used a biomarker in numerous experiments which attempt to correlate respirator fit factors to actual measures of protection afforded to the respirator wearer (Coffey et.al., 1998; Coffey et. al., 1998; Coffey, 1997; Decker 
and Crutchfield, 1993). The concentration of CFC-113 in the exhaled breath samples, in these studies, relate to the leaks that occur during the exercise regiment in which the respirator is worn. The studies attempt to correlate the fit factors of respirators to the simulated workplace exposure; in these experiments, the exposure is to CFC-113. Within the context of these studies it is important to determine if the timing and duration of the leaks during the exercise regiment affect exhaled breath CFC-113 concentrations. The purpose of this project was to compare various CFC-113 exposure scenarios of equivalent doses to determine if the timing, duration and peak amounts affect the amount of Freon-113 that was eliminated in the exhaled breath.

There were three phases to the CFC-113 exposure testing: Phase One, Phase Two, Phase Three.

\section{Phase One}

Phase one compared four separate scenarios: long or short duration exposures administered at the beginning or end of the exercise regiment. The issue that this phase of the study addressed was whether a short duration exposure to a high concentration had the same endexhaled breath concentration as a long duration exposure to a lower concentration given that each total exposure (ppm-minutes) was the same.

The four subjects chosen at random were exposed to three replicates of each of the four scenarios resulting in a total of 12 tests per subject. Each subject wore a flexible cup covering his nose and mouth (nose cup) that was connected to a system that provided either pure breathing-quality air (grade D) or breathing-quality air containing 15 to $20 \mathrm{mg} / \mathrm{m}^{3}$ corn oil and one of two concentrations of CFC-113. The flow rate into the nose cup was 35 LPM. They wore the nose cup for 30 minutes and performed the exercise regiment listed below. During the 
exercise regiment, depending on the test, the subject was administered one of two concentrations of CFC-113. After the exercise regiment, subject was taken to a CFC-free waiting room. At 25, 30 and 35 minutes after removing the nose cup, breath samples were collected. The breath samples were analyzed by a gas chromatograph using both a mass selection detector and an electron capture device.

For test one (Short, End), the subject breathed breathing-quality air for the first 29 minutes and breathing-quality air containing 15 to $20 \mathrm{mg} / \mathrm{m}^{3}$ of corn oil and $500 \mathrm{ppm}$ of CFC for the last minute (see Table 3.1- Experiment Design). In test two (Short, Beginning), the subject breathed breathing quality air containing 15 to $20 \mathrm{mg} / \mathrm{m}^{3}$ of corn oil and $500 \mathrm{ppm}$ of CFC-113 for the first minute and just breathing quality air for the remaining 29 minutes. For test three (Long, Beginning), the subject was placed in a chamber that contained $15-20 \mathrm{mg} / \mathrm{m}^{3}$ of corn oil and 33 ppm of CFC-113 for the first 14 minutes 51 seconds and was exposed to breathingquality air for the remaining 15 minutes and 9 seconds. While in the chamber, the subjects donned a Tyvek suit, rubber gloves and goggles to prevent CFC-113 absorption via dermal routes. In test four (Long, End), the subject breathed air for the first 15 minutes and 9 seconds and then was put in the chamber to breath air containing $15-20 \mathrm{mg} / \mathrm{m}^{3}$ of corn oil and $33 \mathrm{ppm}$ CFC-113. The subjects were exposed to a total of $16.67 \mathrm{ppm}$ (or $500 \mathrm{ppm}-\mathrm{min}$ ) of CFC-113 in each tests.

\section{Phase Two. Beginning vs. End Exposure Scenarios}

Phase two consists of only two tests. The four subjects chosen at random were exposed to three replicates of both scenarios resulting in a total of 6 tests per subject. Phase two compares the breath sample concentrations when the subject was exposed to CFC-113 at the beginning of 
the exercise regiment to breath sample concentrations when the CFC-113 exposure occurred at the end of the exercise regiment (see Table 3.1-Experimental Design). The difference between this phase and phase one is that the subjects were exposed to a total of 3000 ppm-min of CFC113 in this phase (the maximal dose allowable in NIOSH testing).

This testing consisted of four subjects, chosen at random, wearing the nose cup described above. In test one (Beginning), the subjects were exposed to air containing $15-20 \mathrm{mg} / \mathrm{m}^{3}$ of corn oil and 500 ppm of CFC-113 for the first 6 minutes of the exercise regiment, and breathingquality air for the remaining 24 minutes. Test two (End) consisted of the subject being exposed to breathing quality air for the first 24 minutes of the test and to air containing $15-20 \mathrm{mg} / \mathrm{m}^{3}$ of corn oil and 500 ppm of CFC-113 for the last 6 minutes of testing. The flow rate into the nose cup was 35 LPM. They wore the nose cup for 30 minutes and performed the exercise regiment listed below. After the exercise regiment, the subject was taken to a CFC-free waiting room. At 25, 30 and 35 minutes after removing the nose cup, breath samples were taken. The breath samples were analyzed by a gas chromatograph using both a mass selection and an electron capture detector.

\section{Phase Three. Continuous vs. Intermittent Exposure Scenarios}

Phase three compares a continuous exposure scenario to an intermittent one (see Table 3.1-Experiment Design). The four subjects chosen at random were exposed to three replicates of both scenarios resulting in a total of 6 tests per subject. This testing consisted of four subjects, chosen at random, utilizing the CFC-113 delivery system described above.

In test one (INT), the subjects were intermittently exposed to air containing $15-20 \mathrm{mg} / \mathrm{m}^{3}$ of corn oil and 500 ppm of CFC-113 for the first 2 minutes, the 13 th -15 th minute and the $28^{\text {th }}-$ 
30th minute of the exercise regiment, and breathing-quality air for the interim 24 minutes. Each subject is exposed to a total of 6 minutes of $500 \mathrm{ppm}$ of CFC resulting in $3000 \mathrm{ppm}$-minutes of CFC-113 exposure. Test two (CON) consisted of the subject being exposed air containing 15-20 $\mathrm{mg} / \mathrm{m}^{3}$ of corn oil and $100 \mathrm{ppm}$ of CFC-113 for the entire 30 minutes of testing.

The flow rate into the nose cup was 35 LPM. They wore the nose cup for 30 minutes and performed the exercise regiment listed below. After the exercise regiment, the subject was taken to a CFC-free waiting room. At 25, 30 and 35 minutes post exposure, breath samples were taken and analyzed by a gas chromatograph.

\section{CFC-113 Delivery System}

The CFC delivery system was a modified air brush that aerosolized a source of 1:7 Cornoil:CFC-113 solution. The house air at 35 LPM was used to propel the solution into the aerosolizer. Fine tuning of the CFC delivery system allowed for precise adjustments of the CFC113 concentration in the nose cup. A diverting lever was used to divert the CFC-113 to the nose cup or out the exhaust depending on the experimental design. When the CFC-113 was diverted out the exhaust, only breathing quality air was directed to the nose cup. The changes in the nose cup concentration were apparent within seconds.

The concentration of CFC-113 in the nose cup was determined by channeling a small continuous volume to a Wilks MIRAN-1A infrared analyzer (IR).

For Phase 1, tests 2 and 3, which required very low concentrations of CFC-113 (33ppm), the CFC delivery system was too imprecise and unstable. For these tests, the subjects were placed in a chamber containing $33 \mathrm{ppm}$ CFC-113 and corn oil. Again the IR was used to establish and monitor the CFC-113 concentration. The $4 \times 4 \times 7 \mathrm{ft}$ chamber was charged by 
injecting $0.510 \mathrm{ml}$ of $\mathrm{CFC}-113$ in the chamber and allowing it to evaporate and equilibrate. When the test designed called for pure breathing quality air, the subjects would return to the CFC delivery system and don the nose cup.

\section{Exercise Regiment}

In every test of the three phases, the subjects were asked to perform the same exercise regiment. This series of movements was the same one used in the Coffey study that compares fit factors to actual exposure. The exercises are intended to simulate the typical movements made in the workplace by individuals dealing with TB patients that would stress a respirator seal. The simulated workplace motions that were used in this study are as follows:

Bending (2 minutes)

Lifting IV bag onto rack (1 minute)

Injecting syringe into IV bag (1 minute)

Picking up a weight of 25 pounds and carrying it ( 2 minutes)

Twisting body left to right while turning head side to side ( 2 minutes)

Opening ambulance doors (1 minute)

Sitting and breathing normally ( 3 minutes)

Bending at waist and straightening up (3 minutes)

Looking left to right (2 minutes)

Reaching from side to side (2 minutes)

Reaching from waist to overhead (2 minutes)

Sitting and breathing normally ( 2 minutes)

Nodding and turning head (2 minutes) 
Standing and breathing normally (2 minutes)

Reaching overhead (1 minute)

Operate control panel (1 minute)

Walking (1 minute)

\section{Breath Sample Collection}

When sampling, collecting alveolar air yields the most consistent results (APHA, 1988). Alveolar breath samples were collected by sampling the expiratory reserve volume. The process involves a forced expiration that follows a passive exhalation into a plastic sampling tube which has been fitted with uni-directional diaphragms on both ends. The proximal end allows air to enter, while the distal end allows air to exit. As the subject exhaled the expiratory reserve volume through the sampler, the distal end of the tube was capped off with a stopcock. Once that was secure, the proximal end was removed from the mouth and capped off. The samples were then analyzed with the GC. The sampler was equipped with a clamped plastic tube that facilitated sample withdrawal.

\section{Breath Sample Analysis}

The breath samples were analyzed with a gas chromatograph (GC) equipped with a mass selector detector (MSD) and an electron capture device (ECD). ECD gas chromatography provides excellent analytical sensitivity in this study because CFC-113 has six electronegative halogens. The ECD has the added advantage of having low sensitivity to potentially interfering substances in the breath. Furthermore, the high boiling point of CFC-113 facilitated separating it 
from the major low boiling point constituents of the breath such as oxygen, nitrogen, carbon dioxide and water vapor (Decker and Crutchfield, 1993).

The GC/MSD/ECD was calibrated using samples of precisely measured concentrations of CFC-113 vapor as internal standards. The HP software measured CFC-113 detection as areas under the CFC-113 peak. These areas were converted into concentrations (in ppm) using a calibration ratio generated every two weeks. The mean of the 25, 30 and 35 minute exhaled breath time points was used to compare the different tests the subjects underwent. The means were analyzed using paired comparison statistics to determine if the different exposure scenarios were equivalent for each subject.

\section{Exposure Concentration}

The nose cup and chamber CFC-113 concentrations were determined prior to each test and continuously monitored the entire 30 minutes of the exercise regiment with a Wilks MIRAN-1A IR. The IR was calibrated every two weeks at 33, 100, $500 \mathrm{ppm}$. At these concentrations the IR was accurate to 1.0. 


\section{TABLE 3.1-Experimental Design}

Phase 1 Long and Short vs. Beginning and End Exposure Scenarios

Test 1

Short, End (SE)

29 min House Air

1 min CFC/ Corn oil (500 PPM)

Test 2

Short, Beginning (SB)

$1 \mathrm{~min}$ CFC/Corn oil (500 PPM)

29 min House Air

Test 3

Long, Beginning (LB)

15 min 9 sec CFC/Corn oil (33 PPM)

$14 \min 51 \mathrm{sec}$ House Air

Test 4

Long, End (LE)

14 min $51 \mathrm{sec}$ House Air

15 min 9 sec CFC/Corn oil (33 PPM)

Phase 2 Beginning vs. End Exposure Scenarios

Test 1

Beginning (BEG)

6 min CFC/Corn oil (500 PPM)

24 min House Air

Test 2

End (END)

24 min House Air

6 min CFC/corn oil (500 PPM)

Phase 3 Intermittent vs. Continuous Scenarios

Test 1

Intermittent (INT)

2 min CFC (500 PPM)

$10 \mathrm{~min}$ House Air

2 min CFC (500 PPM)

13 min House Air

2 min CFC (500 PPM)

1 min House Air

Test 2

Continuous (CON)

30 min CFC (100 PPM) 


\section{Chapter 4}

\section{Results}

The exhaled breath samples were analyzed at 25, 30 and 35 minutes post exposure and quantitated as area under the CFC-113 peaks. The ECD data for all phases is presented in Appendix A. The table lists subject number, test conducted, date the test was conducted, and each of the three post exposure breath samples (recorded as area under the CFC-113 peak). Only the data collected with the ECD was used in the analysis. Approximately every 2 weeks the GC was calibrated using given concentrations of CFC-113 (see Chapter 4 Materials and Methods-Breath Sample Analysis) and a linear regression line was constructed from the graph of CFC-113 concentration verses area under the CFC-113 peak. The line took the form $y=a x$, where "a" represents the conversion coefficient, " $y$ " represents the area values, and "x" represents the CFC113 concentration in ppm (See Appendix C for Calibration Graphs). Table 4.1 lists the conversion coefficients and the calibration dates that were used to convert exhaled breath sampling areas to concentration in ppm. Each ECD area value was divided by the appropriate conversion coefficient to yield the CFC-113 concentration in ppm. The coefficient calculated on $3 / 25 / 98$ is several fold larger than the previous ones because a filament was changed in the GC and the autotune setting was changed from standard to maximum.

\section{Phase One Results}

Phase 1 compares the short duration, high exposure administration of CFC-113 delivered at the beginning (Short, Beginning or SB) or at the end (Short, End or SE) to a long duration, low exposure administration delivered at the beginning (Long, Beginning or LB) or at the end (Long, 
End or LE) of the exercise regiment. The SB and SE scenarios expose the subjects to $500 \mathrm{ppm}$ of CFC-113 for 1 minute whereas the LB and LE scenarios expose the subjects to $33 \mathrm{ppm}$ CFC113 for 15.15 minutes. There were four subjects in this phase, Subject $1,45,5$ and 8 . The different scenarios were compared only within subjects and inter-subject variability was not considered.

Tables 4.2a, 4.3a, 4.4a, 4.5a list the date each test was conducted, the converted CFC-113 exhaled breath concentrations for the 25, 30 and 35-minute post-exposure samples for each test, and the mean and standard deviation values for the three time points for Subjects 1., 45, 5 and 8, respectively. Figures 4.1, 4.2, 4.3, and 4.4 graphically depict the mean exhaled breath concentrations for each repetition of each test for the subjects of phase one. Tables $4.2 \mathrm{~b}, 4.3 \mathrm{~b}$, 4.4b, and 4.5b list the mean and standard deviation (SD) for each scenario type for each subject respectively. The statistical analysis of these data is presented in Chapter 5 .

\section{Subject 1}

The SE had an average breath concentration of $0.63 \pm 0.03 \mathrm{ppm}$ with a $\mathrm{CV}$ of $6 \%$ (Tables 4.2a and 4.2b). The SB test had an average breath concentration of $0.57 \pm 0.06 \mathrm{ppm}$ with a $\mathrm{CV}$ of $11 \%$. LE had the highest average breath concentration of $0.67 \pm 0.25 \mathrm{ppm}$ and the highest $\mathrm{CV}$ of $37 \%$. The LB scenario had an average exhaled breath concentration of $0.56 \pm$ $0.14 \mathrm{ppm}$ with a $\mathrm{CV}$ of $25 \%$. Although the mean values of each scenario are very similar, standard deviation of the LE test shows a large distribution. It is clear even without conducting any statistical analysis that for Subject 1 the four different scenarios produced equivalent exhaled breath concentrations. Therefore for this subject variable onsets, duration, and magnitude of 
CFC-113 exposure does not alter the exhaled breath concentrations at the 25, 30 and 35 minute post-exposure points so long as the overall dose is equivalent.

Subject 45

The results for Subject 45 show more variability than Subject 1 both in the means between each scenario and within the means of each scenario. The SE scenarios had an average breath concentration of $0.92 \pm 0.12 \mathrm{ppm}$ with a CV of $13 \%$. The SB tests had an average breath concentration of $0.69 \pm 0.02 \mathrm{ppm}$ with a $\mathrm{CV}$ of $3 \%$. LE had an average concentration of $0.51 \pm$ $0.14 \mathrm{ppm}$ and a CV of $27 \%$. The LB tests had an average exhaled breath concentration of $0.89 \pm$ 0.35 ppm with a CV of $40 \%$.

\section{Subject 5}

The results for Subject 5 also show considerable variability between the means of each scenario. The SE scenarios had an average breath concentration of $0.78 \pm 0.10 \mathrm{ppm}$ with a CV of $13 \%$. The SB tests had an average breath concentration of $0.74 \pm 0.14 \mathrm{ppm}$ with a CV of $19 \%$. The LE tests had an average concentration of $0.42 \pm 0.10 \mathrm{ppm}$ and a CV of $23 \%$. The LB scenario had an average exhaled breath concentration of $0.57 \pm 0.27 \mathrm{ppm}$ with a CV of $48 \%$. Although the mean values of each scenario are dissimilar, all but the LB scenario have small CVs. With this subject, the SE scenario has the highest average exhaled breath concentration and LE has the lowest. The mean values of the SE and the SB tests are similar, while the LE and LB mean values are similar. 
Subject 8

The results for Subject 8 are depicted in Table 4.5b. There is very little variability within scenarios (Figure 4.4 and Table 4.5b) and all but LB show very similar mean exhaled breath concentrations. The SE scenario had an average breath concentration of $0.69 \pm 0.03 \mathrm{ppm}$ with a $\mathrm{CV}$ of $4 \%$. The SB test had an average breath concentration of $0.70 \pm 0.11 \mathrm{ppm}$ with a CV of 16\%. LE had an average concentration of $0.76 \pm 0.19 \mathrm{ppm}$ and the highest $\mathrm{CV}$ of $26 \%$. The LB scenario had an average exhaled breath concentration of $0.54 \pm 0.11 \mathrm{ppm}$ with a CV of $21 \%$. The CVs ranged from $4 \%$ to $24 \%$, which suggests that the precision falls within reasonable parameters.

\section{Phase Two Results}

Phase 2 compares breath samples when 500 ppm of CFC-113 was administered at the beginning six minutes (BEG) of the exercise regiment to those when CFC was administered at the last six minutes of the regiment (END). Four subjects were used for this phase, Subjects 3, 16, 22 and 26. The different scenarios were compared only within subjects since inter-subject variability could not be eliminated.

Tables 4.6a, 4.7a, 4.8a and 4.9a show the date each test was conducted, the converted CFC-113 exhaled breath concentrations for the 25, 30 and 35-minute post-exposure samples, the average concentration and standard deviation for each test for Subjects 3, 16, 22 and 26, respectively. Tables $4.6 \mathrm{~b}, 4.7 \mathrm{~b}, 4.8 \mathrm{~b}$, and $4.9 \mathrm{~b}$ summarize the mean, standard deviation and $\mathrm{CV}$ of both the BEG and END scenarios for each subject. Figures 4.5, 4.6, 4.7, and 4.8 graphically depict the mean exhaled breath concentrations for each repetition of each test. 
Subject 3

The BEG scenario had an average exhaled breath concentration of $1.34 \pm 0.58 \mathrm{ppm}$ with a CV of $43 \%$. The END test had an average concentration of $1.51 \pm 0.68 \mathrm{ppm}$ with a CV of $45 \%$. Although the mean breath concentrations for both tests are quite similar, the individual breath samples show a wide distribution in both scenarios, thus there is very little precision between repetitions of the same test (Figure 4.5 , Table $4.6 \mathrm{~b}$ ).

\section{Subject 16}

The results for Subject 16 show more variability than the results for Subject 3. The BEG scenario yielded an average exhaled breath concentration of $1.37 \pm 0.56 \mathrm{ppm}$ with a CV of $41 \%$. The END tests showed an average concentration of $1.94 \pm 0.70 \mathrm{ppm}$ with a CV of $36 \%$. Although the mean breath concentrations for both tests show some difference, the individual breath samples show a large distribution in both scenarios, thus there is questionable precision between repetitions of the same test (Figure 4.6 and Tables $4.7 \mathrm{a}$ and $4.7 \mathrm{~b}$ ).

\section{Subject 22}

Subject 22 tests revealed considerably less variability than Subject 16. The BEG scenarios yielded an average exhaled breath concentration of $1.57 \pm 0.25 \mathrm{ppm}$ with a $\mathrm{CV}$ of $16 \%$ (Table 4.8b). The END tests showed an average concentration of $1.57 \pm 0.43 \mathrm{ppm}$ with a CV of $27 \%$ (Table 4.8b). The mean breath concentrations for both tests are exactly the same. The mean breath samples for both BEG and END tests show good precision (Figure 4.7 and Table 4.8a). For Subject 22 it is clear that CFC-113 exposure at the beginning of the exercise regiment does 
not influence the exhaled breath concentrations any more than exposure at the end of the regiment so long as the overall dose is equivalent.

Subject 26

The results for Subject 26 yielded the most variation. The BEG scenarios yielded an average exhaled breath concentration of $1.04 \pm 0.25 \mathrm{ppm}$ with a $\mathrm{CV}$ of $24 \%$. (Table $4.9 \mathrm{~b})$. The END tests showed an average concentration of $1.83 \pm 0.35 \mathrm{ppm}$ with a CV of $19 \%$ (Table $4.9 \mathrm{~b}$ ). Although the mean breath concentrations for both tests are not similar, the mean breath samples in the BEG tests show a smaller distribution than the END tests, thus there is more precision between repetitions of the BEG tests (Figure 4.8 and Table 4.9a). However, the precision varied from $19 \%$ to $24 \%$, which is within acceptable limits.

\section{Phase Three Results}

Phase 3 compares continuous CFC-113 exposures (CON), 30 minutes of $100 \mathrm{ppm}$, to intermittent exposures, three intermittent 2-minute exposures of $500 \mathrm{ppm}$ (INT). Four subjects were used for this phase, Subjects 4, 10, 19 and 29. The different scenarios were compared within subjects.

Tables 4.10a, 4.11a, 4.12a and 4.13a show the date that the test were conducted, the converted CFC-113 exhaled breath concentrations for the 25, 30 and 35-minute post-exposure samples, and the mean and standard deviation of the three time points for each test for Subjects 4, 10, 19, and 29, respectively. Figures 4.9, 4.10, 4.11 and 4.12 graphically depict the mean exhaled breath concentrations for each repetition of each test of each of the four subjects. Tables 
4.10b, 4.11b, 4.12b, and 4.13b list the mean, SD and CV for each scenario type for Subjects 4, 10,19 , and 29 , respectively.

Subject 4

The CON scenarios yielded an average exhaled breath concentration of $1.44 \pm 0.27 \mathrm{ppm}$ with a CV of $19 \%$ (Table $4.10 \mathrm{~b}$ ). The INT tests showed an average concentration of $1.23 \pm 0.33$ ppm with a $\mathrm{CV}$ of $27 \%$ (Table 4.10b). The mean breath concentrations for both tests are quite similar, and the mean breath samples in both the CON and INT tests show fairly good precision between repetitions of the tests (Figure 4.9 and Table 4.10a).

Subject 10

The INT scenarios yielded an average exhaled breath concentration of $1.15 \pm 0.32 \mathrm{ppm}$ with a CV of $28 \%$ (Table $4.11 \mathrm{~b}$ ). The CON tests showed an average concentration of $1.15 \pm 0.34$ ppm with a CV of $30 \%$ (Table 4.11b). Although the mean breath concentrations for both tests are the same, the mean breath samples for both scenarios show a good deal of variability (Figure 4.10 and Table 4.11a). For this subject, a comparison of the mean exhaled breath samples were the same for both a continuous and an intermittent exposure, thus the nature of CFC-113 exposure does not bias the exhaled breath sample concentration.

\section{Subject 19}

The results for Subject 19 are not as definite as those for Subject 10. The INT scenarios yielded an average exhaled breath concentration of $0.93 \pm 0.21 \mathrm{ppm}$ with a CV of $23 \%$ (Table 4.12b). The CON tests showed an average concentration of $1.24 \pm 0.41 \mathrm{ppm}$ with a CV of $33 \%$ 
(Table 4.12b). Although the mean breath concentrations for both tests are similar, the mean breath samples in the CON scenario show slightly less precision than the INT test (Figure 4.11 and Table 4.12a).

Subject 29

The results for Subject 29 yielded more variation than those of Subject 19 with CV ranging from $36 \%$ to $43 \%$. The INT scenarios yielded an average exhaled breath concentration of $2.01 \pm 0.86 \mathrm{ppm}$ with a CV of $43 \%$ (Table 4.13b). The CON tests showed an average concentration of $1.63 \pm 0.60 \mathrm{ppm}$ with a CV of $36 \%$ (Table 4.13b). Although the mean breath concentrations for both tests are similar, the variability is rather high in both (Figure 4.12 and Table 4.13a). 
TABLE 4.1

Area to Concentration Conversion Coefficients for the ECD-GC

\begin{tabular}{|c|c|}
\hline Calibration Date & Coefficent \\
\hline $1 / 9 / 98$ & 97802 \\
\hline $2 / 23 / 98$ & 99910 \\
\hline $3 / 9 / 98$ & 80211 \\
\hline $3 / 23 / 98$ & 77279 \\
\hline $3 / 25 / 98$ & 186508 \\
\hline
\end{tabular}

Note: The line took the form $y=a x$, where "a" represents the conversion coefficient, "y" represents the area values, and "x" represents the CFC-113 concentration in ppm. See Appendix C for Calibration Graphs. 
TABLE 4.2a

Phase 1 Results for Subject 1

\begin{tabular}{|c|c|c|c|c|c|c|c|}
\hline \multicolumn{4}{|c|}{} & \multicolumn{5}{c|}{ CFC-113 EXHALED BREATH CONCENTRATION } \\
(PPM) \\
\hline Subject & Date & Test & $\mathbf{2 5}$ min. & $\mathbf{3 0}$ min. & $\mathbf{3 5}$ min. & Mean & +/- SD \\
\hline 1 & $3 / 5 / 98$ & SE & 0.70 & 0.58 & 0.71 & $\mathbf{0 . 6 6}$ & $\mathbf{0 . 0 7}$ \\
\hline 1 & $3 / 27 / 98$ & SE & 0.67 & 0.57 & 0.51 & $\mathbf{0 . 5 8}$ & $\mathbf{0 . 0 8}$ \\
\hline 1 & $3 / 31 / 98$ & SE & 0.65 & 0.64 & 0.62 & $\mathbf{0 . 6 4}$ & $\mathbf{0 . 0 1}$ \\
\hline 1 & $2 / 20 / 98$ & SB & 0.67 & 0.52 & 0.74 & $\mathbf{0 . 6 4}$ & $\mathbf{0 . 1 1}$ \\
\hline 1 & $2 / 24 / 98$ & SB & 0.60 & 0.56 & 0.50 & $\mathbf{0 . 5 5}$ & $\mathbf{0 . 0 5}$ \\
\hline 1 & $3 / 19 / 98$ & SB & 0.56 & 0.51 & 0.48 & $\mathbf{0 . 5 2}$ & $\mathbf{0 . 0 4}$ \\
\hline 1 & $2 / 2 / 98$ & LE & 0.97 & 0.87 & 0.89 & $\mathbf{0 . 9 1}$ & $\mathbf{0 . 0 5}$ \\
\hline 1 & $2 / 6 / 98$ & LE & 0.71 & 0.62 & 0.74 & $\mathbf{0 . 6 9}$ & $\mathbf{0 . 0 6}$ \\
\hline 1 & $2 / 27 / 98$ & LE & 0.46 & 0.40 & 0.38 & $\mathbf{0 . 4 1}$ & $\mathbf{0 . 0 4}$ \\
\hline 1 & $2 / 13 / 98$ & LB & 0.69 & 0.67 & 0.64 & $\mathbf{0 . 6 7}$ & $\mathbf{0 . 0 3}$ \\
\hline 1 & $4 / 9 / 98$ & LB & 0.57 & 0.62 & 0.63 & $\mathbf{0 . 6 1}$ & $\mathbf{0 . 0 3}$ \\
\hline 1 & $3 / 26 / 98$ & LB & 0.34 & 0.38 & 0.48 & $\mathbf{0 . 4 0}$ & $\mathbf{0 . 0 7}$ \\
\hline
\end{tabular}

Note: $\mathrm{SE}=$ Short, End; SB= Short, Beginning; LE= Long, End; LB= Long, Beginning 
TABLE 4.2b

Summary of Results for Subject 1

\begin{tabular}{|c|c|c|c|}
\hline Test & Mean & +/- SD & CV (\%) \\
\hline SE & 0.63 & 0.04 & 6 \\
\hline SB & 0.57 & 0.06 & 11 \\
\hline LE & 0.67 & 0.25 & 37 \\
\hline LB & 0.56 & 0.14 & 25 \\
\hline
\end{tabular}


Figure 4.1 Comparison of Phase 1 Scenarios for Subject 1

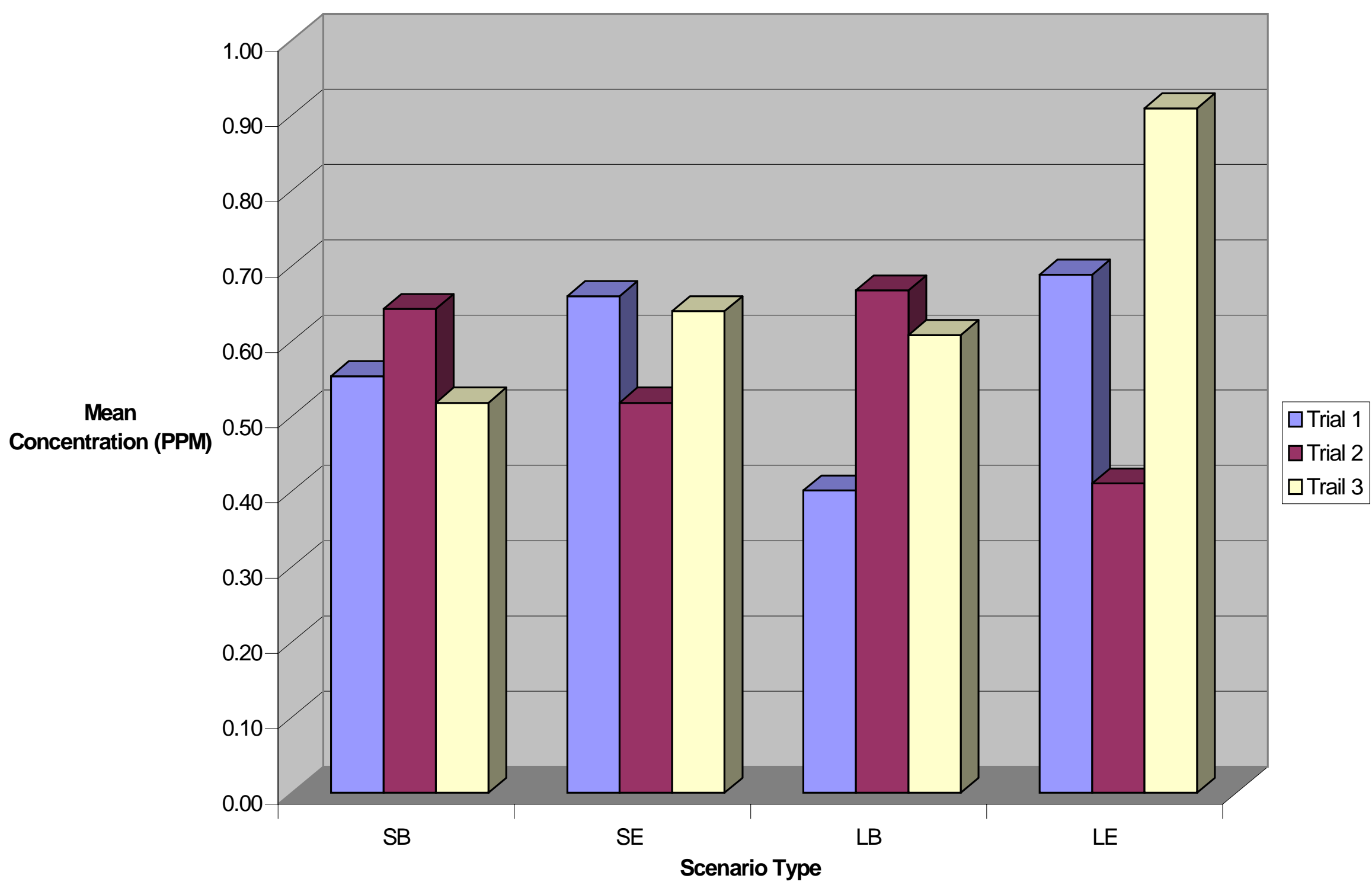


TABLE 4.3a

Phase 1 Results for Subject 45

\begin{tabular}{|c|c|c|c|c|c|c|c|}
\hline \multicolumn{4}{|c|}{} & \multicolumn{5}{|c|}{ CFC-113 EXHALED BREATH CONCENTRATION } \\
(PPM) \\
\hline Subject & Date & Test & $\mathbf{2 5}$ min. & $\mathbf{3 0}$ min. & $\mathbf{3 5}$ min. & Mean & +/- SD \\
\hline 45 & $2 / 5 / 98$ & SE & 1.29 & 1.07 & 0.83 & $\mathbf{1 . 0 6}$ & $\mathbf{0 . 2 3}$ \\
\hline 45 & $4 / 15 / 98$ & SE & 0.88 & 0.72 & 0.91 & $\mathbf{0 . 8 3}$ & $\mathbf{0 . 1 0}$ \\
\hline 45 & $4 / 17 / 98$ & SE & 0.88 & 0.83 & 0.89 & $\mathbf{0 . 8 7}$ & $\mathbf{0 . 0 4}$ \\
\hline 45 & $2 / 12 / 98$ & SB & 0.70 & 0.67 & 0.72 & $\mathbf{0 . 6 9}$ & $\mathbf{0 . 0 2}$ \\
\hline 45 & $3 / 31 / 98$ & SB & 0.67 & 0.74 & 0.71 & $\mathbf{0 . 7 1}$ & $\mathbf{0 . 0 3}$ \\
\hline 45 & $4 / 14 / 98$ & SB & 0.67 & 0.67 & 0.66 & $\mathbf{0 . 6 7}$ & $\mathbf{0 . 0 0}$ \\
\hline 45 & $3 / 26 / 98$ & LE & 0.38 & 0.33 & 0.37 & $\mathbf{0 . 3 6}$ & $\mathbf{0 . 0 3}$ \\
\hline 45 & $4 / 10 / 98$ & LE & 0.54 & 0.51 & 0.51 & $\mathbf{0 . 5 2}$ & $\mathbf{0 . 0 2}$ \\
\hline 45 & $4 / 16 / 98$ & LE & 0.65 & 0.60 & 0.66 & $\mathbf{0 . 6 4}$ & $\mathbf{0 . 0 3}$ \\
\hline 45 & $2 / 19 / 98$ & LB & 0.75 & 0.71 & 0.74 & $\mathbf{0 . 7 3}$ & $\mathbf{0 . 0 2}$ \\
\hline 45 & $3 / 20 / 98$ & LB & 1.23 & 1.09 & 1.55 & $\mathbf{1 . 2 9}$ & $\mathbf{0 . 2 3}$ \\
\hline 45 & $3 / 27 / 98$ & LB & 0.60 & 0.64 & 0.68 & $\mathbf{0 . 6 4}$ & $\mathbf{0 . 0 4}$ \\
\hline
\end{tabular}

Note: $\mathrm{SE}=$ Short, End; $\mathrm{SB}=$ Short, Beginning; LE= Long, End; LB= Long, Beginning 
TABLE 4.3b

Summary of Results for Subject 45

\begin{tabular}{|c|c|c|c|}
\hline Test & Mean & +/-SD & CV (\%) \\
\hline SE & 0.92 & 0.12 & 13 \\
\hline SB & 0.69 & 0.02 & 3 \\
\hline LE & 0.51 & 0.14 & 27 \\
\hline LB & 0.89 & 0.35 & 40 \\
\hline
\end{tabular}


Figure 4.2 Comparison of Phase 1 Scenarios for Subject 45

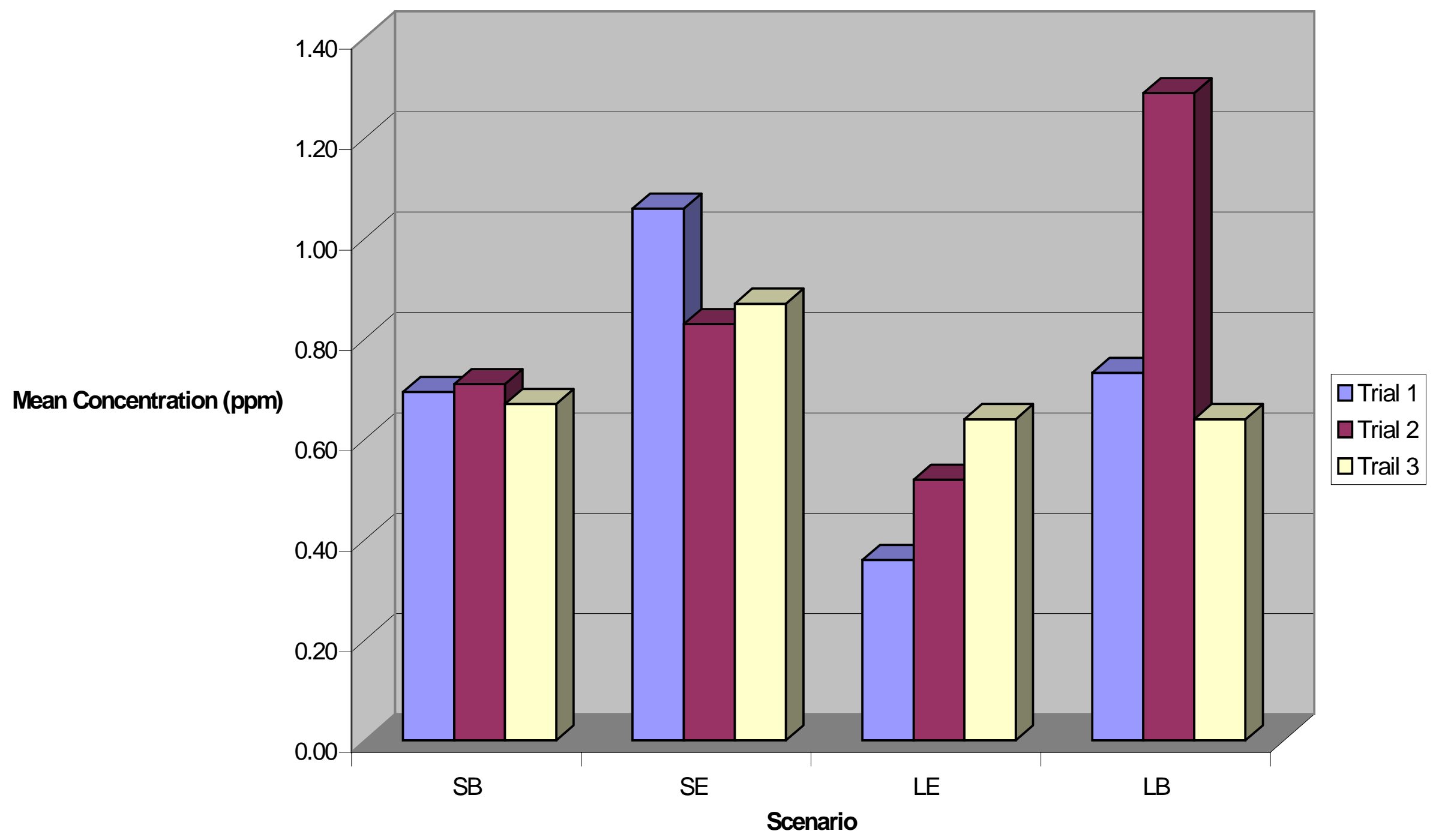


TABLE 4.4a

Phase 1 Results for Subject 5

\begin{tabular}{|c|c|c|c|c|c|c|c|}
\hline \multicolumn{4}{|c|}{} & \multicolumn{5}{c|}{ CFC-113 EXHALED BREATH CONCENTRATION } \\
(PPM) \\
\hline Subject & Date & Test & $\mathbf{2 5}$ min. & $\mathbf{3 0}$ min. & $\mathbf{3 5}$ min. & Mean & +/- SD \\
\hline 5 & $2 / 3 / 98$ & SE & 0.82 & 0.75 & 0.75 & $\mathbf{0 . 7 7}$ & $\mathbf{0 . 0 4}$ \\
\hline 5 & $2 / 24 / 98$ & SE & 0.79 & 0.64 & 0.64 & $\mathbf{0 . 6 9}$ & $\mathbf{0 . 0 9}$ \\
\hline 5 & $3 / 17 / 98$ & SE & 0.95 & 0.87 & 0.85 & $\mathbf{0 . 8 9}$ & $\mathbf{0 . 0 5}$ \\
\hline 5 & $2 / 6 / 98$ & SB & 0.81 & 0.68 & 0.66 & $\mathbf{0 . 7 2}$ & $\mathbf{0 . 0 8}$ \\
\hline 5 & $2 / 17 / 98$ & SB & 0.92 & 0.97 & 0.75 & $\mathbf{0 . 8 8}$ & $\mathbf{0 . 1 2}$ \\
\hline 5 & $3 / 3 / 98$ & SB & 0.66 & 0.63 & 0.54 & $\mathbf{0 . 6 1}$ & $\mathbf{0 . 0 6}$ \\
\hline 5 & $1 / 23 / 98$ & LE & 0.36 & 0.38 & 0.30 & $\mathbf{0 . 3 5}$ & $\mathbf{0 . 0 4}$ \\
\hline 5 & $1 / 30 / 98$ & LE & 0.41 & 0.39 & 0.38 & $\mathbf{0 . 4 0}$ & $\mathbf{0 . 0 2}$ \\
\hline 5 & $2 / 13 / 98$ & LE & 0.52 & 0.53 & 0.55 & $\mathbf{0 . 5 3}$ & $\mathbf{0 . 0 1}$ \\
\hline 5 & $1 / 28 / 98$ & LB & 0.39 & 0.40 & 0.45 & $\mathbf{0 . 4 1}$ & $\mathbf{0 . 0 3}$ \\
\hline 5 & $2 / 10 / 98$ & LB & 0.74 & 1.01 & 0.90 & $\mathbf{0 . 8 8}$ & $\mathbf{0 . 1 3}$ \\
\hline 5 & $2 / 27 / 98$ & LB & 0.44 & 0.39 & 0.40 & $\mathbf{0 . 4 1}$ & $\mathbf{0 . 0 3}$ \\
\hline
\end{tabular}

Note: $S E=$ Short, End; SB= Short, Beginning; LE= Long, End; LB= Long, Beginning 
TABLE 4.4b

Summary of Results for Subject 5

\begin{tabular}{|c|c|c|c|}
\hline Test & Mean & $-/+$ SD & CV (\%) \\
\hline SE & 0.78 & 0.10 & 13 \\
\hline SB & 0.74 & 0.14 & 19 \\
\hline LE & 0.42 & 0.10 & 23 \\
\hline LB & 0.57 & 0.27 & 48 \\
\hline
\end{tabular}


Figure 4.3 Comparison of Phase 1 Scenarios for Subject 5

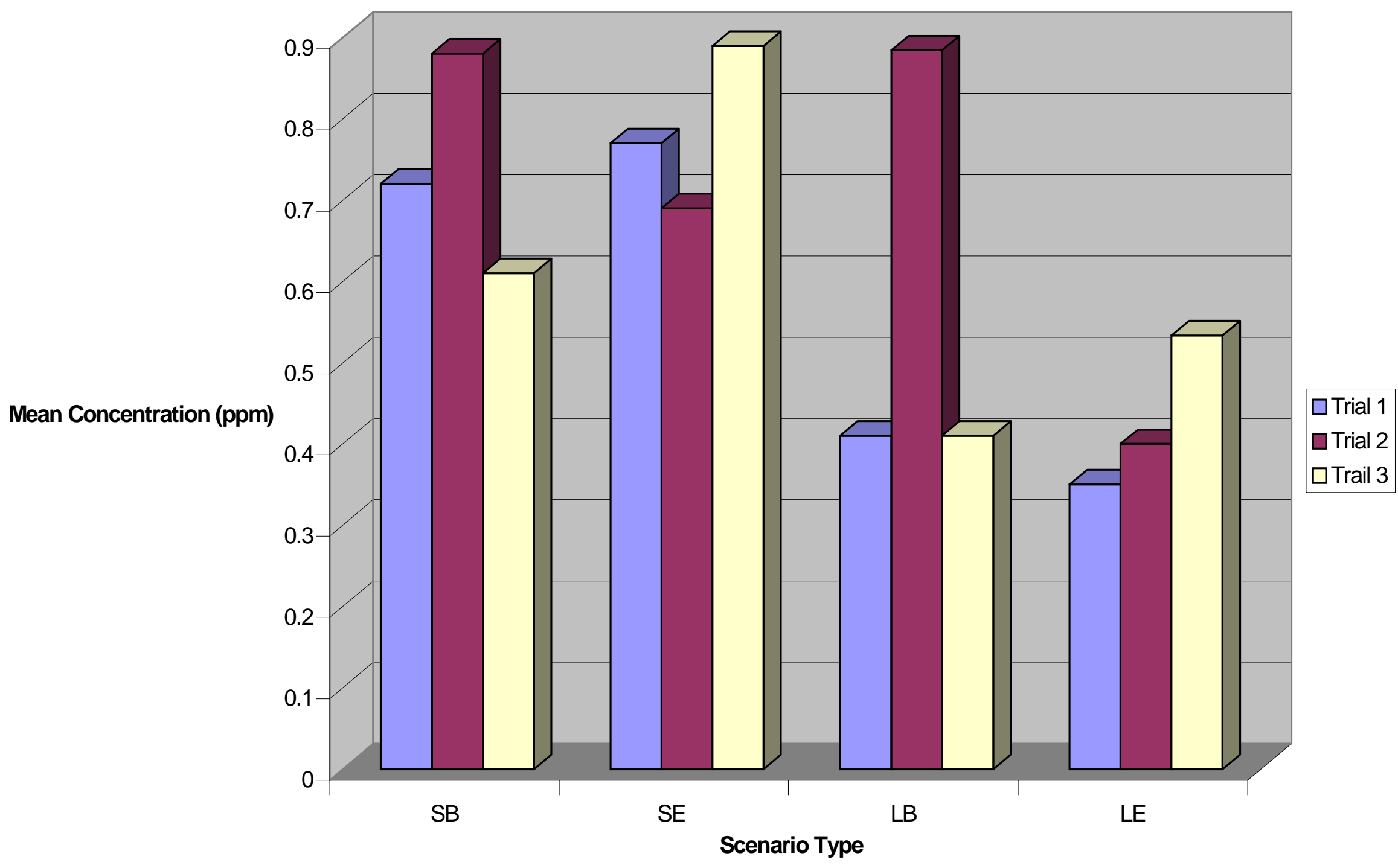


TABLE 4.5a

Phase 1 Results for Subject 8

\begin{tabular}{|c|c|c|c|c|c|c|c|}
\hline \multicolumn{4}{|c|}{} & \multicolumn{5}{|c|}{ CFC-113 EXHALED BREATH CONCENTRATION } \\
(PPM) \\
\hline Subject & Date & Test & $\mathbf{2 5}$ min. & $\mathbf{3 0}$ min. & 35 min. & Mean & +/- SD \\
\hline 8 & $2 / 10 / 98$ & SE & 0.70 & 0.68 & 0.61 & $\mathbf{0 . 6 6}$ & $\mathbf{0 . 0 5}$ \\
\hline 8 & $3 / 3 / 98$ & SE & 0.76 & 0.60 & 0.79 & $\mathbf{0 . 7 2}$ & $\mathbf{0 . 1 0}$ \\
\hline 8 & $3 / 26 / 98$ & SE & 0.70 & 0.77 & 0.63 & $\mathbf{0 . 7 0}$ & $\mathbf{0 . 0 7}$ \\
\hline 8 & $2 / 5 / 98$ & SB & 0.84 & 0.85 & 0.79 & $\mathbf{0 . 8 3}$ & $\mathbf{0 . 0 3}$ \\
\hline 8 & $2 / 24 / 98$ & SB & 0.63 & 0.64 & 0.69 & $\mathbf{0 . 6 5}$ & $\mathbf{0 . 0 3}$ \\
\hline 8 & $4 / 1 / 98$ & SB & 0.64 & 0.56 & 0.64 & $\mathbf{0 . 6 2}$ & $\mathbf{0 . 0 5}$ \\
\hline 8 & $2 / 12 / 98$ & LE & 0.64 & 0.63 & 0.69 & $\mathbf{0 . 6 5}$ & $\mathbf{0 . 0 3}$ \\
\hline 8 & $2 / 26 / 98$ & LE & 0.78 & 0.57 & 0.57 & $\mathbf{0 . 6 4}$ & $\mathbf{0 . 1 2}$ \\
\hline 8 & $3 / 19 / 98$ & LE & 0.97 & 0.94 & 1.04 & $\mathbf{0 . 9 8}$ & $\mathbf{0 . 0 5}$ \\
\hline 8 & $1 / 30 / 98$ & LB & 0.43 & 0.42 & PROB & $\mathbf{0 . 4 2}$ & $\mathbf{0 . 0 1}$ \\
\hline 8 & $2 / 17 / 98$ & LB & 0.58 & 0.63 & 0.70 & $\mathbf{0 . 6 4}$ & $\mathbf{0 . 0 6}$ \\
\hline 8 & $2 / 19 / 98$ & LB & 0.47 & 0.57 & 0.66 & $\mathbf{0 . 5 7}$ & $\mathbf{0 . 0 9}$ \\
\hline
\end{tabular}

Note: SE= Short, End; SB= Short, Beginning; LE= Long, End; LB= Long, Beginning 
TABLE 4.5b

Summary of Results for Subject 8

\begin{tabular}{|c|c|c|c|}
\hline Test & Mean & +/- SD & CV (\%) \\
\hline SE & 0.69 & 0.03 & 4 \\
\hline SB & 0.70 & 0.11 & 16 \\
\hline LE & 0.76 & 0.19 & 26 \\
\hline LB & 0.54 & 0.11 & 21 \\
\hline
\end{tabular}


Figure 4.4 Comparison of Phase 1 Scenarios for Subject 8

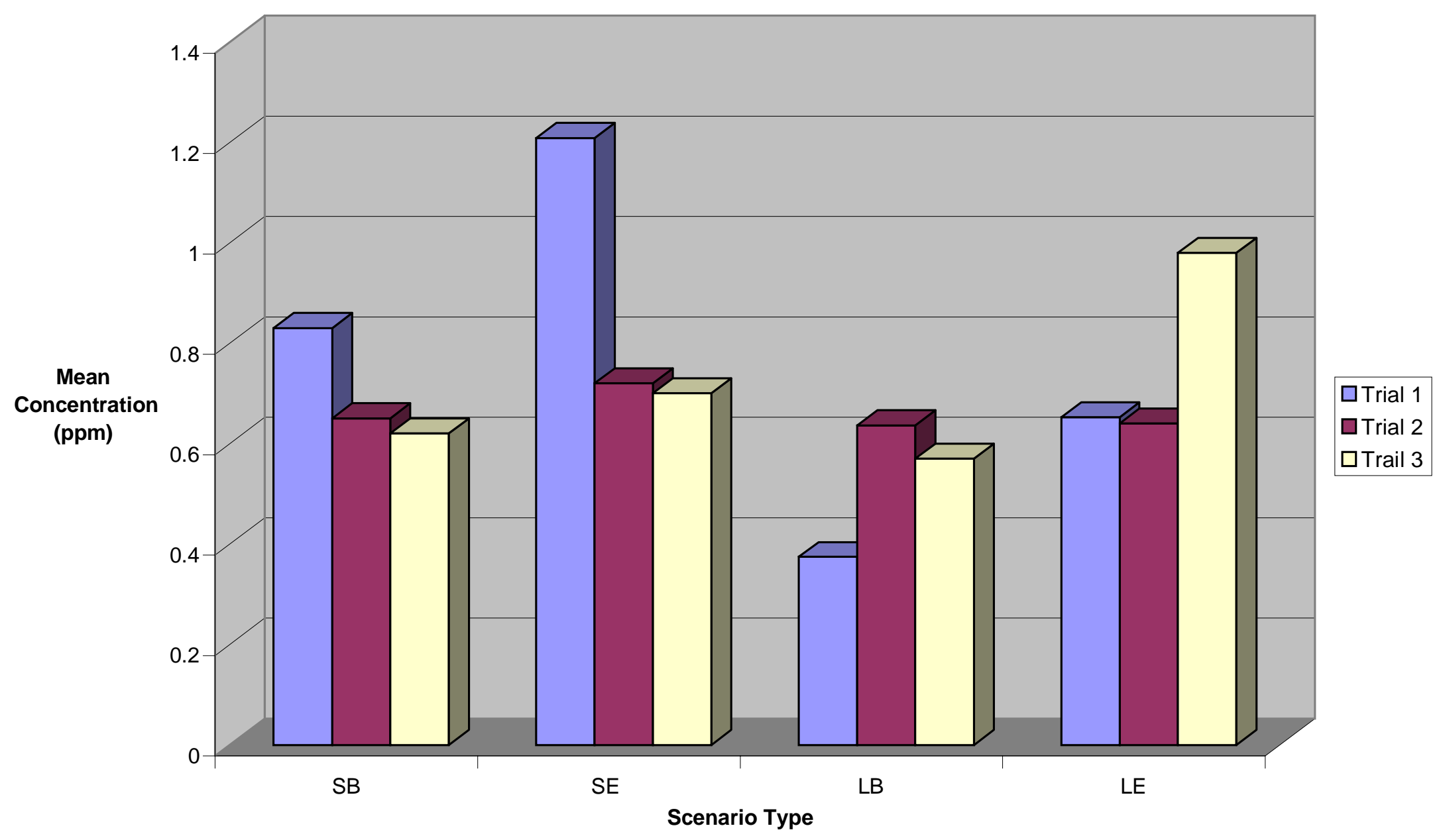


TABLE 4.6a

Results for Subject 3 Comparison of Beginning vs. End Scenarios

\begin{tabular}{|c|c|c|c|c|c|c|c|}
\hline \multicolumn{2}{|c|}{} & \multicolumn{5}{|c|}{ CFC-113 EXHALED BREATH CONCENTRATION } \\
(PPM) \\
\hline Subject & Date & Test & $\mathbf{2 5}$ min. & $\mathbf{3 0}$ min. & $\mathbf{3 5}$ min. & Mean & +/- SD \\
\hline 3 & $2 / 6 / 98$ & BEG & 1.91 & 1.85 & 1.71 & $\mathbf{1 . 8 2}$ & $\mathbf{0 . 1 0}$ \\
\hline 3 & $2 / 20 / 98$ & BEG & 1.40 & 1.55 & 1.53 & $\mathbf{1 . 5 0}$ & $\mathbf{0 . 0 8}$ \\
\hline 3 & $3 / 27 / 98$ & BEG & 0.67 & 0.64 & 0.80 & $\mathbf{0 . 7 0}$ & $\mathbf{0 . 0 9}$ \\
\hline 3 & $2 / 13 / 98$ & END & 0.85 & 0.74 & 0.87 & $\mathbf{0 . 8 2}$ & $\mathbf{0 . 0 7}$ \\
\hline 3 & $2 / 27 / 98$ & END & 1.53 & 1.53 & 1.52 & $\mathbf{1 . 5 3}$ & $\mathbf{0 . 0 1}$ \\
\hline 3 & $3 / 20 / 98$ & END & 2.61 & 2.11 & 1.80 & $\mathbf{2 . 1 7}$ & $\mathbf{0 . 4 1}$ \\
\hline
\end{tabular}

TABLE 4.6b

Summary of Results for Subject 3

\begin{tabular}{|c|c|c|c|}
\hline Test & Mean & +/- SD & CV (\%) \\
\hline BEG & 1.34 & 0.58 & 43 \\
\hline END & 1.51 & 0.68 & 45 \\
\hline
\end{tabular}


Figure 4.5 Comparison of Beginning vs. End Scenarios for Subject 3

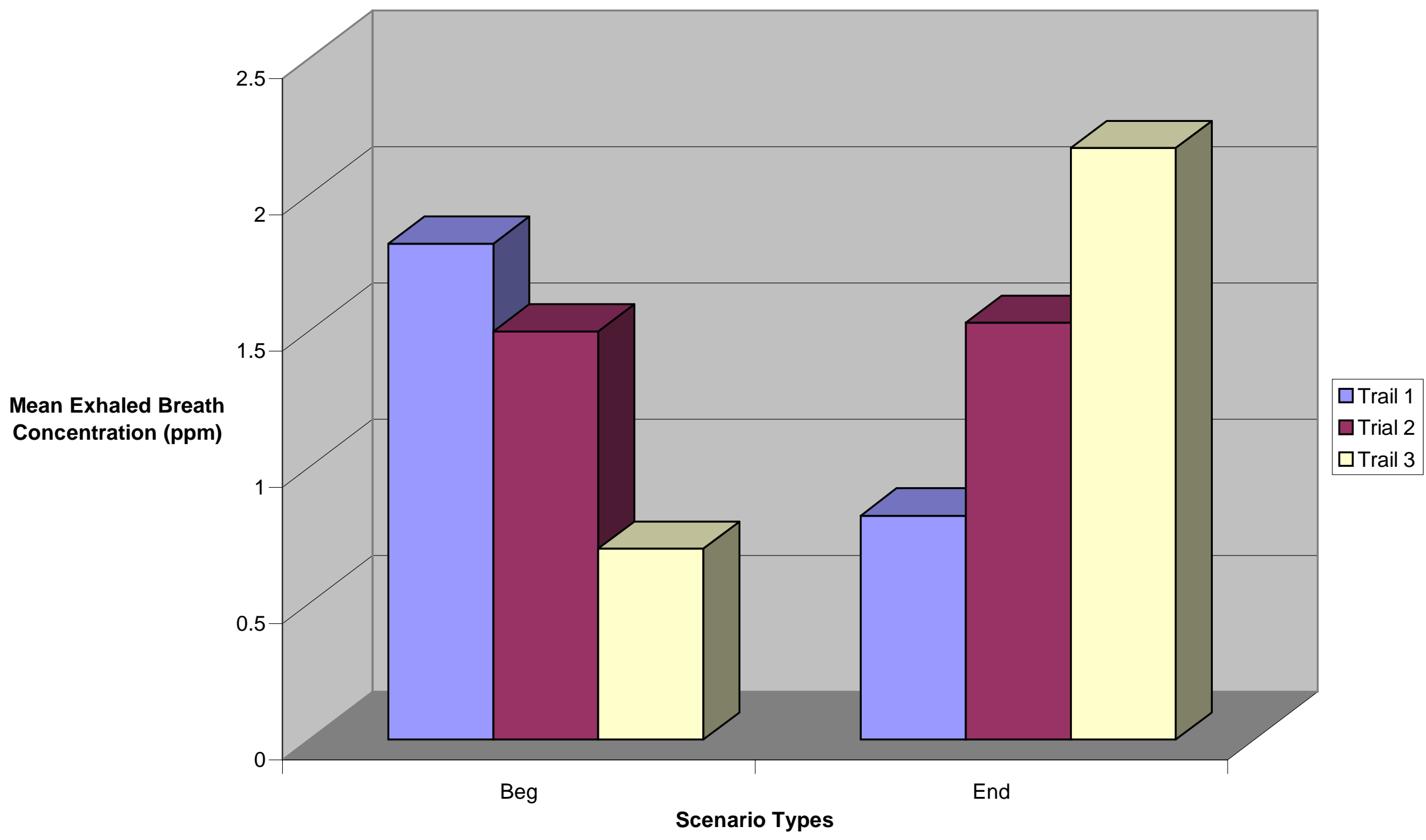


TABLE 4.7a

Results for Subject 16 Comparison of Beginning vs. End Scenarios

\begin{tabular}{|c|c|c|c|c|c|c|c|}
\hline \multicolumn{3}{|c|}{} & \multicolumn{5}{|c|}{ CFC-113 EXHALED BREATH CONCENTRATION } \\
(PPM) \\
\hline Subject & Date & Test & $\mathbf{2 5}$ min. & $\mathbf{3 0}$ min. & $\mathbf{3 5}$ min. & Mean & +/- SD \\
\hline 16 & $2 / 2 / 98$ & BEG & 2.40 & 1.99 & 1.61 & $\mathbf{2 . 0 0}$ & $\mathbf{0 . 4 0}$ \\
\hline 16 & $2 / 23 / 98$ & BEG & 0.90 & 1.03 & 0.92 & $\mathbf{0 . 9 5}$ & $\mathbf{0 . 0 7}$ \\
\hline 16 & $3 / 3 / 98$ & BEG & 1.22 & 1.21 & 1.02 & $\mathbf{1 . 1 5}$ & $\mathbf{0 . 1 1}$ \\
\hline 16 & $3 / 17 / 98$ & END & 2.17 & 1.98 & 1.71 & $\mathbf{1 . 9 5}$ & $\mathbf{0 . 2 3}$ \\
\hline 16 & $3 / 20 / 98$ & END & 3.10 & 2.50 & 2.29 & $\mathbf{2 . 6 3}$ & $\mathbf{0 . 4 2}$ \\
\hline 16 & $3 / 31 / 98$ & END & 1.42 & 1.17 & 1.14 & $\mathbf{1 . 2 4}$ & $\mathbf{0 . 1 5}$ \\
\hline
\end{tabular}

TABLE 4.7b

Summary of Results for Subject 16

\begin{tabular}{|c|c|c|c|}
\hline Test & Mean & +/- SD & CV (\%) \\
\hline BEG & 1.37 & 0.56 & 41 \\
\hline END & 1.94 & 0.70 & 36 \\
\hline
\end{tabular}


Figure 4.6 Comparison of Beginning vs. End Scenarios for Subject 16

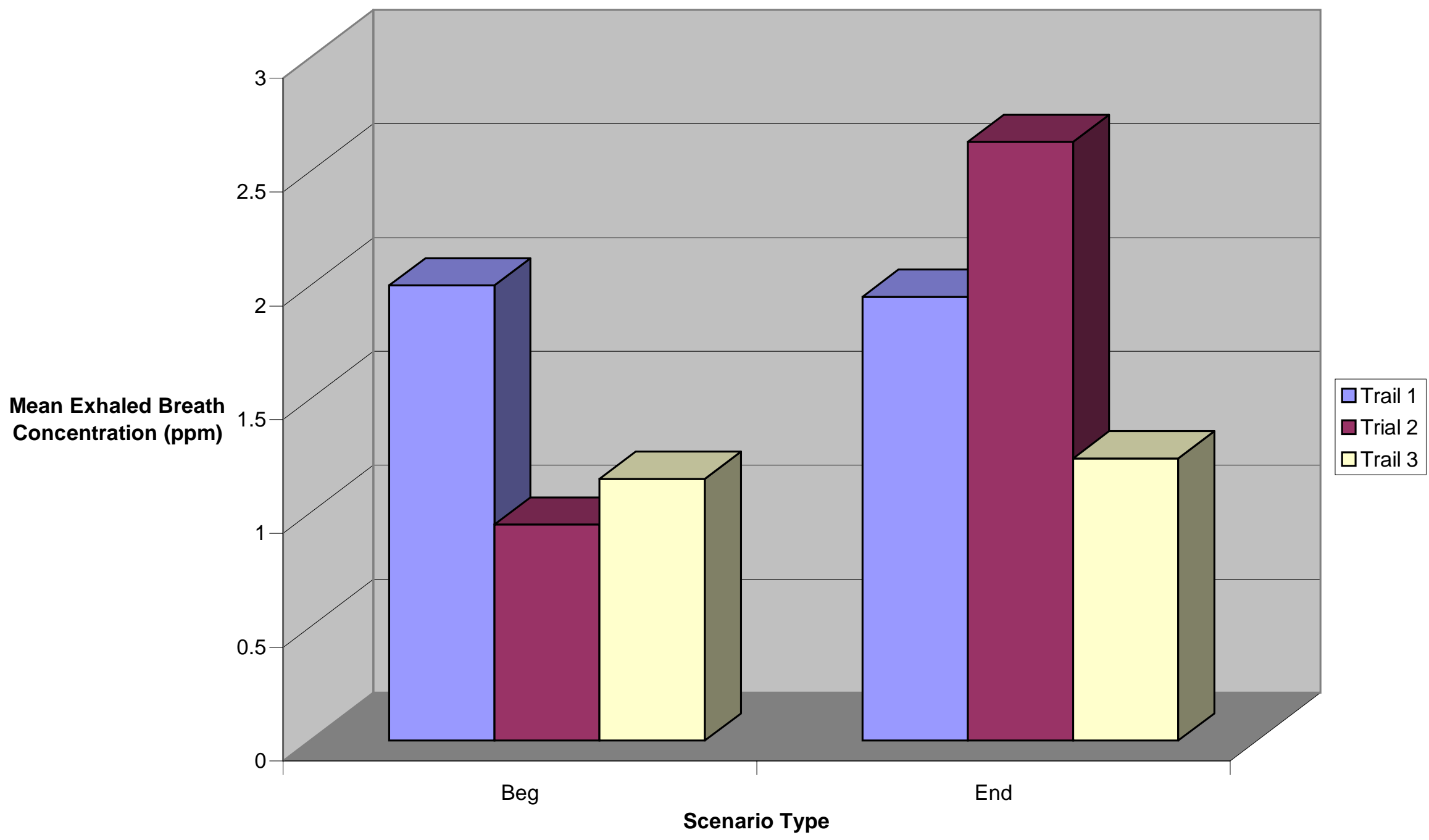


TABLE 4.8a

Results for Subject 22 Comparison of Beginning vs. End Scenarios

\begin{tabular}{|c|c|c|c|c|c|c|c|}
\hline \multicolumn{4}{|c|}{} & \multicolumn{5}{|c|}{ CFC-113 EXHALED BREATH CONCENTRATION } \\
(PPM) \\
\hline Subject & Date & Test & $\mathbf{2 5}$ min. & $\mathbf{3 0}$ min. & $\mathbf{3 5}$ min. & Mean & +/- SD \\
\hline 22 & $2 / 5 / 98$ & BEG & 1.56 & 1.14 & 1.26 & $\mathbf{1 . 3 2}$ & $\mathbf{0 . 2 2}$ \\
\hline 22 & $2 / 26 / 98$ & BEG & 1.68 & 1.69 & 1.34 & $\mathbf{1 . 5 7}$ & $\mathbf{0 . 2 0}$ \\
\hline 22 & $3 / 5 / 98$ & BEG & 2.19 & 1.76 & 1.48 & $\mathbf{1 . 8 1}$ & $\mathbf{0 . 3 6}$ \\
\hline 22 & $1 / 29 / 98$ & END & 2.36 & 2.08 & 1.75 & $\mathbf{2 . 0 6}$ & $\mathbf{0 . 3 0}$ \\
\hline 22 & $2 / 12 / 98$ & END & 1.59 & 1.36 & 1.13 & $\mathbf{1 . 3 6}$ & $\mathbf{0 . 2 3}$ \\
\hline 22 & $2 / 19 / 98$ & END & 1.71 & 1.24 & 0.89 & $\mathbf{1 . 2 8}$ & $\mathbf{0 . 4 1}$ \\
\hline
\end{tabular}

TABLE 4.8b

Summary of Results for Subject 22

\begin{tabular}{|c|c|c|c|}
\hline Test & Mean & +/- SD & CV (\%) \\
\hline BEG & 1.57 & 0.25 & 16 \\
\hline END & 1.57 & 0.43 & 27 \\
\hline
\end{tabular}


Figure 4.7 Comparison of Beginning vs. End Scenarios for Subject 22

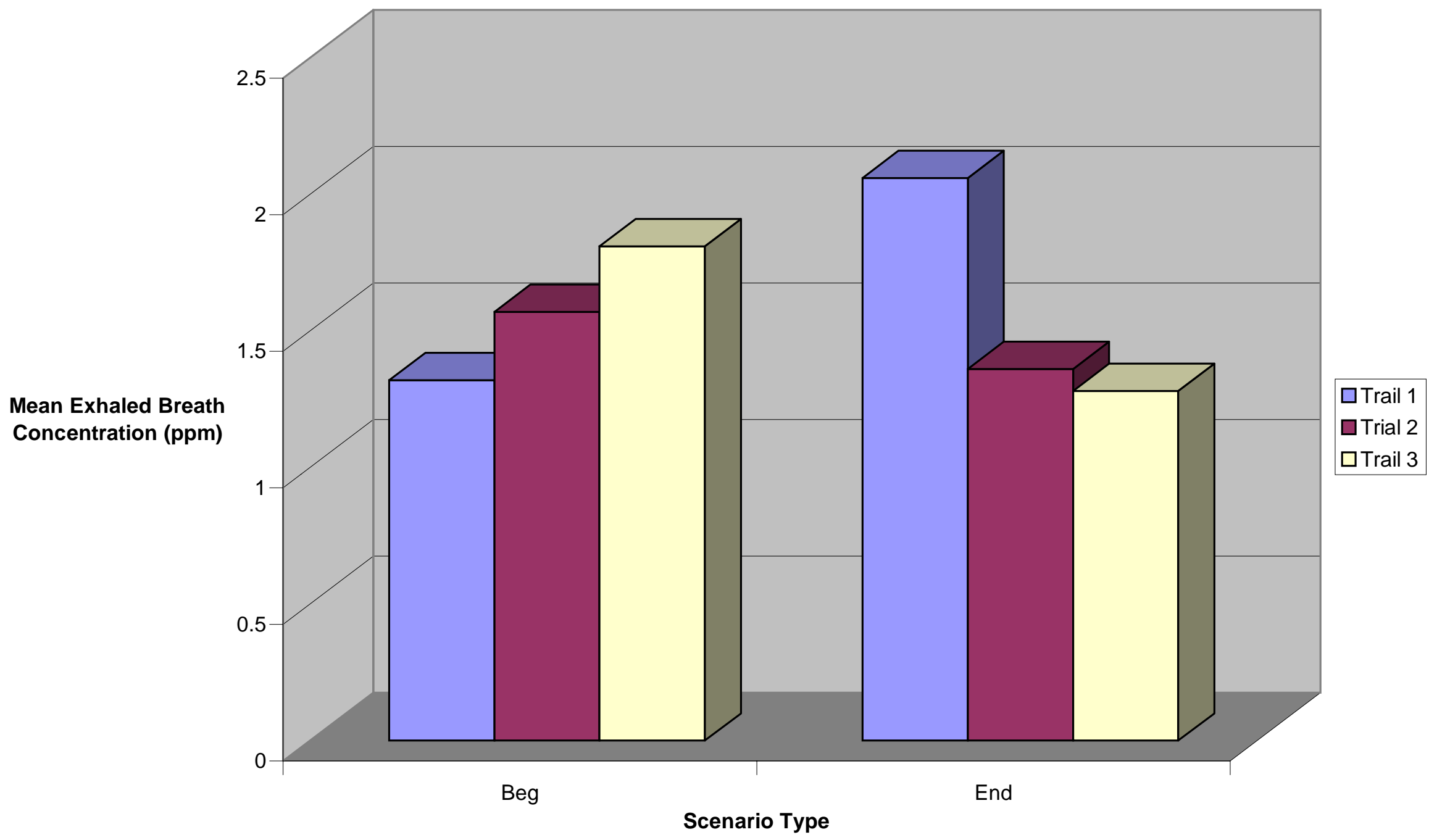


TABLE 4.9a

Results for Subject 26 Comparison of Beginning vs. End Scenarios

\begin{tabular}{|c|c|c|c|c|c|c|c|}
\hline \multicolumn{3}{|c|}{} & \multicolumn{5}{c|}{ CFC-113 EXHALED BREATH CONCENTRATION } \\
(PPM) \\
\hline Subject & Date & Test & $\mathbf{2 5}$ min. & $\mathbf{3 0}$ min. & $\mathbf{3 5}$ min. & Mean & +/- SD \\
\hline 26 & $1 / 23 / 98$ & BEG & 0.98 & 1.04 & 0.72 & $\mathbf{0 . 9 1}$ & $\mathbf{0 . 1 7}$ \\
\hline 26 & $2 / 13 / 98$ & BEG & 0.94 & 0.87 & 0.82 & $\mathbf{0 . 8 8}$ & $\mathbf{0 . 0 6}$ \\
\hline 26 & $2 / 26 / 98$ & BEG & 1.41 & 1.34 & 1.22 & $\mathbf{1 . 3 2}$ & $\mathbf{0 . 1 0}$ \\
\hline 26 & $1 / 29 / 98$ & END & 1.40 & 1.46 & PROB & $\mathbf{1 . 4 3}$ & $\mathbf{0 . 0 4}$ \\
\hline 26 & $2 / 3 / 98$ & END & 2.71 & 1.84 & 1.41 & $\mathbf{1 . 9 9}$ & $\mathbf{0 . 6 6}$ \\
\hline 26 & $3 / 19 / 98$ & END & 2.21 & 1.96 & 2.07 & $\mathbf{2 . 0 8}$ & $\mathbf{0 . 1 3}$ \\
\hline
\end{tabular}

TABLE 4.9b

Summary of Results for Subject 26

\begin{tabular}{|c|c|c|c|}
\hline Test & Mean & +/-SD & CV (\%) \\
\hline BEG & 1.04 & 0.25 & 24 \\
\hline END & 1.83 & 0.35 & 19 \\
\hline
\end{tabular}


Figure 4.8 Comparison of Beginning vs. End Scenarios for Subject 26

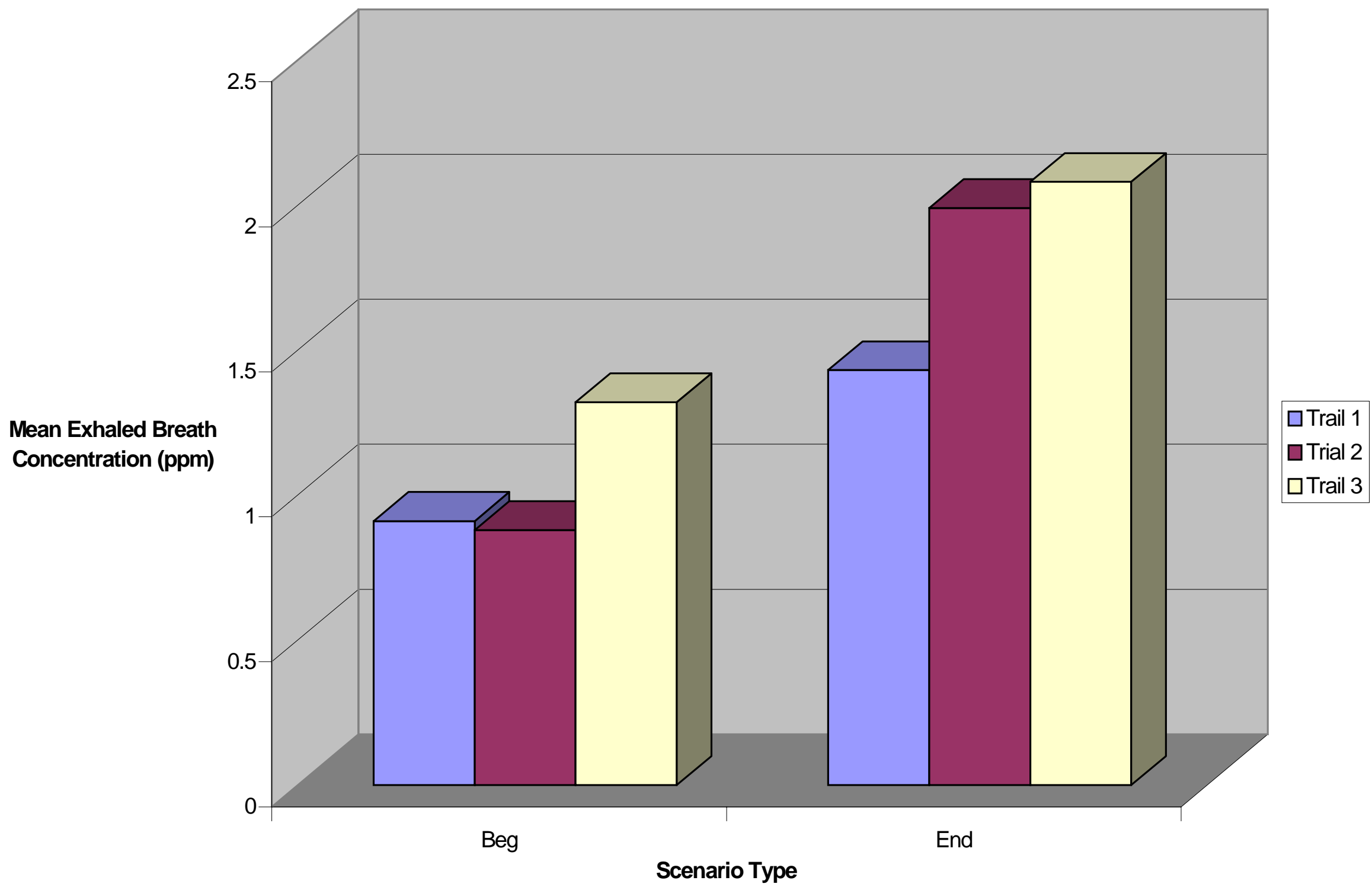


TABLE 4.10a

Results for Subject 4 Comparison of Continuos vs. Intermittent Scenarios

\begin{tabular}{|c|c|c|c|c|c|c|c|}
\hline \multicolumn{2}{|c|}{} & \multicolumn{5}{|c|}{ CFC-113 EXHALED BREATH CONCENTRATION } \\
(PPM) \\
\hline Subject & Date & Test & $\mathbf{2 5}$ min. & $\mathbf{3 0}$ min. & $\mathbf{3 5}$ min. & Mean & +/- SD \\
\hline 4 & $1 / 23 / 98$ & INT & 0.91 & 1.08 & 1.18 & $\mathbf{1 . 0 5}$ & $\mathbf{0 . 1 4}$ \\
\hline 4 & $2 / 13 / 98$ & INT & 1.40 & 0.81 & 0.90 & $\mathbf{1 . 0 3}$ & $\mathbf{0 . 3 2}$ \\
\hline 4 & $2 / 20 / 98$ & INT & 1.86 & 1.49 & 1.48 & $\mathbf{1 . 6 1}$ & $\mathbf{0 . 2 2}$ \\
\hline 4 & $1 / 30 / 98$ & CON & 1.54 & 1.44 & 1.03 & $\mathbf{1 . 3 4}$ & $\mathbf{0 . 2 7}$ \\
\hline 4 & $2 / 6 / 98$ & CON & 1.97 & 1.68 & 1.60 & $\mathbf{1 . 7 5}$ & $\mathbf{0 . 1 9}$ \\
\hline 4 & $2 / 27 / 98$ & CON & 1.34 & 1.50 & 0.90 & $\mathbf{1 . 2 5}$ & $\mathbf{0 . 3 1}$ \\
\hline
\end{tabular}

TABLE 4.10b

Summary of Results for Subject 4

\begin{tabular}{|c|c|c|c|}
\hline Test & Mean & +/- SD & CV (\%) \\
\hline INT & 1.23 & 0.33 & 27 \\
\hline CON & 1.44 & 0.27 & 19 \\
\hline
\end{tabular}


Figure 4.9 Comparison of Intermittent vs. Continuous Scenarios for Subject 4

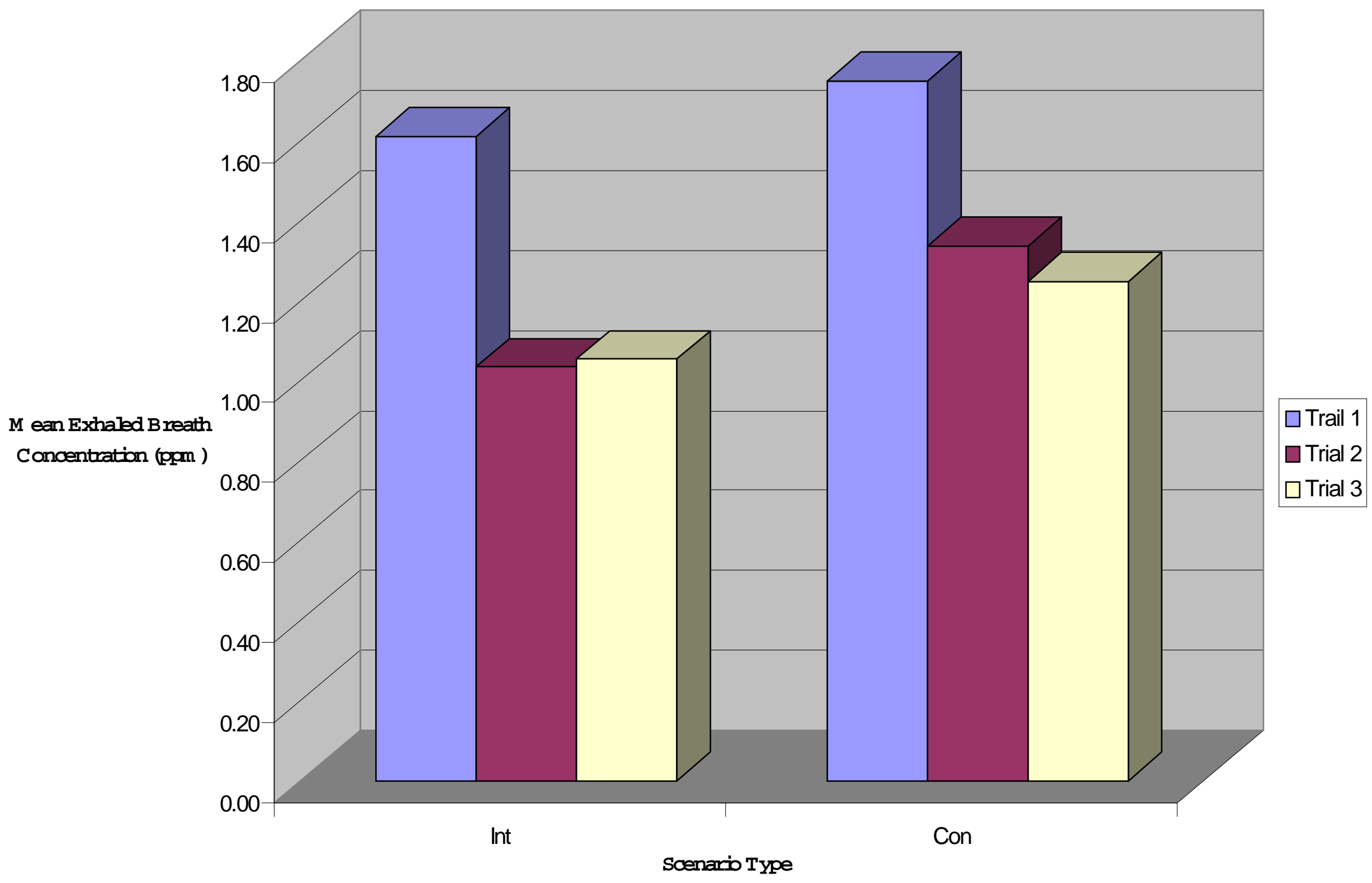


TABLE 4.11a

Results for Subject 10 Comparison of Intermittent vs. Continuous Scenarios

\begin{tabular}{|c|c|c|c|c|c|c|c|}
\hline \multicolumn{2}{|c|}{} & \multicolumn{5}{|c|}{$\begin{array}{c}\text { CFC-113 EXHALED BREATH } \\
\text { CONCENTRATION (PPM) }\end{array}$} \\
\hline Subject & Date & Test & $\mathbf{2 5}$ min. & $\mathbf{3 0}$ min. & $\mathbf{3 5}$ min. & Mean & +/- SD \\
\hline 10 & $2 / 3 / 98$ & INT & 1.50 & 1.66 & 1.39 & $\mathbf{1 . 5 2}$ & $\mathbf{0 . 1 3}$ \\
\hline 10 & $3 / 17 / 98$ & INT & 0.92 & 1.04 & 0.82 & $\mathbf{0 . 9 3}$ & $\mathbf{0 . 1 1}$ \\
\hline 10 & $3 / 24 / 98$ & INT & 1.41 & 0.67 & 0.90 & $\mathbf{0 . 9 9}$ & $\mathbf{0 . 3 8}$ \\
\hline 10 & $1 / 28 / 98$ & CON & 1.20 & 1.16 & 0.79 & $\mathbf{1 . 0 5}$ & $\mathbf{0 . 2 3}$ \\
\hline 10 & $2 / 10 / 98$ & CON & 1.57 & 1.36 & 1.65 & $\mathbf{1 . 5 3}$ & $\mathbf{0 . 1 5}$ \\
\hline 10 & $2 / 24 / 98$ & CON & 1.00 & 0.83 & 0.79 & $\mathbf{0 . 8 7}$ & $\mathbf{0 . 1 1}$ \\
\hline
\end{tabular}

TABLE 4.11b

Summary of Results for Subject 10

\begin{tabular}{|c|c|c|c|}
\hline Test & Mean & +/-SD & CV (\%) \\
\hline INT & 1.15 & 0.32 & 28 \\
\hline CON & 1.15 & 0.34 & 30 \\
\hline
\end{tabular}


Figure 4.10 Comparison of Intermittent vs. Continuous Scenarios for Subject 10

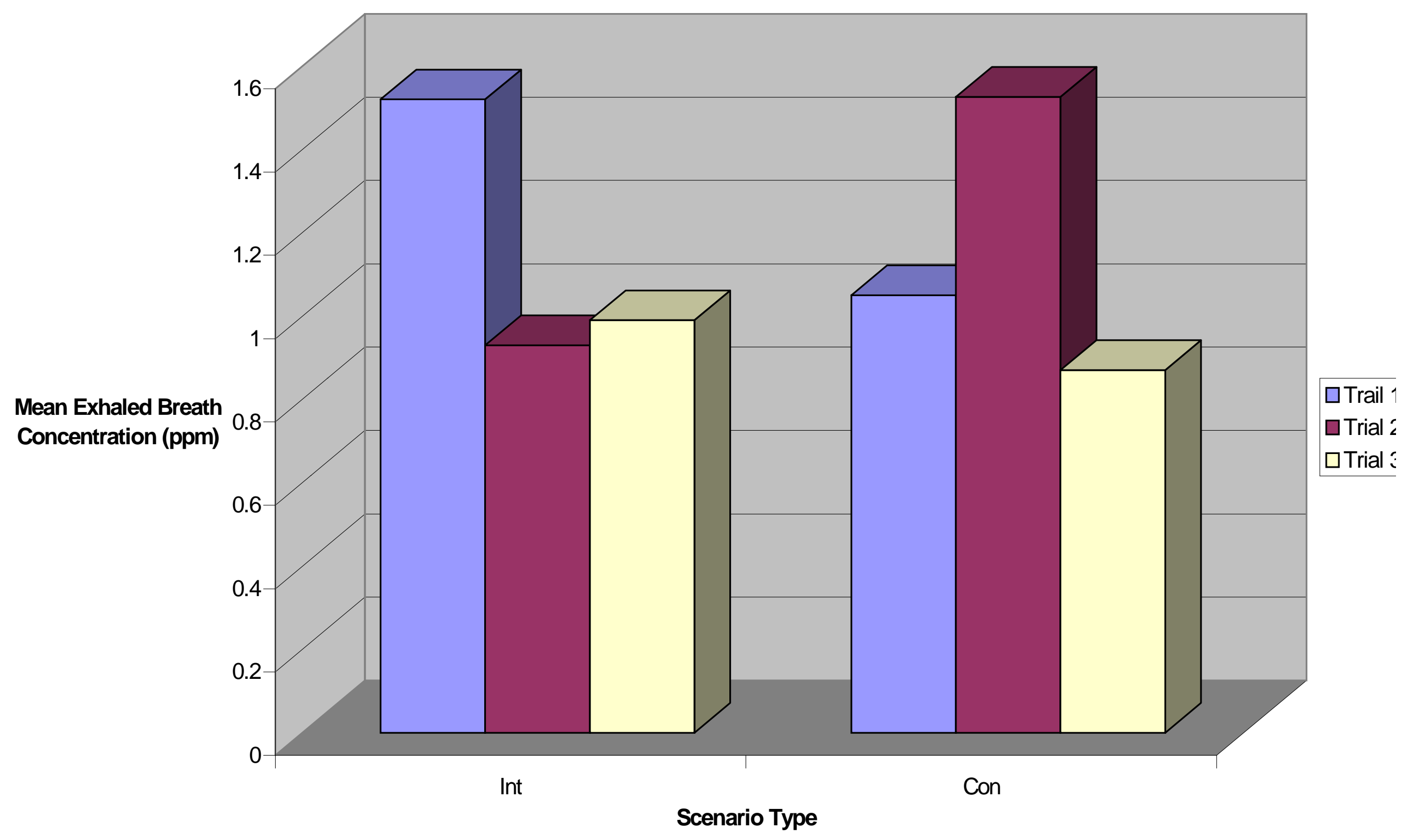


TABLE 4.12a

Results for Subject 19 Comparison of Intermittent vs. Continuous Scenarios

\begin{tabular}{|c|c|c|c|c|c|c|c|}
\hline \multicolumn{2}{|c|}{} & \multicolumn{5}{|c|}{$\begin{array}{c}\text { CFC-113 EXHALED BREATH } \\
\text { CONCENTRATION (PPM) }\end{array}$} \\
\hline Subject & Date & Test & $\mathbf{2 5}$ min. & $\mathbf{3 0}$ min. & $\mathbf{3 5}$ min. & Mean & +/- SD \\
\hline 19 & $2 / 19 / 98$ & INT & 0.79 & 0.70 & 0.59 & $\mathbf{0 . 6 9}$ & $\mathbf{0 . 1 0}$ \\
\hline 19 & $2 / 26 / 98$ & INT & 1.36 & 0.98 & 0.96 & $\mathbf{1 . 1 0}$ & $\mathbf{0 . 2 3}$ \\
\hline 19 & $3 / 5 / 98$ & INT & 1.17 & 1.01 & 0.83 & $\mathbf{1 . 0 0}$ & $\mathbf{0 . 1 7}$ \\
\hline 19 & $2 / 5 / 98$ & CON & 2.04 & 1.67 & 1.35 & $\mathbf{1 . 6 9}$ & $\mathbf{0 . 3 4}$ \\
\hline 19 & $2 / 12 / 98$ & CON & 1.27 & 1.20 & 0.98 & $\mathbf{1 . 1 5}$ & $\mathbf{0 . 1 5}$ \\
\hline 19 & $4 / 2 / 98$ & CON & 0.88 & 0.83 & 0.98 & $\mathbf{0 . 8 9}$ & $\mathbf{0 . 0 8}$ \\
\hline
\end{tabular}

TABLE 4.12b

Summary of Results for Subject 19

\begin{tabular}{|c|c|c|c|}
\hline Test & Mean & +/-SD & CV (\%) \\
\hline INT & 0.93 & 0.21 & 23 \\
\hline CON & 1.24 & 0.41 & 33 \\
\hline
\end{tabular}


Figure 4.11 Comparison of Intermittent vs. Continuous Scenarios for Subject 19

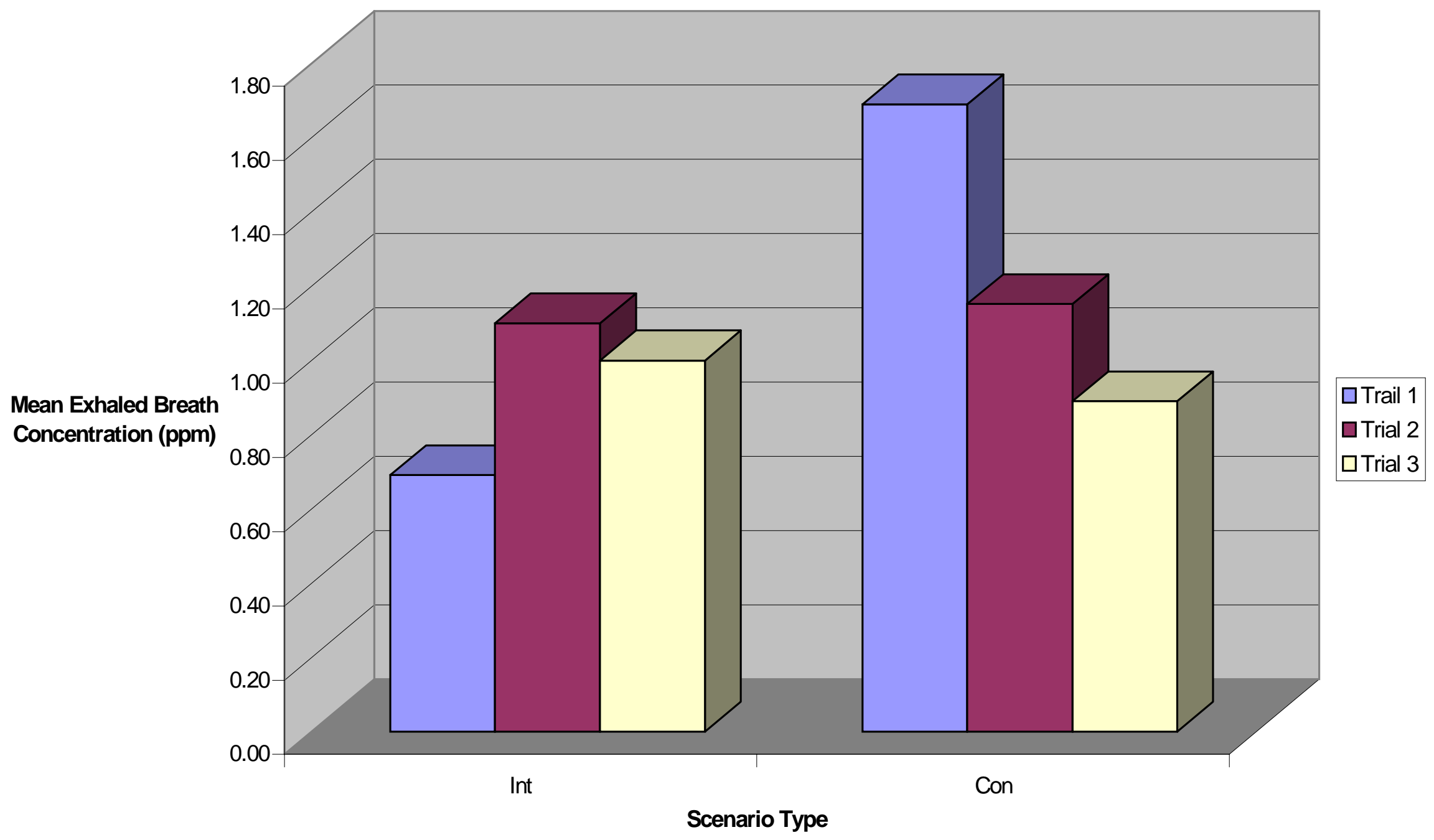


TABLE 4.13a

Results for Subject 29 Comparison of Intermittent vs. Continuous Scenarios

\begin{tabular}{|c|c|c|c|c|c|c|c|}
\hline \multicolumn{2}{|c|}{} & \multicolumn{5}{|c|}{$\begin{array}{c}\text { CFC-113 EXHALED BREATH } \\
\text { CONCENTRATION (PPM) }\end{array}$} \\
\hline Subject & Date & Test & $\mathbf{2 5}$ min. & $\mathbf{3 0}$ min. & $\mathbf{3 5}$ min. & Mean & +/- SD \\
\hline 29 & $2 / 20 / 98$ & INT & 1.64 & 1.65 & 1.31 & $\mathbf{1 . 5 3}$ & $\mathbf{0 . 2 0}$ \\
\hline 29 & $2 / 27 / 98$ & INT & 1.70 & 1.37 & 1.38 & $\mathbf{1 . 4 9}$ & $\mathbf{0 . 1 9}$ \\
\hline 29 & $3 / 20 / 98$ & INT & 3.21 & 2.80 & 2.98 & $\mathbf{3 . 0 0}$ & $\mathbf{0 . 2 1}$ \\
\hline 29 & $1 / 30 / 98$ & CON & 1.72 & 1.66 & 1.56 & $\mathbf{1 . 6 5}$ & $\mathbf{0 . 0 8}$ \\
\hline 29 & $2 / 6 / 98$ & CON & 2.32 & 2.29 & 2.06 & $\mathbf{2 . 2 2}$ & $\mathbf{0 . 1 4}$ \\
\hline 29 & $2 / 13 / 98$ & CON & 0.99 & 1.17 & 0.94 & $\mathbf{1 . 0 3}$ & $\mathbf{0 . 1 2}$ \\
\hline
\end{tabular}

TABLE 4.13b

Summary of Results for Subject 29

\begin{tabular}{|c|c|c|c|}
\hline Test & Mean & +/- SD & CV (\%) \\
\hline INT & 2.01 & 0.86 & 43 \\
\hline CON & 1.63 & 0.60 & 36 \\
\hline
\end{tabular}


Figure 4.12 Comparison of Intermittent vs. Continuous Scenarios for Subject 29

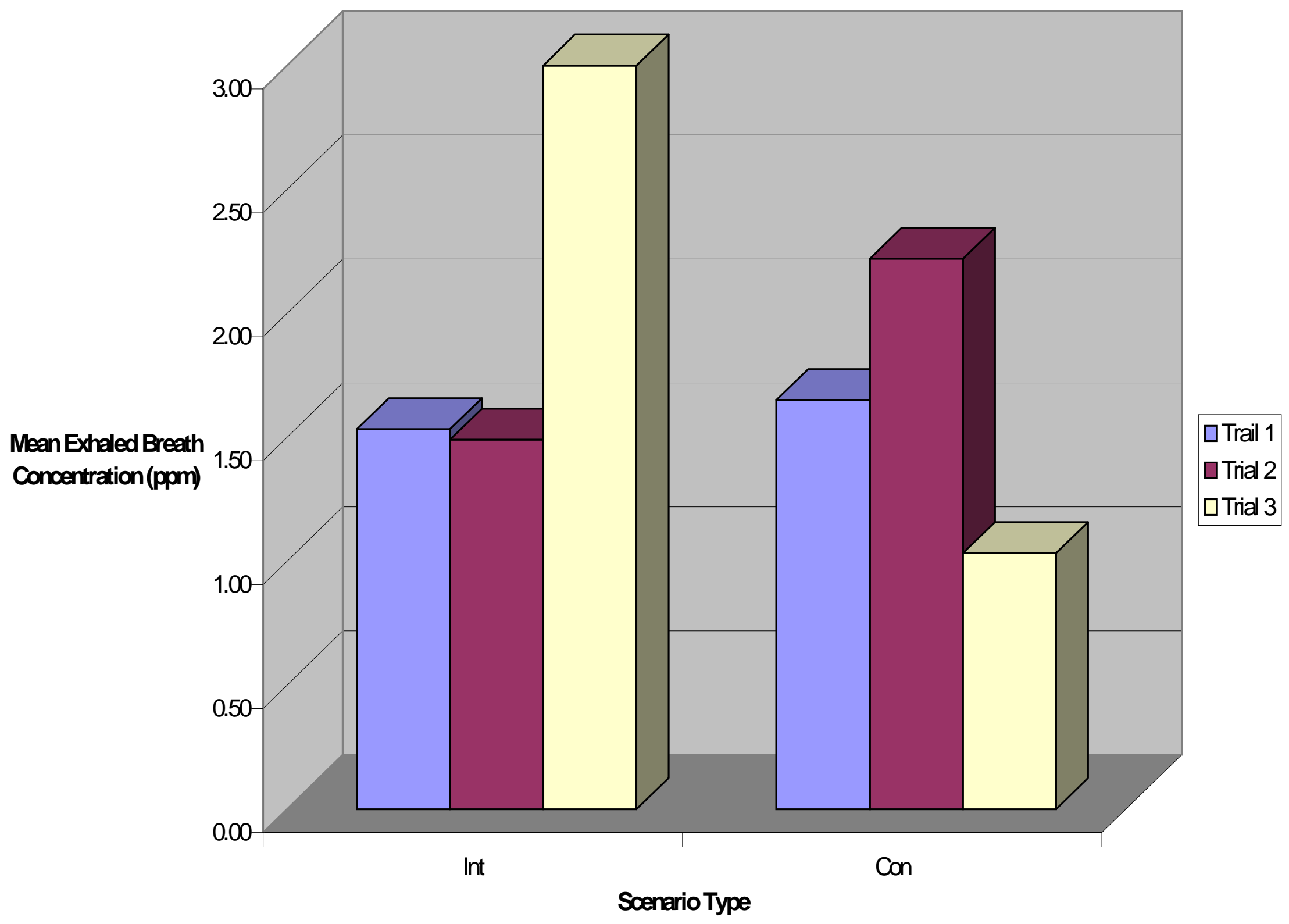




\section{Chapter 5}

\section{Statistical Analysis}

Statistical analysis was performed by using the Statistical Analysis System (SAS) software (SAS Institute, Research Triangle, NC). A general linear models procedure was performed on each subject's data and Duncan's Multiple Range Test for variance was performed to compare the means of each scenario for each subject. These results are presented in Appendix D--SAS Results. A significance level of 5\% was used in all cases $(\alpha=0.05)$.

For Phase 1, which compares the means of LB to LE to SB to SE, the Duncan's Test found no significant difference between the means of each of these scenarios for Subjects 1 and 8. However, the Duncan's Test showed the following grouping for Subjects 5 and 45:

\begin{tabular}{|c|c|c|c|c|}
\hline \multicolumn{5}{|c|}{ Subject 5} \\
\hline \multicolumn{2}{|c|}{ Duncan Grouping } & Mean & $\mathbf{N}$ & Test \\
\hline & $A$ & 0.7833 & 3 & SE \\
\hline $\bar{B}$ & $\bar{A}$ & 0.7367 & 3 & $\overline{\mathrm{SB}}$ \\
\hline $\bar{B}$ & $\bar{A}$ & 0.5667 & 3 & $\overline{L B}$ \\
\hline $\mathrm{B}$ & & 0.4267 & 3 & LE \\
\hline \multicolumn{5}{|c|}{ Subject 45} \\
\hline \multicolumn{2}{|c|}{ Duncan Grouping } & Mean & $\mathbf{N}$ & Test \\
\hline & $\bar{A}$ & 0.9200 & 3 & SE \\
\hline $\bar{B}$ & $\bar{A}$ & 0.8867 & 3 & LB \\
\hline $\bar{B}$ & $A$ & 0.6900 & 3 & $\overline{\mathrm{SB}}$ \\
\hline $\mathrm{B}$ & & 0.5067 & 3 & LE \\
\hline
\end{tabular}

Means with the same letter are not significantly different. Note that with both subjects SE, SB and LB make up one Duncan group, while LB, SB and LE make up another. For both these subjects the SE tests are significantly different from the LE tests. By the General Linear Models Procedure the $\mathrm{P}$ value for subject 45 is 0.1106 and the $\mathrm{P}$ value for Subject 5 is 0.1019 . Thus for 
Subjects 1 and 8, the concentration of end-exhaled breath samples were independent of both the amount and timing of the CFC-113 exposure so long as the dose remained equivalent. For Subjects 5 and 45, all the scenarios are equivalent, except that the SE test tends to yield the highest concentrations which are significantly different from the means of the LE tests. For Subjects 45 and 5, and not for Subjects 1 and 8, the SE and the LE scenarios distinguish from each other.

The General Linear Models Procedure and the Duncan test performed on the means of the Phase 2 scenarios (CFC administered at the end or beginning of the exercise regiment) determined that there was no significant differences in the mean values of the end-exhaled breath samples collected. This was the case for all four subjects tested in Phase 2. Therefore the concentration of the end-exhaled breath samples were not significantly dependent upon timing of the CFC exposure.

The General Linear Models Procedure and the Duncan test performed on the means of the Phase 3 scenarios (CFC administered either continuously or intermittently during the exercise regiment) determined that there was no significant difference in the mean values of the endexhaled breath samples collected. This was the case for all four subjects tested in Phase 3 . Therefore the concentration of the end-exhaled breath samples were not significantly dependent upon the nature of the CFC exposure given that the overall dose remained equivalent. 


\section{Chapter 6}

\section{Discussion and Conclusion}

\section{Scenario Equivalence}

Whether the comparison is between high concentration at the beginning or end of the exercise regiment or low doses at the beginning or end of the regiment, the statistical analysis of phase one reveals that there is no significant differences between the mean concentrations of each scenario, except between the SE and LE scenarios in two cases. These scenarios ranged from a one-minute exposure of $500 \mathrm{ppm}$ CFC to 15.15 minutes of $33 \mathrm{ppm}$ of CFC; the overall dose in any case was 500 ppm-min. Furthermore the Phase 2 study revealed that the end-exhaled breath sample concentrations are independent of the timing of the exposure, whether it occur at the beginning or the end of the exercise regiment. The statistical analysis revealed that the means were not significantly different. In each case the exposure was a 6 minute administration of 500 ppm, which was an overall dose of 3,000 ppm-min. The nature of the administration, whether intermittent or continuous, did not affect the exhaled breath concentration either.

It is not surprising that the timing, duration, or nature of the CFC administration does not confound the breath concentration data because the previous studies on this topic suggest as much. The pharmacokinetics of CFC-113 reveals that CFC-113 has an average half-life of elimination in breath at $0.22 \mathrm{hr}$ in some cases and 4.2 and 52 minutes in other cases; the desaturation curve reaches a plateau at 30 minutes post-exposure and remains constant for the entire 60 minutes (Woolen et. al., 1990; Auton and Woolen, 1991; Decker and Crutchfield, 1993; Das, 1996). These studies also suggest that it takes CFC-113 25 minutes to equilibrate in the blood. The desaturation profile for the first 20 minutes represents first compartment purging (i.e. CFC-113 transferring from the blood to the lungs), while the $2^{\text {nd }}$ compartment purges at a 
constant rate during 30 to 60 minutes post-exposure. Since our experiments consisted of a CFC exposure during a 30 minute exercise regiment followed by at least 25 minutes of no exposure before the first breath sample, the longest time between exposure and sample collection would be 54 minutes (SB scenario) whereas the shortest time would be 25 minutes (as with the SE scenario). Both the longest duration and the shortest duration between exposure and sample collection fall within the time period where the CFC has equilibrated in the blood and elimination has stabilized. During this time the elimination represents second compartment purging. Indeed the statistical analysis of all four subjects tested in Phase 1 reveal that the SB and SE scenarios are not significantly different.

One counterintuitive finding was that for two subjects, the mean exhaled breath samples of the SE tests were significantly different from those from the LB scenarios. It is difficult to speculate why an high concentration exposure administered at the very last minute of the exercise regiment would result in very different exhaled breath samples than a low concentration exposure administered during the first 15 minutes of the regiment. Perhaps this difference reflects the variable time needed to equilibrate a CFC-113 exposure in the residual lung volume when the CFC is present as a large concentration short pulse rather than a low concentration long pulse. It is reasonable to assume that with the long pulse of 15 minutes, the CFC in residual lung volume would have equilibrated and diffused into the blood. Perhaps with a short pulse of a large concentration, the residual lung volume takes longer to equilibrate. This, in turn, may delay the transfer of CFC from the lungs to the blood and thus delay the desaturation profile, thereby extending the first compartment purging passed the 25 minute sample collection time point. Since greater concentrations of CFC-113 are eliminated during the first compartment purging, if such a shift occurred in the desaturation profile, then the SE test would yield higher 
mean concentrations than the other scenarios (as with the cases of Subject 5 and 45). Because the sample collect occurs right at the cusp of the secondary compartment purging, an equilibration delay of a few minutes may dramatically affect the exhaled breath concentrations. The exhaled breath samples may have yielded more consistent results if the collection time were delayed by 10 minutes. There is precedence for this line of reasoning, Fiserova-Bergerova et. al. (1984) noted that the equilibration rate depends the rate at which the chemical is transferred from the environment and that the rate limiting factors are pulmonary ventilation, cardiac output, tissue perfusion, tissue volume and biosolubility. Furthermore, studies have shown that with low solubility gases, such as CFC-113, more of the uptake is recovered in the exhaled air after a shorter exposure than after a longer one (Fiserova-Bergerova et. al., 1980).

\section{Variance}

It is noteworthy that the breath samples for some scenarios had such a high coefficient of variation. This suggests that the method for measuring exposure is imprecise. Although great care was taken to collect end-exhaled breath samples from the subjects, the imprecision may be attributed to the variability with which a subject exhaled into the breath sampler. If the samples do not represent the end-exhaled breath then there is a risk that the CFC would be diluted with the air from the upper lungs. Furthermore, since cardiac output affects CFC-113 absorption into the lungs and consequently into the blood stream, if there is inconsistency in how vigorously the subject engages in the exercises from test to test, this would also influence the amount of CFC113 that would be absorbed and then eliminated from the body. His emotional state, his health or even his body temperature would also affect a subject's heart rate. 
A great deal of variability is introduced into any test that uses human subjects. Many unconsidered physiological factors can alter the desaturation profile of CFC-113 in the body. For instance, subjects who are susceptible to asthma or allergies, may experience an increase in mucus build up in the lungs sporadically that would diminish CFC-113 absorption. Smoking and its long-term damage may delay absorption and elimination. Something as simple as a common cold may add variation to the replicates.

The variation may also be a factor of the devices used in this study. Some variability can be attributed to the variation within the breath samplers themselves. It is not that the variation was due to how the CFC was administered because even when the CFC was administered continuously throughout the 30 -minute regiment, the CVs ranged from $19 \%$ to $43 \%$. Therefore an argument can not be made that perhaps the functional limitations of starting and stopping the CFC delivery system, or of reaching the target concentration during the exposure period contributed to the variability. Likewise, the CVs were just as high, if not higher, when the CFC was administered via a charged chamber rather than by the CFC-delivery system. The concentration within a charged chamber could be stably and consistently maintained for hours at a time, yet exhaled breath samples collected after this type of exposure had CVs as high as $37 \%$ and $25 \%$ for Subject 1 (Chapter 4, Table 4.2b), $40 \%$ and $27 \%$ for Subject 45 (Chapter 4, Table 4.3b), $26 \%$ and $21 \%$ for Subject 8 (Chapter 4, Table $4.5 \mathrm{~b}$ ) and then as high as $23 \%$ and $48 \%$ for Subject 5 (Chapter 4, Table 4.4b).

A great deal of variability can be attributed to the GC conversion coefficients. The data gets converted from area to concentration by using the conversion coefficients calculated when the GC is calibrated. Any errors incurred during calibration or due to GC fluctuation may 
greatly influence the concentration values. Likewise, errors incurred during calibration of the IR may have cause variation from test to test.

Regardless of the cause of the variation, the high degree of variability among the breath samples of the same test no doubt contributed to a high least significant studentized range in the Duncan procedure. The range of any subset of $\mathrm{p}$ sample means must exceed the least significant range before any of the $\mathrm{p}$ means are found to be different (Walpole and Myers, 1985). The sample variance influences the least significant studentized range. Therefore a high degree of variance in the breath samples makes it very difficult for the compared scenario means to be significantly different.

The Duncan's Multiple Range Test for variance was used because it is considered one of the most powerful test, however conducting a Tukey's Test or a Least Significant Difference (LSD) Method on the data would have further validated the findings. The number of replicates was limited to 3 per test for economic and logistics reasons. However, increasing the replicates would increase the power of the Duncan test because this test requires a greater observed difference to detect significantly different pairs of means as the number of means included in the group increases (Walpole et. al., 1998).

\section{Trends}

Although the statistical analysis shows that there are no significant differences between the mean values of the compared scenarios, there do appear to be trends in the data that suggest more intuitive pharmacokinetic mechanisms. With continuous verses intermittent exposures it is difficult to predict which scenario would yield the highest breath concentrations. A continuous exposure might yield a higher breath concentration because the body is exposed to a continuous 
amount over the 30-minute exercise regiment, and one may predict that the CFC has equilibrated in the blood and is continuously being purged during the following 30 minutes. On the other hand, an intermittent exposure exposes the subject to higher concentrations of CFC for shorter periods of time, the last of which is 1 minute before the exercise regiment ends. This may lead to a larger amount of CFC being purged during the collection period roughly 30 minutes postexposure. With Subjects 19 and 4, it appears that the breath concentrations after the CON exposure were greater than after the INT exposures. However, for Subject 10 the mean breath concentrations for each trial of both the CON and the INT scenarios are the same. The general trend in these tests suggests that there was no significant difference between continuous or intermittent exposures, however the CON breath samples tend to contain higher concentrations of CFC-113. This implies that in respirator test leaks that occur continuously over the entire exercise period may not result in significantly different breath concentrations than leaks that occur intermittently throughout the exercise regiment; they may, however, tend to yield slightly higher concentrations.

The BEG vs. END scenarios in phase two tend to yield higher concentrations in the END tests than the BEG tests. In general the statistical analysis and the general trends agree that exposures administered at the beginning of the regiment do not result in different breath concentration than exposure administered at the end of the regiment. This implies that the onset of the leaks either at the beginning or the end of the exercise regiment should not bias the breath sample data, however leaks occurring at the end of the 30 minute exercise might yield slightly higher concentrations than those occurring at the beginning..

The phase one scenario results are a little more difficult to predict. One would expect that regardless of whether and exposure was long or short, those administered at the end of the 
exercise regiment would result in higher breath concentrations. In general that trend is seen in all four subjects, that is either the LE or the SE always yield more CFC in the exhaled breath.. With the four scenarios, there are no obvious or consistent patterns from subject to subject; in two cases the LE trials appear greater than the other three, in 2 other cases, the SE trials yielded higher concentrations. Furthermore, in the two cases where the SE tests were the highest, the LE tests were the lowest. 


\section{Chapter 7}

\section{Recommendations}

The different exposure scenarios designed in this study were intended to represent the possible ways in which leaks might occur during respirator tests that utilize CFC-113 as a challenge agent. The statistical analysis has shown that the onset, duration, and magnitude of the leaks should not bias the exhaled breath sample CFC-113 concentration in respirator studies, with the exception of the SE and LE scenarios for two cases. The statistical analysis supports the concept that the end-exhaled breath sample is representative of the dose that the wearer was exposed to rather than a factor of the leak profile. The great deal of variation in the test repetitions suggests that errors occurred in the experiment. It is possible that the variation in this study masked many of the trends. The variation should be pinpointed and eliminated from further studies.

Some variation may be attributed to the GC calibration coefficient or during IR calibration. In the future it is recommended that anomalous calibration coefficients be examined carefully and perhaps recalculated. I recommend that these instruments be calibrated weekly. Some variability may be reduced if the sample collection times were delayed for 10 minutes or if only the 35-minute post-exposure samples were considered.

Since a great deal of the variation may have been caused by physiological factors, the significance level of future research should be raised to $90 \%(\alpha=0.1)$ and, if practical, the number of replications should be enlarged to increase the strength of the Duncan test. Furthermore, the statistical analysis should include the Least Significant Difference Method and the Tukey Test. 
Finally, future research might want to consider replacing the CFC-113 Delivery System with a modified anesthesiology machine. An anesthesiology machine might ensure more consistent and accurate CFC-113 administration because it would provide a closed system, with precise dosing, and a finely regulated and controlled flow rate. Such a machine could be modified easily for CFC-113 administration, and the mask could be probe to allow samples to be drawn and analyzed by the IR. 


\section{BIBLOGRAPHY}

ACGIH TLVs and BEIs Threshold Limit Values for Chemical Substances and Physical Agents. (1998). American Conference of Governmental Industrial Hygienists, Cincinnati, OH.

Anonymous. 1,1,2-trichloro-1,2,2-trifluoroethane (Trifluorochloroethane, Fluorocarbon No. 113), American Industrial Hygiene Association Journal, 29:521-525.

American Public Health Association: Methods for Biological Monitoring, APHA, Washington, DC (1988).

Astrand, I. (1975). Uptake of solvent in the blood and tissues of man. Scand. J. Work, Environ. \& Health, 199-218.

Auton, T. R., and Woollen, B. H. (1991). A Physiologically based mathematical model for the human inhalation pharmacokinetics of 1,1,2-trichloro-1,2,2-trifluoroethane. Int. Arch. Occup. Environ Health, 63: 133-138.

Code of Federal Regulations, Title 29, Part 1910.1000. Washington, D.C.: U.S. Government Printing Office, 1993.

Coffey, C. C. (1997). Development and comparison of a new quantitative fit test method for health-care industry respirators. Study Protocol Submitted to the Division of Respiratory Disease Studies, National Institute for Occupational Safety and Health, Morgantown, WV.

Coffey, C. C., Campbell, D. L., Myers, W. R., and Zhuang, Z.. (1998). Comparison of six respirator fit test methods with an actual measurement of exposure in a simulated health-care environment: Part II- Protocol Development. Americzn Industrial Hygiene Association Journal 59:862-870.

Coffey, C. C., Campbell, D. L., Myers, W. R., Zhuang, Z., and Das, S. (1998). Comparison of six respirator fit test methods with an actual measurement of exposure in a simulated health-care environment: Part I- Protocol Development. Americzn Industrial Hygiene Association Journal 59:852-861.

Das, S. (1995). Determination of the optimum post-exposure sampling time of subjects exposed to CFC-113. Unpublished Master's problem report, West Virginia University, Morgantown, WV.

Decker, J. A. and Crutchfield, C. D. (1993). Feasibility of a new method to determine respirator performance by biological monitoring of exhaled air. Journal of the International Society for Respiratory Protection, 6-19.

Fiserova-Bergerova, V., Lowry, L.K., and Rosenberg, J. (1989). Biological monitoring II measurements in exhaled air. Applied Industrial Hygiene, 4 (2): F10-F13. 
Fiserova-Bergerova, V., Tichy, M., and Di Carlo, F. J. (1984). Effects of biosolubility on pulmonary uptake and disposition of gases and vapors of lipophilic chemicals. Drug Metabolism Reviews, 15 (5 \& 6): 1033-1070.

Fiserova-Bergerova, V., Vlach, J. and Cassady, J. C. (1980). Predictable "individual differences" in uptake and excretion of gases and lipid soluble vapours simulation study. British Journal of Industrial Medicine, 37: 42-49.

Morgan, A., Black, A., and Belcher, D. R. (1972). Studies on the absorption of halogenated hydrocarbons and their excretion in breath using ${ }^{38} \mathrm{Cl}$ tracer techniques. Ann. Occup. Hyg., 15: 273-282.

NIOSH Pocket Guide to Chemical Hazards. (1997). DHHS (NIOSH) Publ. No. 97-140. National Institute for Occupational Safety and Health, Cincinnati, OH.

Ramsey, J. C. and Andersen, M. E. (1984). A physiologically based description of the inhalation of styrene in rats and humans. Toxicol. Appl. Pharmacol., 73: 159-175.

Reinhardt, C. F., McLaughlin, M., Maxfield, M. E., Mullin, L. S., and Smith, P. E. (1971). Human Exposure to Fluorocarbon 113. American Industrial Hygiene Association Journal, 143152.

SAS Institute Inc.: Statistical Analysis System [Computer Software], Cary, NC: SAS Institute Inc., 1996.

Sato. A. and Nakajima, T. (1979). Partition coefficients of some aromatic hydrocarbons and ketones in water, blood, and oil. British Journal of Industrial Medicine, 36: 231-234.

Stine, K. E. and Brown, T. M. (1996). Principles of Toxicology. New York: Lewis.

Stopps, G. J. and McLaughlin, M. (1967). Psychophysiological testing of human subjects exposed to solvent vapors. American Industrial Hygiene Association Journal, 43-50.

Vainio, H., Nickels, J. and Heinonen, T. (1980). Dose-related Hepatotoxicity of 1,1,2-Trichloro1,2,2-Trifluoroethane in short-term intermittent inhalation exposure in rats. Toxicology, 18 :1725.

Walpole, R. E., Myers, R. H. and Myers, S. L. (1998). Probability and statistics for engineers and scientists $\left(6^{\text {th }}\right.$ Edition). Upper Saddle River, NJ: Heath.

Woollen, B. H., Guest, E. A., Howe, W., Marsh, J. R., Wilson, H. K., Auton, T. R., and Blain, P. G. (1990). Human inhalation pharmacokinetics of 1,1,2-trichloro-1,2,2-trifluoroethane (FC113). Int. Arch. Occup. Environ. Health, 62: 73-78. 


\section{Appendix A \\ Breath Sample Data from the ECD}




\section{Original Data}

\begin{tabular}{|c|c|c|c|c|c|c|c|}
\hline \multirow{2}{*}{ Subject } & \multirow[b]{2}{*}{ Data } & \multirow[b]{2}{*}{ Phase } & \multicolumn{4}{|c|}{ ECD AREA VALUES } & \multirow{2}{*}{$\begin{array}{c}\text { ECD } \\
\text { CAL. CO. }\end{array}$} \\
\hline & & & Test & $25 \mathrm{~min}$. & $30 \mathrm{~min}$. & $35 \mathrm{~min}$. & \\
\hline 1 & $3 / 26 / 98$ & 1 & LB & PROB & 71106 & 89835 & 186508 \\
\hline 1 & 2/13/98 & 1 & LB & 67845 & 65800 & 62146 & 97802 \\
\hline 1 & 4/9/98 & 1 & LB & 106545 & 115829 & 117757 & 186508 \\
\hline 1 & 2/6/98 & 1 & LE & 69123 & 60744 & 72084 & 97802 \\
\hline 1 & 2/27/98 & 1 & LE & 45814 & 39535 & 37818 & 99910 \\
\hline 1 & 2/2/98 & 1 & LE & 94752 & 84776 & 87319 & 97802 \\
\hline 1 & $2 / 24 / 98$ & 1 & SB & 59828 & 55982 & 50071 & 99910 \\
\hline 1 & 2/20/98 & 1 & SB & 65487 & 51064 & 72024 & 97802 \\
\hline 1 & 3/19/98 & 1 & SB & 45252 & 41165 & 38339 & 80211 \\
\hline 1 & $3 / 27 / 98$ & 1 & SE & 124739 & 106805 & 95027 & 186508 \\
\hline 1 & 3/31/98 & 1 & SE & 120465 & 120206 & 116111 & 186508 \\
\hline 1 & $3 / 5 / 98$ & 1 & SE & 69720 & 57970 & 70673 & 99910 \\
\hline 3 & 2/6/98 & 2 & BEG & 186788 & 180553 & 167708 & 97802 \\
\hline 3 & 2/20/98 & 2 & BEG & 137387 & 152019 & 150047 & 97802 \\
\hline 3 & $3 / 27 / 98$ & 2 & BEG & 125532 & 119001 & 149683 & 186508 \\
\hline 3 & 2/13/98 & 2 & END & 83424 & 72545 & 85211 & 97802 \\
\hline 3 & 2/27/98 & 2 & END & 152947 & 153299 & 152255 & 99910 \\
\hline 3 & 3/20/98 & 2 & END & 209217 & 169518 & 144501 & 80211 \\
\hline 4 & 2/6/98 & 3 & $\mathrm{CON}$ & 192190 & 164682 & 156955 & 97802 \\
\hline 4 & 1/30/98 & 3 & CON & 150599 & 140485 & 101142 & 97802 \\
\hline 4 & 2/27/98 & 3 & CON & 133673 & 149475 & 90122 & 99910 \\
\hline 4 & 2/20/98 & 3 & INT & 181973 & 146039 & 144742 & 97802 \\
\hline 4 & 2/13/98 & 3 & INT & 136458 & 79130 & 87906 & 97802 \\
\hline 4 & 1/23/98 & 3 & INT & 88809 & 105581 & 115113 & 97802 \\
\hline 5 & 2/10/98 & 1 & LB & 72854 & 98882 & 87769 & 97802 \\
\hline 5 & 2/27/98 & 1 & LB & 43935 & 38910 & 40184 & 99910 \\
\hline 5 & 1/28/98 & 1 & LB & 38422 & 38918 & 44061 & 97802 \\
\hline 5 & $1 / 30 / 98$ & 1 & LE & 40416 & 38507 & 36983 & 97802 \\
\hline 5 & 2/13/98 & 1 & LE & 51243 & 51858 & 53551 & 97802 \\
\hline 5 & 1/23/98 & 1 & LE & 35428 & 36759 & 29233 & 97802 \\
\hline 5 & 2/6/98 & 1 & SB & 79575 & 66117 & 64613 & 97802 \\
\hline 5 & 2/17/98 & 1 & SB & 89741 & 95346 & 73278 & 97802 \\
\hline 5 & 3/3/98 & 1 & SB & 65907 & 62913 & 53993 & 99910 \\
\hline 5 & 2/3/98 & 1 & SE & 79874 & 72872 & 73296 & 97802 \\
\hline 5 & 2/24/98 & 1 & SE & 78989 & 63814 & 64092 & 99910 \\
\hline 5 & 3/17/98 & 1 & SE & 76273 & 69613 & 68316 & 80211 \\
\hline 8 & $1 / 30 / 98$ & 1 & LB & 42045 & 40741 & PROB & 97802 \\
\hline 8 & 2/19/98 & 1 & LB & 46386 & 56059 & 64658 & 97802 \\
\hline 8 & 2/17/98 & 1 & LB & 56647 & 61667 & 68258 & 97802 \\
\hline 8 & 2/12/98 & 1 & LE & 62914 & 61132 & 67331 & 97802 \\
\hline 8 & 3/19/98 & 1 & LE & 77575 & 75147 & 83538 & 80211 \\
\hline
\end{tabular}




$\begin{array}{cccccccc}\text { Subject } & \text { Data } & \text { Phase } & \text { Test } & \mathbf{2 5} \text { min. } & \mathbf{3 0} \text { min. } & \mathbf{3 5} \text { min. } & \text { CAL. CO. } \\ 8 & 2 / 26 / 98 & 1 & \text { LE } & 77778 & 56510 & 56530 & 99910 \\ 8 & 2 / 24 / 98 & 1 & \text { SB } & 62898 & 63962 & 68856 & 99910 \\ 8 & 2 / 5 / 98 & 1 & \text { SB } & 82639 & 82850 & 77336 & 97802 \\ 8 & 4 / 1 / 98 & 1 & \text { SB } & 119985 & 105091 & 120233 & 186508 \\ 8 & 2 / 10 / 98 & 1 & \text { SE } & 125420 & 120604 & 108463 & 97802 \\ 8 & 3 / 3 / 98 & 1 & \text { SE } & 75662 & 60221 & 79376 & 99910 \\ 8 & 3 / 26 / 98 & 1 & \text { SE } & 130729 & 144274 & 118271 & 186508 \\ 10 & 2 / 10 / 98 & 3 & \text { CON } & 153102 & 133093 & 161690 & 97802 \\ 10 & 2 / 24 / 98 & 3 & \text { CON } & 100287 & 82817 & 78938 & 99910 \\ 10 & 1 / 28 / 98 & 3 & \text { CON } & 117823 & 113012 & 77130 & 97802 \\ 10 & 3 / 17 / 98 & 3 & \text { INT } & 73589 & 83665 & 65973 & 80211 \\ 10 & 2 / 3 / 98 & 3 & \text { INT } & 146597 & 162078 & 136108 & 97802 \\ 10 & 3 / 24 / 98 & 3 & \text { INT } & 109173 & 51395 & 69282 & 186508 \\ 16 & 2 / 2 / 98 & 2 & \text { BEG } & 234829 & 194486 & 156982 & 97802 \\ 16 & 3 / 3 / 98 & 2 & \text { BEG } & 121669 & 120938 & 102333 & 99910 \\ 16 & 2 / 23 / 98 & 2 & \text { BEG } & 90346 & 103405 & 92179 & 99910 \\ 16 & 3 / 17 / 98 & 2 & \text { END } & 173858 & 158833 & 137291 & 80211 \\ 16 & 3 / 31 / 98 & 2 & \text { END } & 264555 & 217504 & 212430 & 186508 \\ 16 & 3 / 20 / 98 & 2 & \text { END } & 248798 & 200481 & 184056 & 80211 \\ 19 & 4 / 2 / 98 & 3 & \text { CON } & 163365 & 154023 & 182170 & 186508 \\ 19 & 2 / 5 / 98 & 3 & \text { CON } & 199102 & 163545 & 131747 & 97802 \\ 19 & 2 / 12 / 98 & 3 & \text { CON } & 124307 & 117432 & 96200 & 97802 \\ 19 & 3 / 5 / 98 & 3 & \text { INT } & 117229 & 100860 & 82628 & 99910 \\ 19 & 2 / 26 / 98 & 3 & \text { INT } & 136255 & 98342 & 95872 & 99910 \\ 19 & 2 / 19 / 98 & 3 & \text { INT } & 76814 & 68120 & 57812 & 97802 \\ 22 & 2 / 5 / 98 & 2 & \text { BEG } & 153003 & 111426 & 123172 & 97802 \\ 22 & 2 / 26 / 98 & 2 & \text { BEG } & 167616 & 169202 & 133388 & 99910 \\ 22 & 3 / 5 / 98 & 2 & \text { BEG } & 219124 & 175747 & 148304 & 99910 \\ 22 & 1 / 29 / 98 & 2 & \text { END } & 230660 & 203104 & 171566 & 97802 \\ 22 & 2 / 19 / 98 & 2 & \text { END } & 167259 & 121219 & 87196 & 97802 \\ 22 & 2 / 12 / 98 & 2 & \text { END } & 155726 & 133323 & 110188 & 97802 \\ & & & & & & & \end{array}$




$\begin{array}{cccccccc}\text { Subject } & \text { Data } & \text { Phase } & \text { Test } & \mathbf{2 5} \text { min. } & \mathbf{3 0} \text { min. } & \mathbf{3 5} \text { min. } & \text { CAL. CO. } \\ 26 & 2 / 26 / 98 & 2 & \text { BEG } & 141066 & 134187 & 121553 & 99910 \\ 26 & 2 / 13 / 98 & 2 & \text { BEG } & 91983 & 85291 & 80631 & 97802 \\ 26 & 1 / 23 / 98 & 2 & \text { BEG } & 95786 & 101496 & 70174 & 97802 \\ 26 & 1 / 29 / 98 & 2 & \text { END } & 137058 & 143059 & \text { PROB } & 97802 \\ 26 & 3 / 19 / 98 & 2 & \text { END } & 177338 & 157070 & 166358 & 80211 \\ 26 & 2 / 3 / 98 & 2 & \text { END } & 264705 & 180313 & 138063 & 97802 \\ 29 & 1 / 30 / 98 & 3 & \text { CON } & 167884 & 162435 & 152983 & 97802 \\ 29 & 2 / 13 / 98 & 3 & \text { CON } & 96916 & 114700 & 91672 & 97802 \\ 29 & 2 / 6 / 98 & 3 & \text { CON } & 226852 & 223722 & 201145 & 97802 \\ 29 & 2 / 20 / 98 & 3 & \text { INT } & 160838 & 161480 & 127739 & 97802 \\ 29 & 3 / 20 / 98 & 3 & \text { INT } & 257392 & 224576 & 238790 & 80211 \\ 29 & 2 / 27 / 98 & 3 & \text { INT } & 170259 & 136892 & 138032 & 99910 \\ 45 & 2 / 19 / 98 & 3 & \text { LB } & 73006 & 69213 & 72793 & 97802 \\ 45 & 3 / 27 / 98 & 1 & \text { LB } & 112071 & 118715 & 127695 & 186508 \\ 45 & 3 / 20 / 98 & 1 & \text { LB } & 98264 & 87729 & 124328 & 80211 \\ 45 & 4 / 16 / 98 & 1 & \text { LE } & 121859 & 112279 & 123809 & 186508 \\ 45 & 4 / 10 / 98 & 1 & \text { LE } & 101222 & 95376 & 95887 & 186508 \\ 45 & 3 / 26 / 98 & 1 & \text { LE } & 71297 & 62020 & 69502 & 186508 \\ 45 & 4 / 14 / 98 & 1 & \text { SB } & 124737 & 124587 & 123573 & 186508 \\ 45 & 3 / 31 / 98 & 1 & \text { SB } & 125746 & 138244 & 132898 & 186508 \\ 45 & 2 / 12 / 98 & 1 & \text { SB } & 68453 & 65340 & 70041 & 97802 \\ 45 & 4 / 17 / 98 & 1 & \text { SE } & 164926 & 153876 & 166846 & 186508 \\ 45 & 2 / 5 / 98 & 1 & \text { SE } & 125825 & 104876 & 81035 & 97802 \\ 45 & 4 / 15 / 98 & 1 & \text { SE } & 163333 & 133772 & 169347 & 186508\end{array}$




\section{Appendix B}

\section{Photos of CFC-113 Delivery System and Chamber}


Figure B1

CFC-113 Delivery System

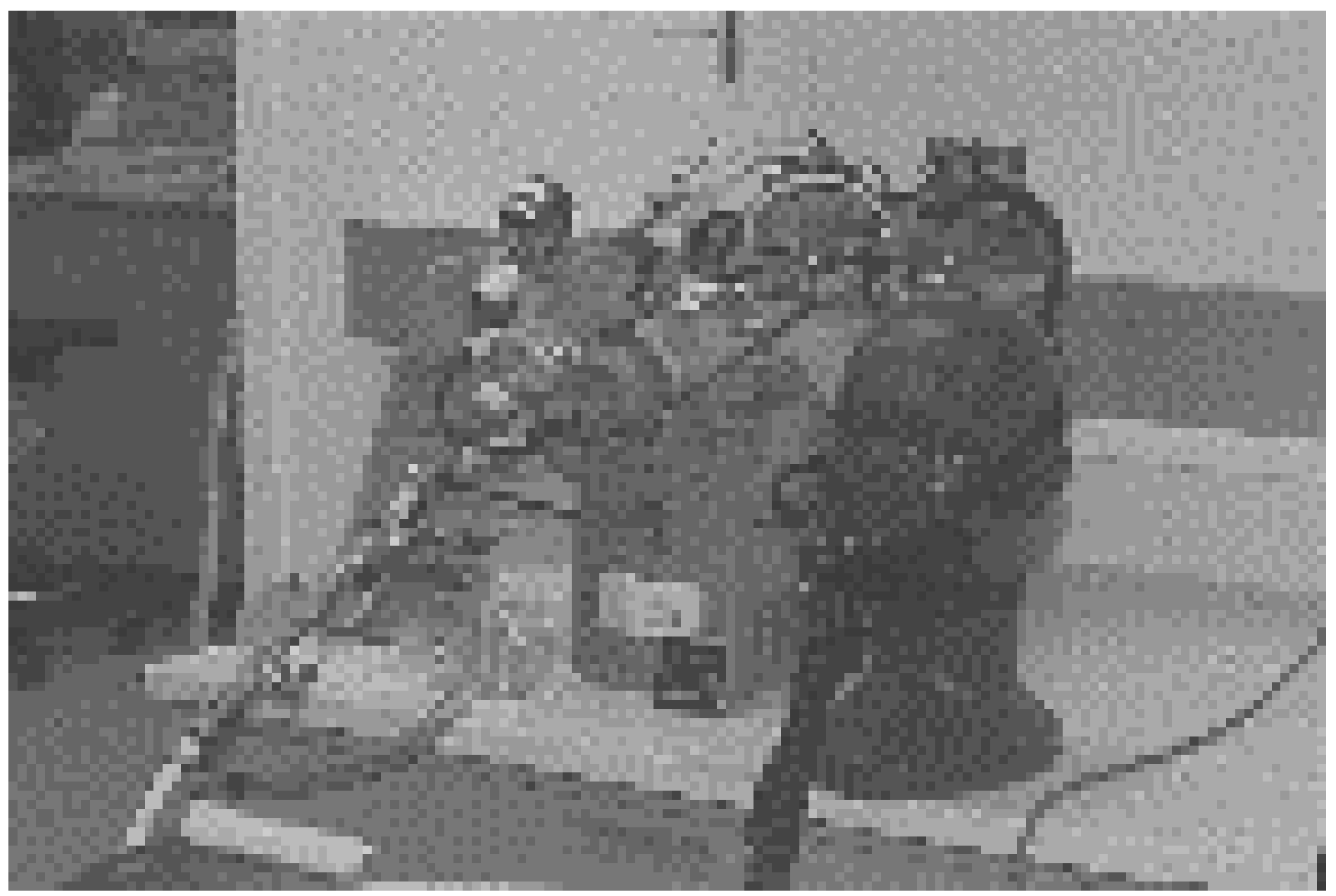


Figure B2

\section{Subject Donning CFC-113 Delivery System}

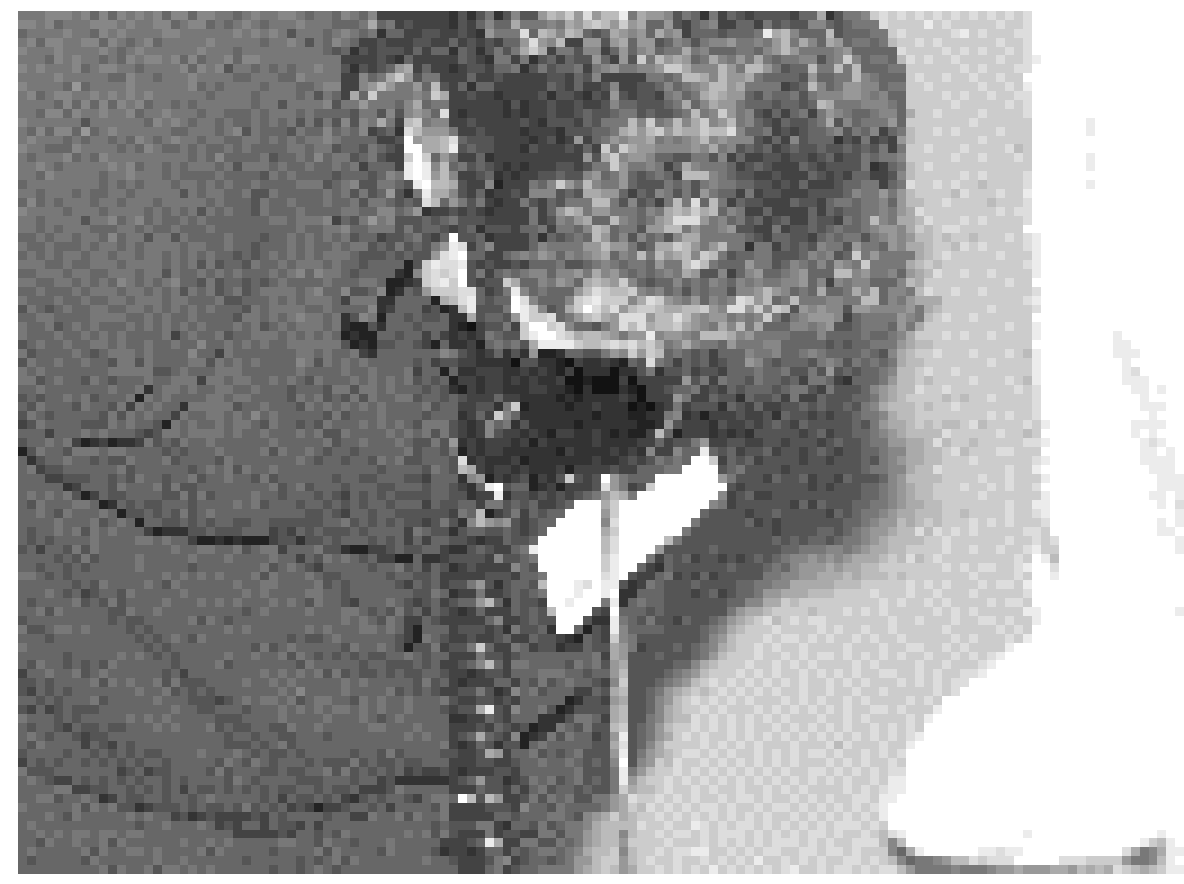


Figure B3

Subject in a Charged Chamber

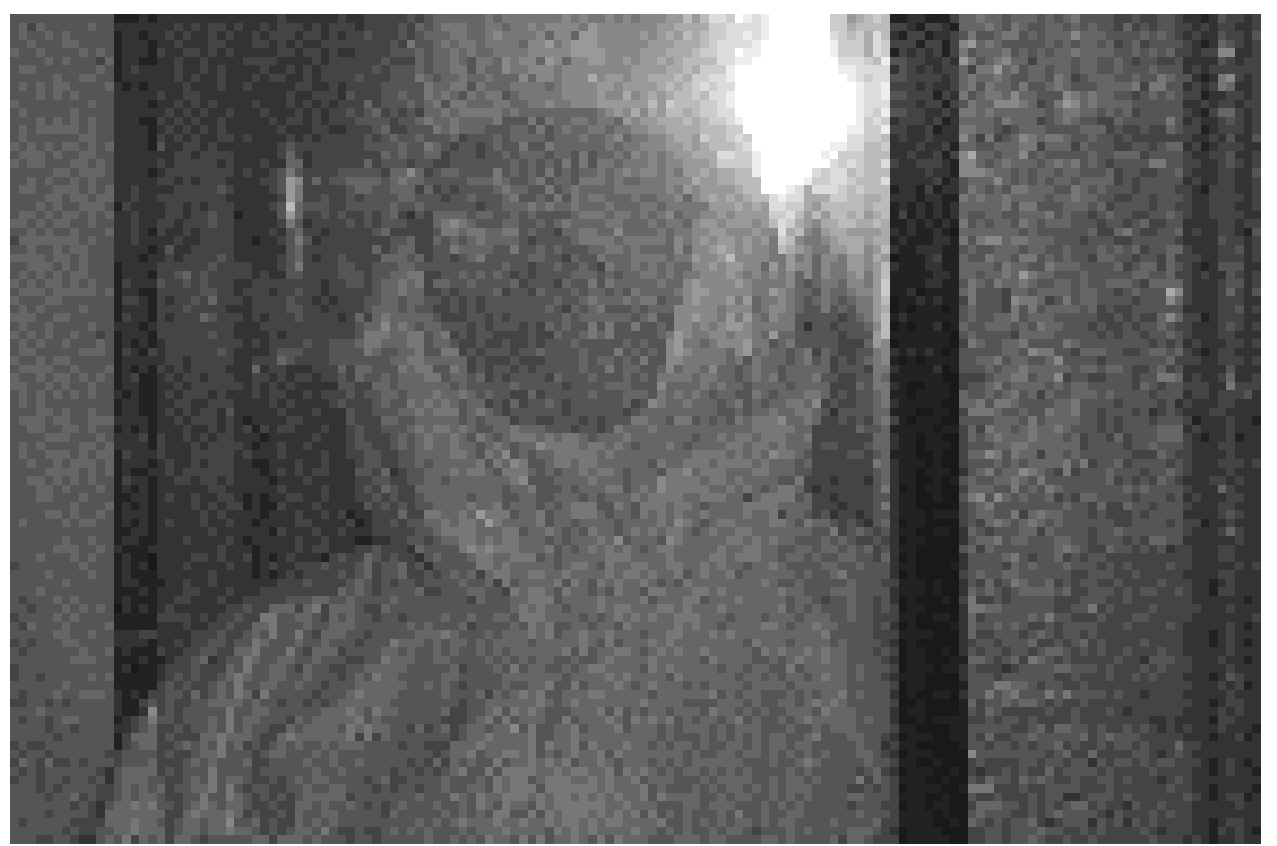




\section{Appendix C}

\section{Calibration Graphs}




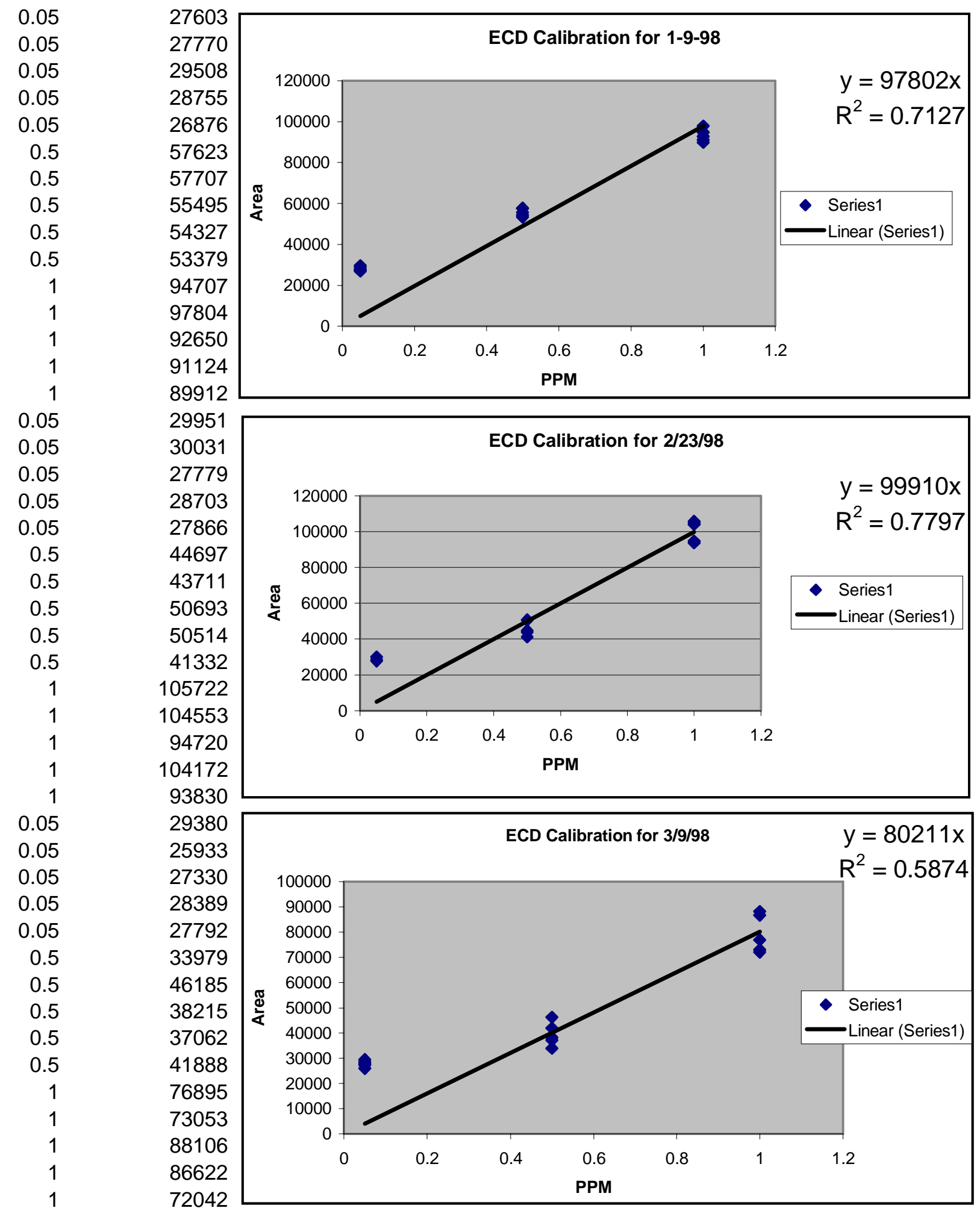




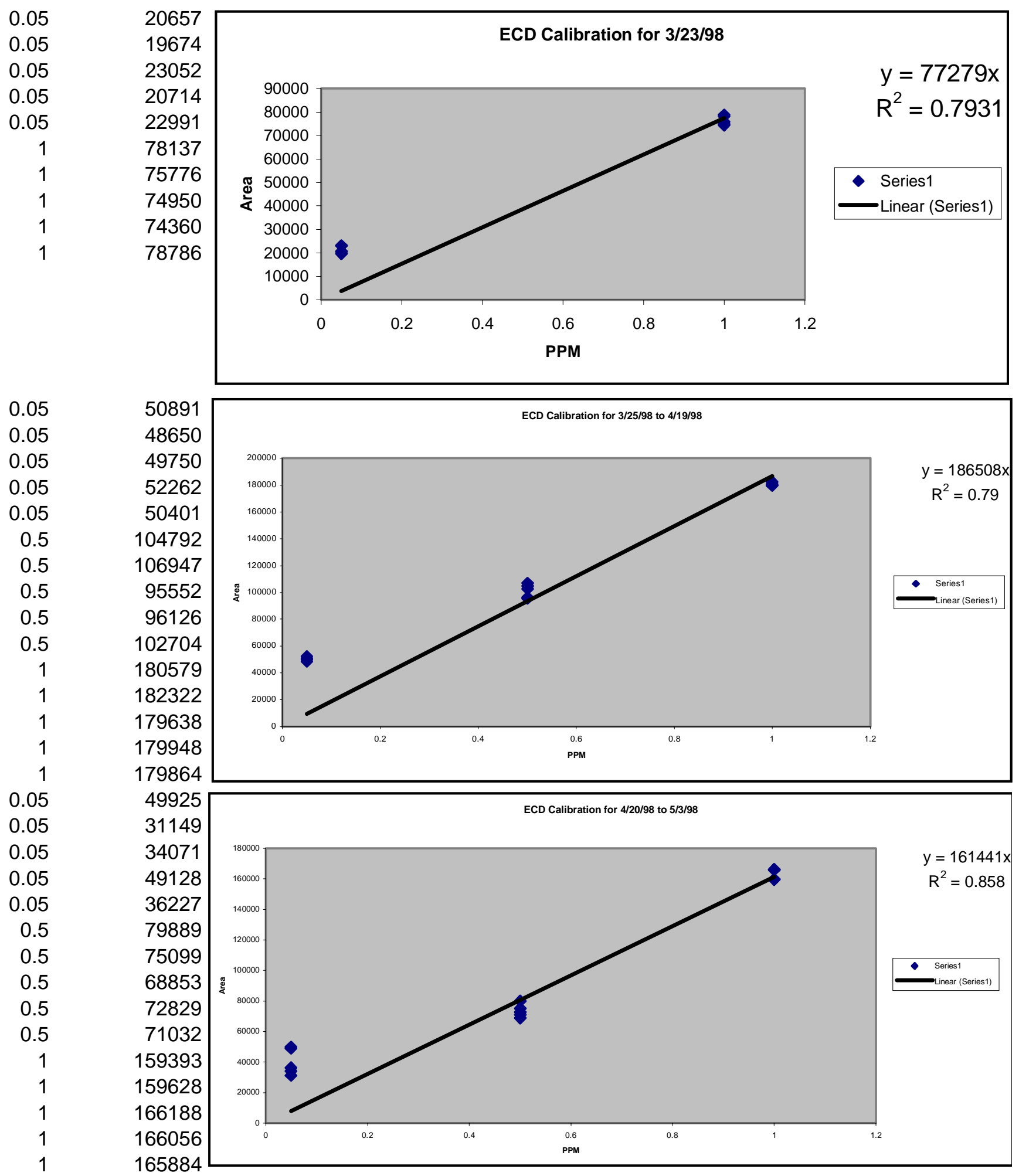


Appendix D

SAS Results 


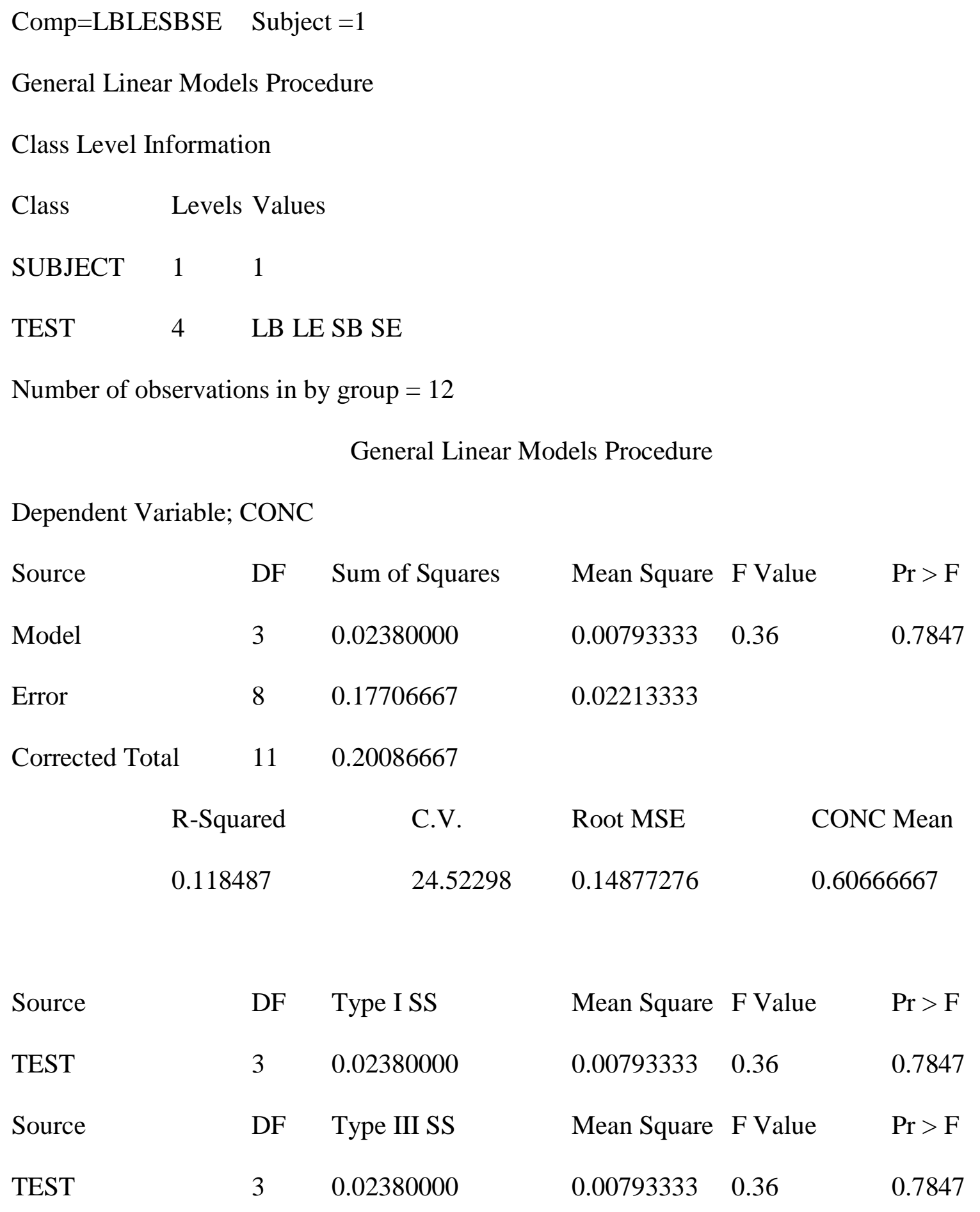


General Linear Models Procedure

\section{Duncan's Multiple Range Test for variable: CONC}

Note: This test controls the type I comparisonwise error rate, not the experimentwise error rate

\begin{tabular}{llll} 
Alpha= $=0.05 \quad \mathrm{df}=8$ & \multicolumn{4}{l}{$\mathrm{MSE}=0.022133$} \\
Number of Means & 2 & 3 & 4 \\
Critical Range & .2801 & .2919 & .2985
\end{tabular}

Means with the same letter are not significantly different.

$\begin{array}{cccc}\text { Duncan Grouping } & \text { Mean } & \text { N } & \text { TEST } \\ \text { A } & 0.6700 & 3 & \text { LE } \\ \text { A } & 0.6267 & 3 & \text { SE } \\ \text { A } & 0.5700 & 3 & \text { SB } \\ \text { A } & 0.5600 & 3 & \text { LB }\end{array}$




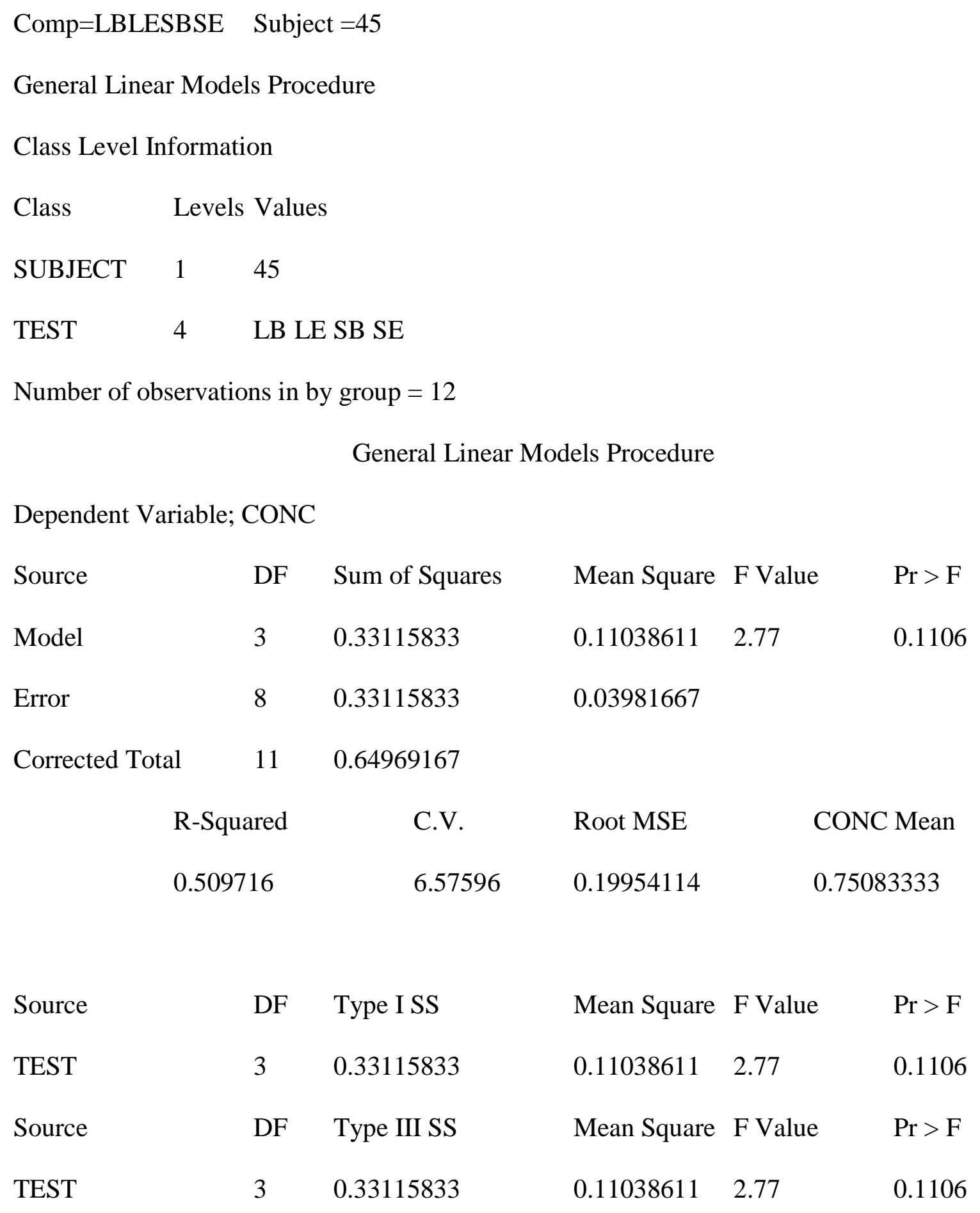




$$
\text { Subject }=45
$$

\section{General Linear Models Procedure}

\section{Duncan's Multiple Range Test for variable: CONC}

Note: This test controls the type I comparisonwise error rate, not the experimentwise error rate

$\begin{array}{lllll}\text { Alpha=0.05 } \quad \mathrm{df}=8 & \mathrm{MSE}=0.039817 \\ \text { Number of Means } & 2 & 3 & 4 \\ \text { Critical Range } & .3757 & .3915 & .4004\end{array}$

Means with the same letter are not significantly different.

$\begin{array}{ccccc}\text { Duncan Grouping } & \text { Mean } & \text { N } & \text { TEST } \\ & \text { A } & 0.9200 & 3 & \text { SE } \\ \text { B } & \text { A } & 0.8867 & 3 & \text { LB } \\ \text { B } & \text { A } & 0.6900 & 3 & \text { SB } \\ \text { B } & & 0.5067 & 3 & \text { LE }\end{array}$




\section{Comp=LBLESBSE $\quad$ Subject $=5$}

General Linear Models Procedure

Class Level Information

Class Levels Values

$\begin{array}{lll}\text { SUBJECT } & 1 & 5\end{array}$

TEST $4 \quad 4$ LB LE SB SE

Number of observations in by group $=12$

General Linear Models Procedure

Dependent Variable; CONC

$\begin{array}{lccccr}\text { Source } & \text { DF } & \text { Sum of Squares } & \text { Mean Square F Value } & \text { Pr }>\text { F } \\ \text { Model } & 3 & 0.24070000 & 0.08023333 & 2.90 & 0.1019 \\ \text { Error } & 8 & 0.22166667 & 0.02770833 & \\ \text { Corrected Total } & 11 & 0.46236667 & & \\ & & & & \\ & \text { R-Squared } & \text { C.V. } & \text { Root MSE } & \text { CONC Mean } \\ & & & & & \\ & 0.520583 & 26.49202 & 0.16645820 & 0.62833333\end{array}$

$\begin{array}{llllll}\text { Source } & \text { DF } & \text { Type I SS } & \text { Mean Square } & \text { F Value } & \text { Pr }>\text { F } \\ \text { TEST } & 3 & 0.24070000 & 0.08023333 & 2.90 & 0.1019 \\ \text { Source } & \text { DF } & \text { Type III SS } & \text { Mean Square } & \text { F Value } & \text { Pr }>\text { F } \\ \text { TEST } & 3 & 0.24070000 & 0.08023333 & 2.90 & 0.1019\end{array}$




$$
\text { Subject }=5
$$

\section{General Linear Models Procedure}

\section{Duncan's Multiple Range Test for variable: CONC}

Note: This test controls the type I comparisonwise error rate, not the experimentwise error rate

$\begin{array}{lllll}\text { Alpha }=0.05 \quad \mathrm{df}=8 & \mathrm{MSE}=0.027708 \\ \text { Number of Means } & 2 & 3 & 4 \\ \text { Critical Range } & .3134 & .3266 & .3340\end{array}$

Means with the same letter are not significantly different.

$\begin{array}{ccccc}\text { Duncan Grouping } & \text { Mean } & \text { N } & \text { TEST } \\ & \text { A } & 0.7833 & 3 & \text { SE } \\ \text { B } & \text { A } & 0.7367 & 3 & \text { SB } \\ \text { B } & \text { A } & 0.5667 & 3 & \text { LB } \\ \text { B } & & 0.4267 & 3 & \text { LE }\end{array}$




\begin{tabular}{|c|c|c|c|c|c|}
\hline \multicolumn{3}{|c|}{ Comp $=$ LBLESBSE $\quad$ Subject $=8$} & & & \\
\hline \multicolumn{6}{|c|}{ General Linear Models Procedure } \\
\hline \multicolumn{6}{|c|}{ Class Level Information } \\
\hline Class & \multicolumn{5}{|c|}{ Levels Values } \\
\hline SUBJECT & \multicolumn{5}{|l|}{8} \\
\hline TEST & \multicolumn{5}{|c|}{ LB LE SB SE } \\
\hline \multicolumn{6}{|c|}{ Number of observations in by group $=12$} \\
\hline \multicolumn{6}{|c|}{ General Linear Models Procedure } \\
\hline \multicolumn{6}{|c|}{ Dependent Variable; CONC } \\
\hline Source & $\mathrm{DF}$ & Sum of Squares & Mean Square & F Value & $\operatorname{Pr}>\mathrm{F}$ \\
\hline Model & 3 & 0.19070000 & 0.06356667 & 1.66 & 0.2522 \\
\hline Error & 8 & 0.30680000 & 0.03835000 & & \\
\hline \multirow[t]{3}{*}{ Corrected Tota } & 11 & 0.49750000 & & & \\
\hline & R-Squared & C.V. & Root MSE & \multicolumn{2}{|c|}{ CONC Mean } \\
\hline & 0.383317 & 27.38903 & 0.19583156 & \multicolumn{2}{|c|}{0.71500000} \\
\hline Source & $\mathrm{DF}$ & Type I SS & Mean Square & F Value & $\operatorname{Pr}>\mathrm{F}$ \\
\hline TEST & 3 & 0.19070000 & 0.06356667 & 1.66 & 0.2522 \\
\hline Source & $\mathrm{DF}$ & Type III SS & Mean Square & F Value & $\operatorname{Pr}>\mathrm{F}$ \\
\hline TEST & 3 & 0.19070000 & 0.06356667 & 1.66 & 0.2522 \\
\hline
\end{tabular}




$$
\text { Subject }=8
$$

\section{General Linear Models Procedure}

\section{Duncan's Multiple Range Test for variable: CONC}

Note: This test controls the type I comparisonwise error rate, not the experimentwise error rate
Alpha $=0.05 \quad \mathrm{df}=8 \quad \mathrm{MSE}=0.03835$
Number of Means $\quad 2 \quad 3 \quad 4$
$\begin{array}{llll}\text { Critical Range } \quad .3687 & .3842 \quad .3929\end{array}$

Means with the same letter are not significantly different.

$\begin{array}{rlcc}\text { Duncan Grouping } & \text { Mean } & \text { N } & \text { TEST } \\ \text { A } & 0.8767 & 3 & \text { SE } \\ \text { A } & 0.7567 & 3 & \text { LE } \\ \text { A } & 0.7000 & 3 & \text { SB } \\ \text { A } & 0.5267 & 3 & \text { LB }\end{array}$


Comp=begend $\quad$ Subject $=16$

General Linear Models Procedure

Class Level Information

Class Levels Values

$\begin{array}{lll}\text { SUBJECT } & 1 & 16\end{array}$

TEST 2 BEG END

Number of observations in by group $=6$

General Linear Models Procedure

Dependent Variable: CONC

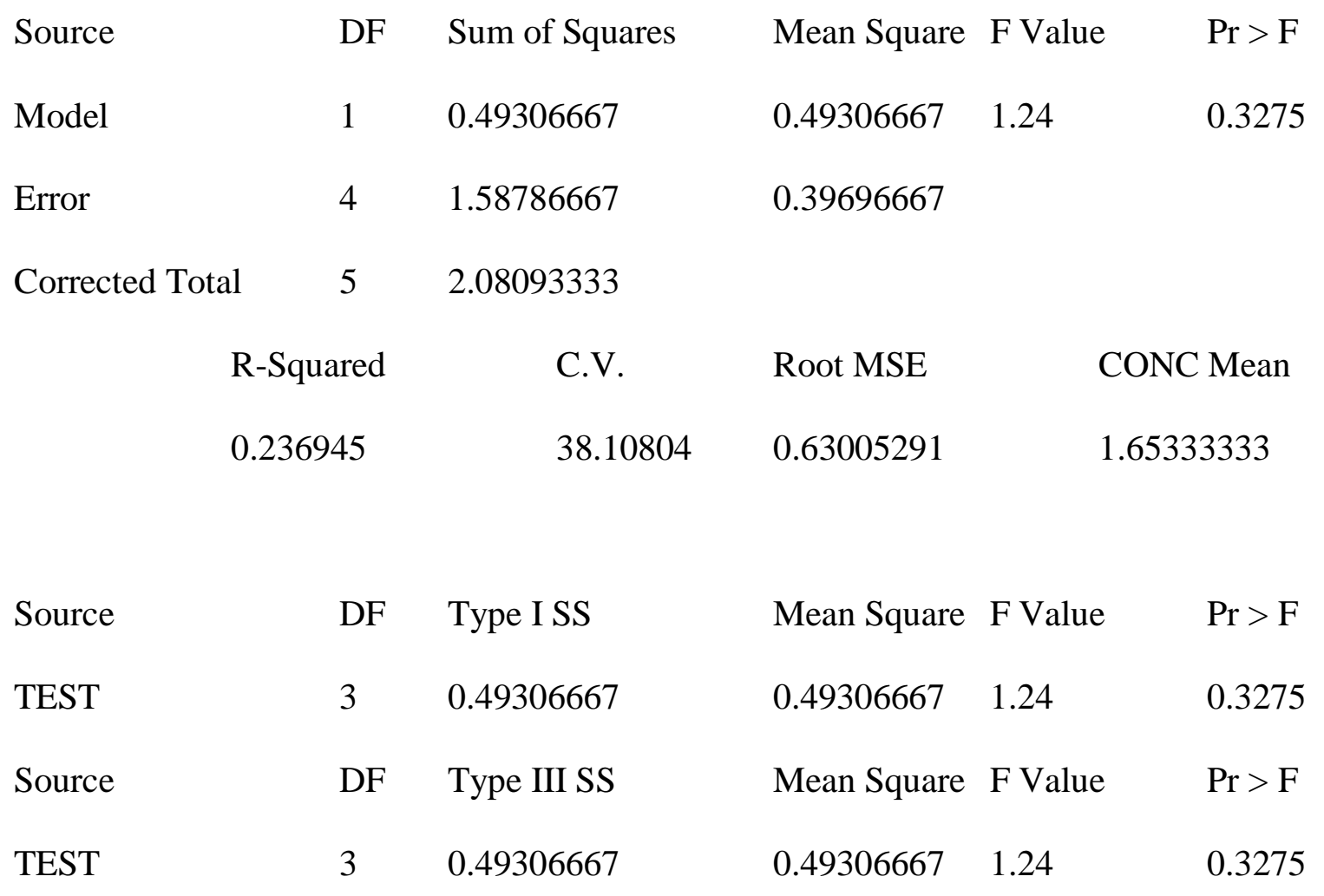




$$
\text { Subject }=16
$$

\section{General Linear Models Procedure}

\section{Duncan's Multiple Range Test for variable: CONC}

Note: This test controls the type I comparisonwise error rate, not the experimentwise error rate

$$
\text { Alpha }=0.05 \quad \mathrm{df}=4 \quad \mathrm{MSE}=0.396967
$$

Number of Means 2

Critical Range $\quad 1.428$

Means with the same letter are not significantly different.

$\begin{array}{rlll}\text { Duncan Grouping } & \text { Mean } & \text { N } & \text { TEST } \\ \text { A } & 1.9400 & 3 & \text { END } \\ \text { A } & 1.3667 & 3 & \text { BEG }\end{array}$


Comp=begend $\quad$ Subject $=22$

General Linear Models Procedure

Class Level Information

Class Levels Values

$\begin{array}{lll}\text { SUBJECT } & 1 & 22\end{array}$

TEST 2 BEG END

Number of observations in by group $=6$

General Linear Models Procedure

Dependent Variable: CONC

\begin{tabular}{|c|c|c|c|c|c|}
\hline Source & $\mathrm{DF}$ & Sum of Squares & Mean Square & F Value & $\operatorname{Pr}>\mathrm{F}$ \\
\hline Model & 1 & 0.00000000 & 0.00000000 & 0.00 & 1.0000 \\
\hline Error & 4 & 0.48833333 & 0.12208333 & & \\
\hline \multirow[t]{3}{*}{ Corrected Total } & 5 & 0.48833333 & & & \\
\hline & ared & C.V. & Root MSE & \multicolumn{2}{|c|}{ CONC Mean } \\
\hline & & 22.30240 & 0.34940425 & \multicolumn{2}{|c|}{1.56666667} \\
\hline Source & $\mathrm{DF}$ & Type I SS & Mean Square & F Value & $\operatorname{Pr}>\mathrm{F}$ \\
\hline TEST & 1 & 0.00000000 & 0.00000000 & 0.00 & 1.0000 \\
\hline Source & $\mathrm{DF}$ & Type III SS & Mean Square & F Value & $\operatorname{Pr}>F$ \\
\hline TEST & 1 & 0.00000000 & 0.00000000 & 0.00 & 1.0000 \\
\hline
\end{tabular}


Subject $=22$

General Linear Models Procedure

Duncan's Multiple Range Test for variable: CONC

Note: This test controls the type I comparisonwise error rate, not the experimentwise error rate
Alpha $=0.05 \quad \mathrm{df}=4 \quad \mathrm{MSE}=0.122083$

Number of Means 2

Critical Range $\quad .7921$

Means with the same letter are not significantly different.

$\begin{array}{rlll}\text { Duncan Grouping } & \text { Mean } & \mathrm{N} & \text { TEST } \\ \mathrm{A} & 1.5667 & 3 & \mathrm{BEG} \\ \mathrm{A} & 1.5667 & 3 & \text { END }\end{array}$


Comp=begend $\quad$ Subject $=26$

General Linear Models Procedure

Class Level Information

Class Levels Values

SUBJECT 126

TEST 2 BEG END

Number of observations in by group $=6$

General Linear Models Procedure

Dependent Variable: CONC

\begin{tabular}{|c|c|c|c|c|c|}
\hline Source & $\mathrm{DF}$ & Sum of Squares & Mean Square & F Value & $\operatorname{Pr}>\mathrm{F}$ \\
\hline Model & 1 & 0.82140000 & 0.82140000 & 6.25 & 0.0667 \\
\hline Error & 4 & 0.52533333 & 0.13133333 & & \\
\hline \multirow[t]{3}{*}{ Corrected Total } & 5 & 1.34673333 & & & \\
\hline & ared & C.V. & Root MSE & \multicolumn{2}{|c|}{ CONC Mean } \\
\hline & & 25.76299 & 0.36239941 & \multicolumn{2}{|c|}{1.40666667} \\
\hline Source & $\mathrm{DF}$ & Type I SS & Mean Square & F Value & $\operatorname{Pr}>\mathrm{F}$ \\
\hline TEST & 1 & 0.82140000 & 0.82140000 & 6.25 & 0.0667 \\
\hline Source & $\mathrm{DF}$ & Type III SS & Mean Square & F Value & $\operatorname{Pr}>\mathrm{F}$ \\
\hline TEST & 1 & 0.82140000 & 0.82140000 & 6.25 & 0.0667 \\
\hline
\end{tabular}


Subject $=26$

General Linear Models Procedure

Duncan's Multiple Range Test for variable: CONC

Note: This test controls the type I comparisonwise error rate, not the experimentwise error rate

Alpha $=0.05 \quad \mathrm{df}=4 \quad \mathrm{MSE}=0.131333$

Number of Means 2

Critical Range $\quad .8215$

Means with the same letter are not significantly different.

$\begin{array}{rlrr}\text { Duncan Grouping } & \text { Mean } & \text { N } & \text { TEST } \\ \text { A } & 1.7767 & 3 & \text { END } \\ \text { A } & 1.0367 & 3 & \text { BEG }\end{array}$


Comp=begend $\quad$ Subject $=3$

General Linear Models Procedure

Class Level Information

Class Levels Values

$\begin{array}{lll}\text { SUBJECT } & 1 & 3\end{array}$

$\begin{array}{lll}\text { TEST } & 2 & \text { BEG END }\end{array}$

Number of observations in by group $=6$

General Linear Models Procedure

Dependent Variable: CONC

$\begin{array}{lrrrrr}\text { Source } & \text { DF } & \text { Sum of Squares } & \text { Mean Square } & \text { F Value } & \text { Pr }>\text { F } \\ \text { Model } & 1 & 0.04166667 & 0.04166667 & 0.11 & 0.7615 \\ \text { Error } & 4 & 1.57766667 & 0.39441667 & \\ \text { Corrected Total } & 5 & 1.61933333 & & \\ & & & & & \\ & \text { R-Squared } & \text { C.V. } & \text { Root MSE } & \text { CONC Mean } \\ & 0.025731 & 44.12361 & 0.62802601 & 1.423333333\end{array}$

$\begin{array}{llclll}\text { Source } & \text { DF } & \text { Type I SS } & \text { Mean Square } & \text { F Value } & \text { Pr }>\text { F } \\ \text { TEST } & 1 & 0.04166667 & 0.04166667 & 0.11 & 0.7615 \\ \text { Source } & \text { DF } & \text { Type III SS } & \text { Mean Square } & \text { F Value } & \text { Pr > F } \\ \text { TEST } & 1 & 0.04166667 & 0.04166667 & 0.11 & 0.7615\end{array}$


Subject $=3$

General Linear Models Procedure

Duncan's Multiple Range Test for variable: CONC

Note: This test controls the type I comparisonwise error rate, not the experimentwise error rate
Alpha $=0.05 \quad \mathrm{df}=4 \quad \mathrm{MSE}=0.394417$

Number of Means 2

Critical Range $\quad 1.424$

Means with the same letter are not significantly different.

$\begin{array}{rlll}\text { Duncan Grouping } & \text { Mean } & \mathrm{N} & \text { TEST } \\ \mathrm{A} & 1.5067 & 3 & \text { END } \\ \mathrm{A} & 1.3400 & 3 & \mathrm{BEG}\end{array}$




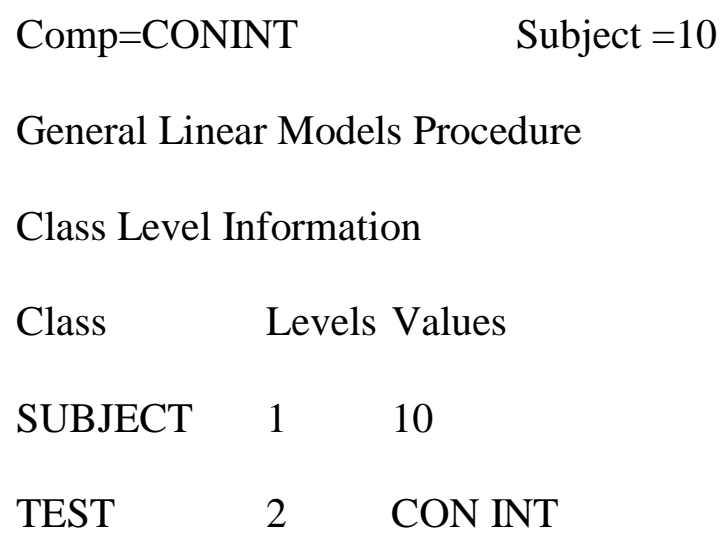

Number of observations in by group $=6$

General Linear Models Procedure

Dependent Variable: CONC

\begin{tabular}{|c|c|c|c|c|c|}
\hline Source & DF & Sum of Squares & Mean Square & F Value & $\operatorname{Pr}>\mathrm{F}$ \\
\hline Model & 1 & 0.05801667 & 0.05801667 & 0.27 & 0.6289 \\
\hline Error & 4 & 0.84966667 & 0.21241667 & & \\
\hline \multirow[t]{3}{*}{ Corrected Total } & 5 & 0.90768333 & & & \\
\hline & ared & C.V. & Root MSE & \multicolumn{2}{|c|}{ CONC Mean } \\
\hline & 917 & 43.82442 & 0.46088683 & \multicolumn{2}{|c|}{1.05166667} \\
\hline Source & $\mathrm{DF}$ & Type I SS & Mean Square & F Value & $\operatorname{Pr}>F$ \\
\hline TEST & 1 & 0.05801667 & 0.05801667 & 0.27 & 0.6289 \\
\hline Source & $\mathrm{DF}$ & Type III SS & Mean Square & F Value & $\operatorname{Pr}>F$ \\
\hline TEST & 1 & 0.05801667 & 0.05801667 & 0.27 & 0.6289 \\
\hline
\end{tabular}




$$
\text { Subject }=10
$$

\section{General Linear Models Procedure}

\section{Duncan's Multiple Range Test for variable: CONC}

Note: This test controls the type I comparisonwise error rate, not the experimentwise error rate

$$
\text { Alpha }=0.05 \quad \mathrm{df}=4 \quad \mathrm{MSE}=0.212417
$$

Number of Means 2

Critical Range $\quad 1.045$

Means with the same letter are not significantly different.

$\begin{array}{rlll}\text { Duncan Grouping } & \text { Mean } & \text { N } & \text { TEST } \\ \text { A } & 1.1500 & 3 & \text { CON } \\ \text { A } & 0.9533 & 3 & \text { INT }\end{array}$


Comp $=$ CONINT $\quad$ Subject $=19$

General Linear Models Procedure

Class Level Information

Class Levels Values

$\begin{array}{lll}\text { SUBJECT } & 1 & 19\end{array}$

$\begin{array}{lll}\text { TEST } & 2 & \text { CON INT }\end{array}$

Number of observations in by group $=6$

General Linear Models Procedure

Dependent Variable: CONC

\begin{tabular}{|c|c|c|c|c|c|}
\hline Source & $\mathrm{DF}$ & Sum of Squares & Mean Square & F Value & $\operatorname{Pr}>\mathrm{F}$ \\
\hline Model & 1 & 0.14726667 & 0.14726667 & 1.39 & 0.3041 \\
\hline Error & 4 & 0.42446667 & 0.10611667 & & \\
\hline Corrected Total & 5 & 0.57173333 & & & \\
\hline & ared & C.V. & Root MSE & & CONC Mean \\
\hline & & 29.97750 & 0.32575553 & & 1.08666667 \\
\hline Source & $\mathrm{DF}$ & Type I SS & Mean Square & F Value & $\operatorname{Pr}>F$ \\
\hline TEST & 1 & 0.14726667 & 0.14726667 & 1.39 & 0.3041 \\
\hline Source & $\mathrm{DF}$ & Type III SS & Mean Square & F Value & $\operatorname{Pr}>F$ \\
\hline TEST & 1 & 0.14726667 & 0.14726667 & 1.39 & 0.3041 \\
\hline
\end{tabular}




$$
\text { Subject }=19
$$

\section{General Linear Models Procedure}

\section{Duncan's Multiple Range Test for variable: CONC}

Note: This test controls the type I comparisonwise error rate, not the experimentwise error rate

$$
\text { Alpha }=0.05 \quad \mathrm{df}=4 \quad \mathrm{MSE}=0.10611667
$$

Number of Means 2

Critical Range $\quad 1.045$

Means with the same letter are not significantly different.

$\begin{array}{rlll}\text { Duncan Grouping } & \text { Mean } & \text { N } & \text { TEST } \\ \text { A } & 1.2433 & 3 & \text { CON } \\ \text { A } & 0.9300 & 3 & \text { INT }\end{array}$


Comp $=$ CONINT $\quad$ Subject $=29$

General Linear Models Procedure

Class Level Information

Class Levels Values

$\begin{array}{lll}\text { SUBJECT } & 1 & 29\end{array}$

$\begin{array}{lll}\text { TEST } & 2 & \text { CON INT }\end{array}$

Number of observations in by group $=6$

General Linear Models Procedure

Dependent Variable: CONC

$\begin{array}{lrrrrr}\text { Source } & \text { DF } & \text { Sum of Squares } & \text { Mean Square } & \text { F Value } & \text { Pr }>\text { F } \\ \text { Model } & 1 & 0.20906667 & 0.20906667 & 0.38 & 0.5700 \\ \text { Error } & 4 & 2.18933333 & 0.54733333 & \\ \text { Corrected Total } & 5 & 2.39840000 & & \\ & & & & \\ & \text { R-Squared } & \text { C.V. } & \text { Root MSE } & \text { CONC Mean } \\ & 0.087169 & 40.64944 & 0.73981980 & 1.82000000\end{array}$

$\begin{array}{llllll}\text { Source } & \text { DF } & \text { Type I SS } & \text { Mean Square } & \text { F Value } & \text { Pr }>\text { F } \\ \text { TEST } & 1 & 0.20906667 & 0.20906667 & 0.38 & 0.5700 \\ \text { Source } & \text { DF } & \text { Type III SS } & \text { Mean Square } & \text { F Value } & \text { Pr }>\text { F } \\ \text { TEST } & 1 & 0.20906667 & 0.20906667 & 0.38 & 0.5700\end{array}$


Subject $=29$

General Linear Models Procedure

Duncan's Multiple Range Test for variable: CONC

Note: This test controls the type I comparisonwise error rate, not the experimentwise error rate

Alpha $=0.05 \quad \mathrm{df}=4 \quad \mathrm{MSE}=0.547333$

Number of Means 2

Critical Range $\quad 1.677$

Means with the same letter are not significantly different.

$\begin{array}{rlll}\text { Duncan Grouping } & \text { Mean } & \text { N } & \text { TEST } \\ \text { A } & 2.0067 & 3 & \text { INT } \\ \text { A } & 1.6333 & 3 & \text { CON }\end{array}$


Comp $=$ CONINT $\quad$ Subject $=4$

General Linear Models Procedure

Class Level Information

Class Levels Values

$\begin{array}{lll}\text { SUBJECT } & 1 & 4\end{array}$

$\begin{array}{lll}\text { TEST } & 2 & \text { CON INT }\end{array}$

Number of observations in by group $=6$

General Linear Models Procedure

Dependent Variable: CONC

\begin{tabular}{|c|c|c|c|c|c|}
\hline Source & $\mathrm{DF}$ & Sum of Squares & Mean Square & F Value & $\operatorname{Pr}>F$ \\
\hline Model & 1 & 0.07041667 & 0.07041667 & 0.78 & 0.4257 \\
\hline Error & 4 & 0.35886667 & 0.08971667 & & \\
\hline Corrected Total & 5 & 0.42928333 & & & \\
\hline & ared & C.V. & Root MSE & & CONC Mean \\
\hline & & 22.38063 & 0.29952741 & & 1.33833333 \\
\hline Source & $\mathrm{DF}$ & Type I SS & Mean Square & F Value & $\operatorname{Pr}>\mathrm{F}$ \\
\hline TEST & 1 & 0.07041667 & 0.07041667 & 0.78 & 0.4257 \\
\hline Source & $\mathrm{DF}$ & Type III SS & Mean Square & F Value & $\operatorname{Pr}>\mathrm{F}$ \\
\hline TEST & 1 & 0.07041667 & 0.07041667 & 0.78 & 0.4257 \\
\hline
\end{tabular}


Subject $=4$

General Linear Models Procedure

Duncan's Multiple Range Test for variable: CONC

Note: This test controls the type I comparisonwise error rate, not the experimentwise error rate

Alpha $=0.05 \quad \mathrm{df}=4 \quad \mathrm{MSE}=0.089717$

Number of Means 2

Critical Range $\quad 0.6790$

Means with the same letter are not significantly different.

$\begin{array}{rlcl}\text { Duncan Grouping } & \text { Mean } & \text { N } & \text { TEST } \\ \text { A } & 1.4467 & 3 & \text { CON } \\ \text { A } & 1.2300 & 3 & \text { INT }\end{array}$

